\title{
SARS-CoV-2 Reinfection Is a New Challenge for the Effectiveness of Global Vaccination Campaign: A Systematic Review of Cases Reported in Literature
}

\author{
Lorenzo Lo Muzio 1,2,*(D), Mariateresa Ambosino ${ }^{1}$, Eleonora Lo Muzio ${ }^{3}$ and Mir Faeq Ali Quadri 4 (D) \\ 1 Department of Clinical and Experimental Medicine, University of Foggia, 70122 Foggia, Italy; \\ mariateresaambrosino@libero.it \\ 2 Consorzio Interuniversitario Nazionale per la Bio-Oncologia (C.I.N.B.O.), 66100 Chieti, Italy \\ 3 Department of Translational Medicine and for Romagna, University of Ferrara, 44121 Ferrara, Italy; \\ eleonoralomuzio@gmail.com \\ 4 Department of Preventive Dental Sciences, Jazan University, Jazan 82511, Saudi Arabia; \\ dr.faeq.quadri@gmail.com \\ * Correspondence: lorenzo.lomuzio@unifg.it
}

\section{check for}

updates

Citation: Lo Muzio, L.; Ambosino, M.; Lo Muzio, E.; Quadri, M.F.A. SARS-CoV-2 Reinfection Is a New Challenge for the Effectiveness of Global Vaccination Campaign: A Systematic Review of Cases Reported in Literature. Int. J. Environ. Res. Public Health 2021, 18, 11001. https://doi.org/10.3390/ ijerph182011001

Academic Editor: Paul B. Tchounwou

Received: 18 August 2021

Accepted: 9 October 2021

Published: 19 October 2021

Publisher's Note: MDPI stays neutral with regard to jurisdictional claims in published maps and institutional affiliations.

Copyright: (c) 2021 by the authors. Licensee MDPI, Basel, Switzerland. This article is an open access article distributed under the terms and conditions of the Creative Commons Attribution (CC BY) license (https:/ / creativecommons.org/licenses/by/ $4.0 /)$.

\begin{abstract}
Reinfection with SARS-CoV-2 seems to be a rare phenomenon. The objective of this study is to carry out a systematic search of literature on the SARS-CoV-2 reinfection in order to understand the success of the global vaccine campaigns. A systematic search was performed. Inclusion criteria included a positive RT-PCR test of more than 90 days after the initial test and the confirmed recovery or a positive RT-PCR test of more than 45 days after the initial test that is accompanied by compatible symptoms or epidemiological exposure, naturally after the confirmed recovery. Only 117 articles were included in the final review with 260 confirmed cases. The severity of the reinfection episode was more severe in $92 / 260$ (35.3\%) with death only in 14 cases. The observation that many reinfection cases were less severe than initial cases is interesting because it may suggest partial protection from disease. Another interesting line of data is the detection of different clades or lineages by genome sequencing between initial infection and reinfection in 52/260 cases (20\%). The findings are useful and contribute towards the role of vaccination in response to the COVID-19 infections. Due to the reinfection cases with SARS-CoV-2, it is evident that the level of immunity is not $100 \%$ for all individuals. These data highlight how it is necessary to continue to observe all the prescriptions recently indicated in the literature in order to avoid new contagion for all people after healing from COVID-19 or becoming asymptomatic positive.
\end{abstract}

Keywords: coronavirus; reinfection; COVID-19; SARS-CoV-2; systematic review

\section{Introduction}

The novel coronavirus (SARS-CoV-2) outbreak since December 2019 has continued to exhibit devastating consequences, and was declared as a pandemic by the World Health Organization in early 2020 [1-3]. To date, as of 17 October 2021, 240,421,359 infections have been confirmed, with 4,895,034 deaths [4]. In many countries, the vaccination campaign has started with the use of various vaccines recently put on the market and the total number of vaccine doses administered is 6,609,632,994. However, a new problem is emerging with regard to the evolution of the behavior of SARS-CoV-2: the possibility of reinfection of healed subjects after the first infection. On 25 August 2020, the first case of reinfection of SARS-CoV-2 was reported in international literature [5]. This event pointed out that infection by this virus does not uniformly confer protective immunity to all infected individuals [6]. Therefore, several critical questions are intriguing the researchers. Is SARS-CoV-2 reinfection a widespread phenomenon or is it limited to few subjects with immune deficits or specific comorbidities [6]? Can this phenomenon be due to a too weak, too short, or too narrow natural immune response to SARS-CoV-2, that is unable to protect 
from subsequent exposure [6]? What is the clinical behavior, in regard to the evolution of the reinfections? Can these reinfected patients transmit the viruses? This important problem needs to be addressed, because the possibility of reinfection could drastically reduce the effectiveness of the vaccination campaigns in progress. Protective, sustainable and long-lasting immunity following COVID-19 infection is uncertain, but it is essential for the efficacity of vaccine strategy.

For some viruses, the first infection can provide lifelong immunity, for seasonal coronaviruses protective immunity is short-lived [7]. Over the years, other viruses responsible for various infectious respiratory diseases have been able to present reinfection in the originally cured subjects, such as the coronavirus HCoV-NL63 (NL63) [8] and the human respiratory syncytial virus (hRSV) [9].

The SARS-CoV-2 pandemic poses a challenge regarding the follow-up of recovered patients and the question of the reinfection risk. Several reports confirmed that most patients with SARS-CoV-2 produce antibodies against spike and N-proteins of the virus within 30 days after the infection [10,11]. In fact, an outbreak of the virus on a fishery vessel showed that fishers with prior neutralizing antibodies against SARS-CoV-2 were not reinfected [12]. The potential mechanisms that mediate immunity post-COVID-19 are not yet fully understood. COVID-19 typically follows a course similar to other respiratory viral illnesses, and it is self-limiting in more than $80 \%$ of cases [13]. An innate immune response involving $\mathrm{T}$ cells and $\mathrm{B}$ cells is activated, leading to the production of neutralizing antiviral antibodies [13]. The specific IgM antibody response starts to peak within the first 7 days [13]. Specific IgG and IgA antibodies develop a few days after IgM and are hypothesized to persist at low levels, conferring lifelong protective antibodies [14]. While this hypothesis may hold true for symptomatic patients, emerging data have revealed negative IgM and IgG during the early convalescent phase in asymptomatic patients [15] and $40 \%$ of asymptomatic patients became seronegative for $\operatorname{IgG} 8$ weeks after discharging compared with $12.9 \%$ who were seronegative for the symptomatic group [15]. A seronegative status could leave open the possibility of reinfection. Immunosuppression and comorbid diseases can be other risk factors for a reinfection [16].

However, a distinction must be made between prolonged shedding/reactivation and true reinfection [17], in fact one of the features of SARS-CoV-2 infection is prolonged virus shedding. Several studies reported persistent or recurrent elimination of viral RNA in nasopharyngeal samples starting from first contact with a positive subject [18-20]. For this reason, recently the Center for Disease Control and Prevention (CDC) released a guidance protocol designed to identify cases of real SARS-CoV-2 reinfection [21]. This guidance defines some criteria about sequencing parameters, epidemiological data and laboratory diagnostic data (Table 1). Specifically, investigative criteria include a positive RT-PCR test more than 90 days after the initial test in healed patients or a positive RT-PCR test more than 45 days after the initial test that is accompanied by compatible symptoms or epidemiological exposure, after confirmed healing.

Another emerging problem that can influence the possibility of reinfection and the vaccination efficacity is the new variants of SARS-CoV-2, such us alpha, beta, gamma and delta. A recent study on 9119 patients with SAS-CoV-2 infection identified reinfection in 63 cases $(0.7 \%, 95 \%$ confidence interval $0.5-0.9 \%)$ [22]. The mean period between two positive tests was $116 \pm 21$ days [22]. There were no significant differences based on age or sex, while nicotine dependence/tobacco use, asthma were higher in patients with reinfection [22]. There was a significantly lower rate of pneumonia, heart failure, and acute kidney injury during reinfection compared with primary infection [22]. There were two deaths $(3.2 \%)$ associated with reinfection [22]. 
Table 1. Protocol of Center for Disease Control and Prevention for investigating suspected SARS$\mathrm{CoV}-2$ reinfection.

\begin{tabular}{lll}
\hline \multicolumn{1}{c}{ Investigative Criteria } & \multicolumn{1}{c}{ Laboratory Evidence } \\
\hline 1. & $\begin{array}{l}\text { People with detected SARS-CoV-2 RNA } \\
\text { (if detected by RT-PCR, only include if Ct } \\
\text { value }<33 \text { or if Ct value unavailable) } \geq 90 \\
\text { days after the first detection of }\end{array}$ & $\begin{array}{l}\text { Best evidence } \\
\text { Differing clades as defined in Nextstrain and } \\
\text { GARS-CoV-2 RNA, whether or not }\end{array}$ \\
$\begin{array}{l}\text { Gecond infection, ideally coupled with other } \\
\text { symptoms were present }\end{array}$ & $\begin{array}{l}\text { evidence of actual infection (e.g., high viral } \\
\text { titers in each sample or positive for } \\
\text { subgenomic mRNA, and culture) }\end{array}$ \\
\hline
\end{tabular}

2. People with detection of SARS-CoV-2 RNA (if detected by RT-PCR, only include if $\mathrm{Ct}$ value $<33$ or if $\mathrm{Ct}$ value unavailable) $\geq 45$ days after the first detection of SARS-CoV-2 RNA

AND

with a symptomatic second episode and no obvious alternate etiology for COVID-19-like symptoms or close contact with a person known to have laboratory-confirmed COVID-19

\author{
Moderate evidence \\ $>2$ nucleotide differences per month ${ }^{*}$ in \\ consensus between sequences that meet quality \\ metrics above, ideally coupled with other \\ evidence of actual infection (e.g., high viral \\ titers in each sample or positive for \\ subgenomic mRNA, and culture)
} Poor evidence but possible
$\leq 2$ nucleotide differences per month * in
consensus between sequences that meet quality
metrics above or $>2$ nucleotide differences per
month ${ }^{*}$ in consensus between sequences that
do not meet quality metrics above, ideally
coupled with other evidence of actual infection
(e.g., high viral titers in each sample or positive
for subgenomic mRNA, and culture)

* The mutation rate of SARS-CoV-2 is estimated at 2 nucleotide differences per month, therefore if suspected reinfection occurs 90 days after initial infection, moderate evidence would require $>6$ nucleotide differences.

Another study conducted in Switzerland reported five cases of reinfection (1\%) in 498 seropositive individuals followed for 35 weeks [23]. Breathnach et al. examined data of 10,727 patients with COVID-19 in the first wave and individuated eight reinfection cases $(0.07 \%)$, all in female patients, and only one was admitted in hospital [24]. Bongiovanni et al. examined 677 subjects with at least a positive nasopharyngeal swab, 328 during the first wave and 349 during the second individuating $13(1.9 \%)$ cases of reinfection [25]. Vitale et al. examined a cohort of 1579 patients and reported five reinfections $(0.31 \%, 95 \%$ CI, $0.03-0.58 \%$ ), of whom only one was hospitalized and the mean (SD) interval between primary infection and reinfection was longer than 230 (90) days [26].

The understanding of COVID-19 reinfection will be key in guiding government and public health policy decisions in the coming months.

A systematic review of literature was performed in order to individuate cases of reinfection for SARS-CoV-2. To date there are more than 300 reported cases of COVID-19 reinfection from different countries such as United States [27], Ecuador [28], Hong Kong [5], and Belgium [29]. It is necessary to understand if all these cases are really reinfection.

\section{Materials and Methods}

This systematic review of literature on reinfections of SARS-CoV-2 was conducted in August 2021. Our study adhered to the Preferred Reporting Items for Systematic Reviews and Meta-Analyses (PRISMA) checklist to ensure the reliability and validity of this study and results. 


\subsection{Data Sources}

By application of a systematic search and using the keywords in the online databases including PubMed, Scopus, Web of Science, Science Direct, EMBASE, and preprint servers (MedRxiv, BioRxiv, and SSRN) on 31 July 2021, we extracted all the papers published in English from December 2019 to July 2021. We included several combinations of keywords in the following orders to conduct the search strategy: (1) "CoVID-19" or "SARS-CoV-2" or "2019-nCoV" [all field]; (2) "Reinfection" or "Re-infection" [all field].

\subsection{Study Selection}

Three independent investigators retrieved the studies that were the most relevant by titles and abstracts (ELM, LLM, MA). Subsequently, the full text of the retrieved papers was reviewed, and the most relevant papers were chosen according to the eligibility criteria. Then, we extracted the relevant data and organized them in tables. The original papers that were peer-reviewed and published in English and fulfilled the eligibility criteria were included in the final report, together with two works not reviewed at the time of preparation of this report [30,31].

The following inclusion criteria was used: a positive RT-PCR test carried out more than 90 days after the initial test in healed patients or a positive RT-PCR test carried out more than 45 days after the initial test that is accompanied by compatible symptoms or epidemiological exposure, after confirmed healing. This criteria corresponds to the CDC protocol designed to identify cases of real SARS-CoV-2 reinfection (Table 1) [32].

We considered the exclusion criteria for this study as follows: (1) papers conveying non-human studies including in vitro observations or articles focusing on animal experiments; (2) papers in which their full text were out of access; (3) any suspicious and duplicated results in the databases.

\subsection{Data Extraction}

After summarizing, we transferred the information of the authors, type of article (e.g., case reports), publication date, country of origin, age, gender, and clinical symptoms to a data extraction sheet. Three independent investigators collected this information and subsequently organized them in the tables. Finally, to ensure no duplications or overlap existed in the content, all the selected articles were cross-checked by other authors.

\subsection{Quality and Risk of Bias Assessment}

As aforementioned, we applied the PRISMA checklist to ensure the quality and reliability of selected articles. Two independent researchers evaluated the consistency and quality of the articles and the risk of bias. In either case of discrepancy in viewpoints, a third independent researcher resolved the issue. The full text of selected articles was read, and the key findings were extracted.

Included studies underwent quality check and risk of bias assessment. This qualitative analysis was performed according Murad's quality checklist of case series and case report [33]. As reported, the scale consists of four parameters, to evaluate the (a) patient selection; (b) exposure ascertainment; (c) causality; (d) reporting. Each section contains one to four question to be addressed. As it is suggested we performed an overall judgement about methodological quality since questions 4,5 and 6 are mostly relevant to cases of adverse drug events. Each requested field will be considered as adequate, inadequate or not evaluable. The table showing this tool for evaluating the methodological quality of case reports and case series, is reported in the original manuscript [33].

\section{Results}

In this study, 117 documents were identified using the systematic search strategy. After a primary review of 2201 retrieved articles, 379 duplicates were removed, and the title and abstract of the remaining 1822 resources were reviewed. After applying the selection 
criteria, only 117 articles met the inclusion criteria and were included in the final review (Figure 1). Therefore, the cases confirmed according to these parameters were 260 (Table 2).

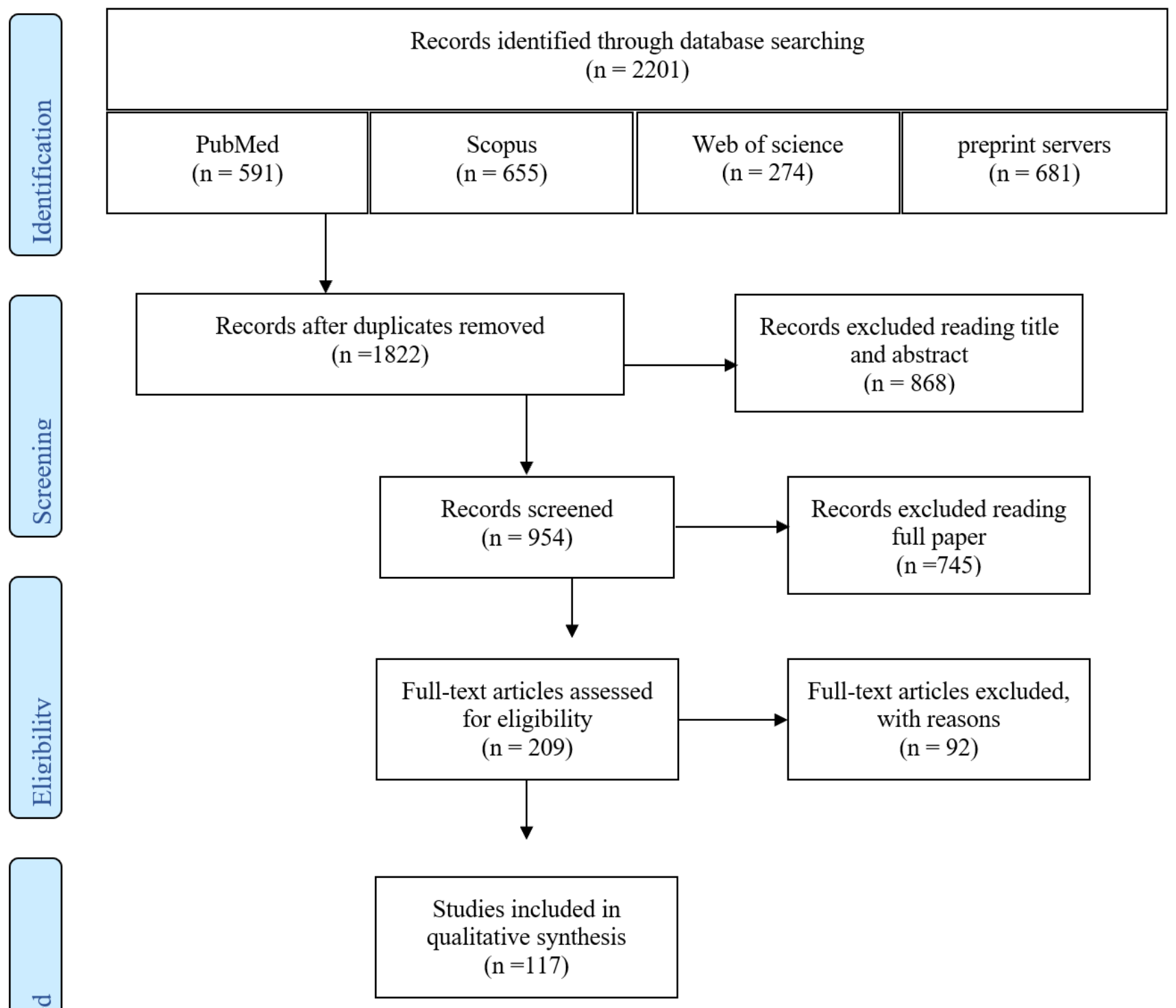

Figure 1. Flow diagram for the selection process of identified articles. 


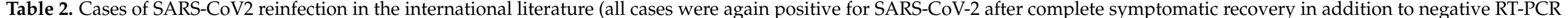
test for SARS-CoV-2, according to WHO recommendations [34]).

\begin{tabular}{|c|c|c|c|c|c|c|c|c|c|}
\hline & Authors & Year & $\begin{array}{l}\text { Patient } \\
\text { Country }\end{array}$ & Patient & $\begin{array}{l}\text { Interval Time between } 1 \\
\text { Infection and Reinfection }\end{array}$ & Viral Genome Sequence & COVID-19 & Symptoms & $\begin{array}{l}\text { Antibody after First } \\
\text { Infection or } \\
\text { Reinfection } \\
\end{array}$ \\
\hline \multirow[t]{2}{*}{1.} & \multirow{2}{*}{$\begin{array}{l}\text { Abu-Raddad LJ et al. } \\
\text { [35]—-case } 27\end{array}$} & \multirow{2}{*}{2021} & \multirow{2}{*}{ Qatar } & \multirow{2}{*}{$\begin{array}{l}\text { 25-29-year-old } \\
\text { man }\end{array}$} & \multirow{2}{*}{46} & \multirow{2}{*}{$\begin{array}{l}9 \mathrm{SNVs} \text { compared to initial } \\
\text { infection strain, including D614G }\end{array}$} & Mild & $\mathrm{N} / \mathrm{A}$ & \multirow{2}{*}{$\mathrm{N} / \mathrm{A}$} \\
\hline & & & & & & & Mild & $\mathrm{N} / \mathrm{A}$ & \\
\hline \multirow[t]{2}{*}{2.} & \multirow{2}{*}{$\begin{array}{l}\text { Abu-Raddad LJ et al. } \\
\text { [35]—case } 33\end{array}$} & \multirow{2}{*}{2021} & \multirow{2}{*}{ Qatar } & \multirow{2}{*}{$\begin{array}{l}\text { 40-44-year-old } \\
\text { man }\end{array}$} & \multirow{2}{*}{71} & \multirow{2}{*}{$\begin{array}{l}11 \mathrm{SNV} \text { s compared to initial } \\
\text { infection strain, including D614G }\end{array}$} & Mild & $\mathrm{N} / \mathrm{A}$ & \multirow{2}{*}{$\mathrm{N} / \mathrm{A}$} \\
\hline & & & & & & & Mild & N/A & \\
\hline \multirow{2}{*}{3.} & \multirow{2}{*}{$\begin{array}{l}\text { Abu-Raddad LJ et al. } \\
\text { [35]—case } 20\end{array}$} & \multirow{2}{*}{2021} & \multirow{2}{*}{ Qatar } & \multirow{2}{*}{$\begin{array}{l}\text { 45-49-year-old } \\
\text { woman }\end{array}$} & \multirow{2}{*}{88} & \multirow{2}{*}{$\begin{array}{l}\text { 3 SNVs compared to initial } \\
\text { infection strain, including D614G }\end{array}$} & Mild & $\mathrm{N} / \mathrm{A}$ & \multirow{2}{*}{$\begin{array}{l}\text { ROCHE elecsys } \\
\text { antiSARS-CoV-2 } \\
\text { negative at time of } \\
\text { reinfection }\end{array}$} \\
\hline & & & & & & & Mild & $\mathrm{N} / \mathrm{A}$ & \\
\hline \multirow{2}{*}{4.} & \multirow{2}{*}{$\begin{array}{l}\text { Abu-Raddad LJ et al. } \\
\text { [35]—case } 44\end{array}$} & \multirow{2}{*}{2021} & \multirow{2}{*}{ Qatar } & \multirow{2}{*}{$\begin{array}{l}\text { 25-29-year-old } \\
\text { woman }\end{array}$} & \multirow{2}{*}{55} & \multirow{2}{*}{$\begin{array}{l}1 \mathrm{SNVs} \text { compared to initial } \\
\text { infection strain, including D614G }\end{array}$} & Mild & N/A & \multirow{2}{*}{$\mathrm{N} / \mathrm{A}$} \\
\hline & & & & & & & Mild & N/A & \\
\hline \multirow[b]{2}{*}{5.} & \multirow[b]{2}{*}{$\begin{array}{l}\text { Adrielle dos Santos L et al. } \\
\text { [36] }\end{array}$} & \multirow[b]{2}{*}{2021} & & 44-year-old & & $20 \mathrm{~A}$ & Mild & $\begin{array}{c}\text { Dry cough, dyspnea, dysgeusia, } \\
\text { diarrhea, asthenia, sneezing/runny } \\
\text { nose }\end{array}$ & \\
\hline & & & Brazil & $\begin{array}{l}\text { with systemic } \\
\text { arterial } \\
\text { hypertension, } \\
\text { obesity }\end{array}$ & 53 & Clade B.1.1.28 & Worse & $\begin{array}{l}\text { Dry cough, dyspnea, fever, myalgia, } \\
\text { asthenia, arthralgia, headache, } \\
\text { nausea/vomiting, sneezing/runny } \\
\text { nose, severe respiratory symptoms and } \\
\text { was admitted to ICU, dying after } 20 \\
\text { days of symptoms }\end{array}$ & $\mathrm{N} / \mathrm{A}$ \\
\hline & [37] & 2021 & & healthcare man & 200 & 201/501Y.V1.Britain variant B.1.17 & Milder & $\begin{array}{l}\text { Sore throat, slight general malaise, nasal } \\
\text { congestion, tiredness }\end{array}$ & $\begin{array}{l}\text { Rapid antibody test: } \\
\text { positive }\end{array}$ \\
\hline & & & & 36-vear-old & & & Mild & $\begin{array}{l}\text { Lethargy, fatigue, shortness of breath, } \\
\text { headache, fever, chills }\end{array}$ & \\
\hline 7. & Ahmadian S et al. [38] & 2021 & Iran & healthcare man & 60 & $\mathrm{~N} / \mathrm{A}$ & Milder & $\begin{array}{l}\text { Eye infection, fever, fatigue, shortness } \\
\text { of breath, muscle pain }\end{array}$ & $\mathrm{N} / \mathrm{A}$ \\
\hline 8 & Ahmed A et al [39] & 2021 & Pakictan & Healthcare worker & 118 & $\mathrm{~N} / \mathrm{A}$ & Mild & Arthralgia, weakness, anosmia, ageusia & 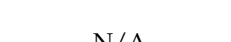 \\
\hline 0. & Anmed A et dit. [ST] & 2021 & Pakistan & $\operatorname{man}$ & 118 & N/A & Milder & Fever, sore throat, dry cough & N/A \\
\hline 9 & Ahmed A et al [39] & 2021 & Pakistan & Healthcare worker & 86 & $\mathrm{~N} / \mathrm{A}$ & Mild & Fever, sore throat & N/A \\
\hline . & 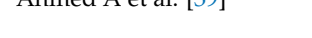 & 2021 & Takistan & $\operatorname{man}$ & 06 & N $/ \mathrm{A}$ & Milder & Sinusitis & $\mathrm{N} / \mathrm{A}$ \\
\hline
\end{tabular}


Table 2. Cont.

\begin{tabular}{|c|c|c|c|c|c|c|c|c|}
\hline Authors & Year & $\begin{array}{l}\text { Patient } \\
\text { Country }\end{array}$ & Patient & $\begin{array}{l}\text { Interval Time between } 1 \\
\text { Infection and Reinfection }\end{array}$ & Viral Genome Sequence & COVID-19 & Symptoms & $\begin{array}{l}\text { Antibody after First } \\
\text { Infection or } \\
\text { Reinfection } \\
\end{array}$ \\
\hline \multirow{2}{*}{ Ak R et al. [40] } & \multirow{2}{*}{2021} & \multirow{2}{*}{ Pakistan } & \multirow{2}{*}{ 40-year-old male } & \multirow{2}{*}{94} & \multirow{2}{*}{ N/A } & Mild & Fever & \multirow{2}{*}{ N/A } \\
\hline & & & & & & Worse & Sore throat, cough, diarrhea & \\
\hline \multirow[b]{2}{*}{ Aldossary B et al. [41] } & \multirow[b]{2}{*}{2021} & \multirow[b]{2}{*}{ Bahrain } & \multirow{2}{*}{$\begin{array}{c}\text { 47-year-old } \\
\text { woman without } \\
\text { comorbidities }\end{array}$} & \multirow[b]{2}{*}{60} & \multirow[b]{2}{*}{ N/A } & Mild & Mild respiratory tract symptoms & \multirow[b]{2}{*}{$\mathrm{N} / \mathrm{A}$} \\
\hline & & & & & & Worse & $\begin{array}{l}\text { Abdominal pain, fulminant hepatic } \\
\text { failure }>\text { death }\end{array}$ & \\
\hline $\begin{array}{l}\text { 12. Ali A. et al. [42] } \\
\text { Patient } 1\end{array}$ & 2020 & Iran & $\begin{array}{l}\text { 20s year age range, } \\
\text { male }\end{array}$ & $89 * *$ & N/A & Mild & Fever, myalgia & $\begin{array}{l}6.7 \mathrm{IgG}(\mathrm{s} / \mathrm{ca}) \text { after } \\
\text { recovery }\end{array}$ \\
\hline \multirow{2}{*}{$\begin{array}{l}\text { 13. Ali A. et al. [42] } \\
\text { Patient } 2\end{array}$} & \multirow[b]{2}{*}{2020} & \multirow[b]{2}{*}{ Iran } & \multirow{2}{*}{$\begin{array}{l}\text { 30s year age range, } \\
\text { female }\end{array}$} & \multirow[b]{2}{*}{$55^{* *}$} & \multirow[b]{2}{*}{$\mathrm{N} / \mathrm{A}$} & Mild & Fever, myalgia & \multirow{2}{*}{$\begin{array}{l}10.3 \mathrm{IgG}(\mathrm{s} / \mathrm{ca}) \text { after } \\
\text { recovery }\end{array}$} \\
\hline & & & & & & Worse & $\begin{array}{l}\text { Fever, loss of taste and smell, myalgia, } \\
\text { cough }\end{array}$ & \\
\hline 14. Ali A. et al. [42] & \multirow{2}{*}{2020} & \multirow{2}{*}{ Iran } & \multirow{2}{*}{$\begin{array}{l}\text { 40s year age range, } \\
\text { male }\end{array}$} & $55^{* *}$ & $\mathrm{~N} / \mathrm{A}$ & Mild & Fever, myalgia & $15.5 \operatorname{IgG}(\mathrm{s} / \mathrm{ca})$ after \\
\hline Patient 5 & & & & 30 & N $/ \mathrm{A}$ & Mild & Fever, myalgia, cough & recovery \\
\hline 15. Ali A. et al. [42] & & & & & & Mild & Fever, myalgia & \\
\hline Patient 8 & 2020 & Iran & $\begin{array}{l}\text { 50s year age range, } \\
\text { male }\end{array}$ & $46^{* *}$ & N/A & Worse & $\begin{array}{l}\text { Fever, loss of taste and smell, myalgia, } \\
\text { cough }\end{array}$ & $\begin{array}{l}\text { 10.3 } 1 \text { gecovery } \\
\text { recter }\end{array}$ \\
\hline Patient 9 & 2020 & Hart & female & 30 & N/A & Milder & Fever, myalgia, cough & recovery \\
\hline 17. Ali A. et al. [42] & & & 40s year age ranoe & & & Mild & Fever, myalgia & $722 \mathrm{JoG}(\mathrm{s} / \mathrm{ca})$ after \\
\hline Patient 11 & 2020 & Iran & male & $76^{* 4}$ & N/A & Worse & $\begin{array}{l}\text { Fever, loss of taste and smell, myalgia, } \\
\text { cough }\end{array}$ & recovery \\
\hline 18. Ali A. et al. [42] & & & & & & Mild & Fever, myalgia & $112 \mathrm{ICC}(\mathrm{s} / \mathrm{c}$ ) \\
\hline Patient 12 & 2020 & Iran & $\begin{array}{l}\text { female } \\
\text { fese, }\end{array}$ & $45^{* *}$ & $\mathrm{~N} / \mathrm{A}$ & Worse & $\begin{array}{l}\text { Fever, loss of taste and smell, myalgia, } \\
\text { cough }\end{array}$ & recovery \\
\hline 19. Ali A. et al. [42] & & & 40 s year age range & & & Mild & Fever, loss of taste and smell, myalgia & $1251 \mathrm{LoG}(\mathrm{s} / \mathrm{ca}$ a after \\
\hline Patient 14 & 2020 & Iran & $\begin{array}{l}\text { male } \\
\text { mons }\end{array}$ & $50 * *$ & N/A & Mild & $\begin{array}{l}\text { Fever, loss of taste and smell, myalgia, } \\
\text { cough }\end{array}$ & recovery \\
\hline 20. Ali A. et al. [42] & & & & & & Mild & Fever, cough & $7.11 \mathrm{IgG}(\mathrm{s} / \mathrm{ca})$ after \\
\hline Patient 16 & 2020 & Iran & male & $62^{* *}$ & N/A & Worse & $\begin{array}{l}\text { Fever, loss of taste and smell, myalgia, } \\
\text { cough }\end{array}$ & recovery \\
\hline
\end{tabular}


Table 2. Cont.

\begin{tabular}{|c|c|c|c|c|c|c|c|c|}
\hline Authors & Year & $\begin{array}{l}\text { Patient } \\
\text { Country }\end{array}$ & Patient & $\begin{array}{c}\text { Interval Time between } 1 \\
\text { Infection and Reinfection }\end{array}$ & Viral Genome Sequence & COVID-19 & Symptoms & $\begin{array}{l}\text { Antibody after First } \\
\text { Infection or } \\
\text { Reinfection }\end{array}$ \\
\hline $\begin{array}{l}\text { 21. Ali A. et al. [42] } \\
\text { Patient } 17\end{array}$ & 2020 & Iran & $\begin{array}{l}\text { 40s year age } \\
\text { range, female }\end{array}$ & $49^{* *}$ & N/A & Mild & Fever & $\begin{array}{l}8.37 \mathrm{IgG}(\mathrm{s} / \mathrm{ca}) \text { after } \\
\text { recovery }\end{array}$ \\
\hline \multirow{2}{*}{$\begin{array}{l}\text { 22. Ali A. et al. [42] } \\
\text { Patient } 18\end{array}$} & \multirow[b]{2}{*}{2020} & \multirow[b]{2}{*}{ Iran } & \multirow{2}{*}{$\begin{array}{l}40 \text { s year age } \\
\text { range, male }\end{array}$} & \multirow[b]{2}{*}{$72^{* *}$} & \multirow[b]{2}{*}{ N/A } & Mild & Fever & \multirow{2}{*}{$\begin{array}{l}5.11 \mathrm{IgG}(\mathrm{s} / \mathrm{ca}) \text { after } \\
\text { recovery }\end{array}$} \\
\hline & & & & & & Worse & $\begin{array}{l}\text { Fever, loss of taste and smell, } \\
\text { myalgia, cough }\end{array}$ & \\
\hline \multirow{2}{*}{$\begin{array}{l}\text { 23. Ali A. et al. [42] } \\
\text { Patient } 20\end{array}$} & \multirow{2}{*}{2020} & \multirow{2}{*}{ Iran } & \multirow{2}{*}{$\begin{array}{l}30 \text { s year age } \\
\text { range, male }\end{array}$} & \multirow{2}{*}{$59 * *$} & \multirow{2}{*}{ N/A } & Mild & $\begin{array}{l}\text { Fever, loss of taste and smell, } \\
\text { myalgia }\end{array}$ & \multirow{2}{*}{$\begin{array}{c}\text { 6.3 IgG }(\mathrm{s} / \mathrm{ca}) \text { after } \\
\text { recovery }\end{array}$} \\
\hline & & & & & & Mild & $\begin{array}{l}\text { Fever, loss of taste and smell, } \\
\text { myalgia, cough }\end{array}$ & \\
\hline \multirow{2}{*}{$\begin{array}{l}\text { 24. Ali A. et al. [42] } \\
\text { Patient } 22\end{array}$} & \multirow[b]{2}{*}{2020} & \multirow[b]{2}{*}{ Iran } & \multirow[b]{2}{*}{$\begin{array}{l}50 \text { s year age } \\
\text { range, male }\end{array}$} & \multirow[b]{2}{*}{$53^{* *}$} & \multirow[b]{2}{*}{ N/A } & Mild & Fever, myalgia & \multirow[b]{2}{*}{$\begin{array}{c}9.3 \mathrm{IgG}(\mathrm{s} / \mathrm{ca}) \text { after } \\
\text { recovery }\end{array}$} \\
\hline & & & & & & Worse & $\begin{array}{l}\text { Fever, loss of taste and smell, } \\
\text { myalgia, cough }\end{array}$ & \\
\hline $\begin{array}{l}\text { 25. Ali A. et al. [42] } \\
\text { Patient } 23\end{array}$ & 2020 & Iran & $\begin{array}{l}\text { 20s year age } \\
\text { range, male }\end{array}$ & $49^{* *}$ & N/A & Mild & Fever, myalgia & $\begin{array}{c}7.25 \operatorname{IgG}(\mathrm{s} / \mathrm{ca}) \text { after } \\
\text { recovery }\end{array}$ \\
\hline 26. Ali A. et al. [42] & 2020 & Iran & 40s year age & $52 * *$ & N/A & Mild & Fever, myalgia & $6.21 \mathrm{IgG}(\mathrm{s} / \mathrm{ca})$ after \\
\hline Patient 24 & $20 \angle 0$ & Iran & range, female & $52 \cdots$ & N/A & Worse & Loss of taste and smell, myalgia & recovery \\
\hline 27. Ali A. et al. [42] & 2020 & Iran & 20s year age & $54^{* *}$ & $\mathrm{~N} / \mathrm{A}$ & Mild & Fever & 11.9 $\mathrm{IgG}(\mathrm{s} / \mathrm{ca})$ after \\
\hline Patient 25 & 2020 & Iran & range, female & 54 & N/A & Mild & Fever, cough & recovery \\
\hline 28. Ali A. et al. [42] & 2020 & Iran & $\begin{array}{l}\text { 30s year age } \\
\text { range male }\end{array}$ & $138 * *$ & $\mathrm{~N} / \mathrm{A}$ & Moderate & $\begin{array}{l}\text { Fever, loss of taste and smell, } \\
\text { myalgia, cough }\end{array}$ & $2.08 \operatorname{IgG}(\mathrm{s} / \mathrm{ca})$ after \\
\hline Patient 26 & & & & & & Asymptomatic & Asymptomatic & \\
\hline & & & 46-year-old & & & Mild & Sore throat & \\
\hline 29. AlFehaidi A et al. [43] & 2020 & Qatar & $\begin{array}{l}\text { woman with } \\
\text { mild asthma }\end{array}$ & 80 & N/A & Moderate & $\begin{array}{l}\text { Chest pain, fever, sore throat, body } \\
\text { pain, cough, mild dyspnea }\end{array}$ & $\mathrm{N} / \mathrm{A}$ \\
\hline
\end{tabular}


Table 2. Cont.

\begin{tabular}{|c|c|c|c|c|c|c|c|c|c|}
\hline & Authors & Year & $\begin{array}{l}\text { Patient } \\
\text { Country }\end{array}$ & Patient & $\begin{array}{l}\text { Interval Time between } 1 \\
\text { Infection and Reinfection }\end{array}$ & Viral Genome Sequence & COVID-19 & Symptoms & $\begin{array}{c}\text { Antibody after First } \\
\text { Infection or } \\
\text { Reinfection } \\
\end{array}$ \\
\hline \multirow[t]{2}{*}{30.} & \multirow[t]{2}{*}{ Alshukairi AN et al. [44] } & \multirow[t]{2}{*}{2021} & \multirow[t]{2}{*}{ Saudi Arabia } & $\begin{array}{l}\text { 51-year-old } \\
\text { woman with } \\
\text { autologous } \\
\text { hematopoietic } \\
\text { stem cell } \\
\text { transplantation for } \\
\text { follicular }\end{array}$ & \multirow[t]{2}{*}{160} & $19 \mathrm{~B}$ & Mild & Fever, cough, malaise, and headache & \multirow[t]{2}{*}{$\begin{array}{l}\text { Negative COVID-19 } \\
\text { serology after 1st } \\
\text { infection and } \\
\text { reinfection }\end{array}$} \\
\hline & & & & lymphoma & & $20 \mathrm{~B}$ & Mild & Fever and dyspnea & \\
\hline 31. & Amikishiyes S et al. [16] & 2021 & Turkey & $\begin{array}{l}\text { 34-year-old man } \\
\text { with chronic } \\
\text { glomerulonephri- } \\
\text { tis } \\
\end{array}$ & $>150$ & $\mathrm{~N} / \mathrm{A}$ & Worse & $\begin{array}{l}\text { Cough, fever, bilateral infiltrates at } \\
\text { computed chest tomography }\end{array}$ & $\mathrm{N} / \mathrm{A}$ \\
\hline \multirow[b]{2}{*}{32.} & \multirow[b]{2}{*}{ Amorin MR et al. [45] } & \multirow[b]{2}{*}{2021} & \multirow[b]{2}{*}{ Brazil } & \multirow{2}{*}{$\begin{array}{l}\text { 35-year-old } \\
\text { healthcare worker } \\
\text { woman }\end{array}$} & \multirow[b]{2}{*}{55} & \multirow[b]{2}{*}{$\mathrm{N} / \mathrm{A}$} & Mild & $\begin{array}{l}\text { Fever, headache, chills, sneezing, } \\
\text { coryza, myalgia }\end{array}$ & \multirow[b]{2}{*}{$\mathrm{N} / \mathrm{A}$} \\
\hline & & & & & & & Mild & $\begin{array}{l}\text { Headache, nasal congestion, } \\
\text { odynophagia, ageusia, anosmia }\end{array}$ & \\
\hline \multirow{2}{*}{33.} & \multirow{2}{*}{ Amorin MR et al. [45] } & \multirow{2}{*}{2021} & \multirow{2}{*}{ Brazil } & \multirow{2}{*}{$\begin{array}{l}\text { 61-year-old } \\
\text { healthcare worker } \\
\text { woman with } \\
\text { chronic bronchitis }\end{array}$} & \multirow{2}{*}{170} & \multirow{2}{*}{$\mathrm{N} / \mathrm{A}$} & Mild & $\begin{array}{c}\text { Headache, cough, myalgia, } \\
\text { odynophagia, coryza, diarrhea, ageusia }\end{array}$ & \multirow{2}{*}{$\mathrm{N} / \mathrm{A}$} \\
\hline & & & & & & & Mild & $\begin{array}{l}\text { Cough, myalgia, odynophagia, anosmia, } \\
\text { diarrhea }\end{array}$ & \\
\hline 34. & Amorin MR et al. [45] & 2021 & Brazil & $\begin{array}{c}\text { 40-year-old } \\
\text { healthcare worker } \\
\text { woman }\end{array}$ & 131 & $\mathrm{~N} / \mathrm{A}$ & Mild & $\begin{array}{l}\text { Odynophagia, sneezing, coryza, } \\
\text { diarrhea, ageusia, anosmia }\end{array}$ & $\mathrm{N} / \mathrm{A}$ \\
\hline & & & & 40-year-old & & & Mild & $\begin{array}{l}\text { Fever, headache, myalgia, coryza, dry } \\
\text { cough, vomiting, malaise }\end{array}$ & \\
\hline 35 . & Amorin MR et al. [45] & 2021 & Brazil & $\begin{array}{l}\text { healthcare worker } \\
\text { woman }\end{array}$ & 148 & $\mathrm{~N} / \mathrm{A}$ & Mild & $\begin{array}{l}\text { Odynophagia, dry cough, myalgia, } \\
\text { malaise, coryza, headache }\end{array}$ & $\mathrm{N} / \mathrm{A}$ \\
\hline 36. & Arteaga-Livias K et al. & 2021 & Peru & $\begin{array}{c}\text { 42-year-old } \\
\text { healthcare worker }\end{array}$ & 107 & N/A & $\begin{array}{l}\text { Mild with } \\
\text { home } \\
\text { management }\end{array}$ & $\begin{array}{l}\text { Odynophagia, headache, malaise, } \\
\text { rhinorrhea, ageusia, anosmia, cough }\end{array}$ & IgM and IgG+ \\
\hline & & & & woman & & & $\begin{array}{l}\text { Worse with } \\
\text { home } \\
\text { management }\end{array}$ & $\begin{array}{l}\text { Chest pain, productive cough, anosmia, } \\
\text { pneumonia }\end{array}$ & \\
\hline 37. & Atici S et al. [47] & 2021 & Turkey & $\begin{array}{c}\text { 46-year-old } \\
\text { healthcare worker } \\
\text { man }\end{array}$ & 114 & $\mathrm{~N} / \mathrm{A}$ & Moderate & $\begin{array}{c}\text { Fever, sore throat, headache, cough, } \\
\text { weakness, nausea and diarrhea, } \\
\text { bilateral ground glass opacities and } \\
\text { peribronchial thickening predominating } \\
\text { on the right } \\
\text { lung }\end{array}$ & $\mathrm{N} / \mathrm{A}$ \\
\hline & & & & & & & Mild & $\begin{array}{c}\text { Sore throat, fever, headache, myalgia, } \\
\text { weakness and nausea }\end{array}$ & \\
\hline
\end{tabular}


Table 2. Cont.

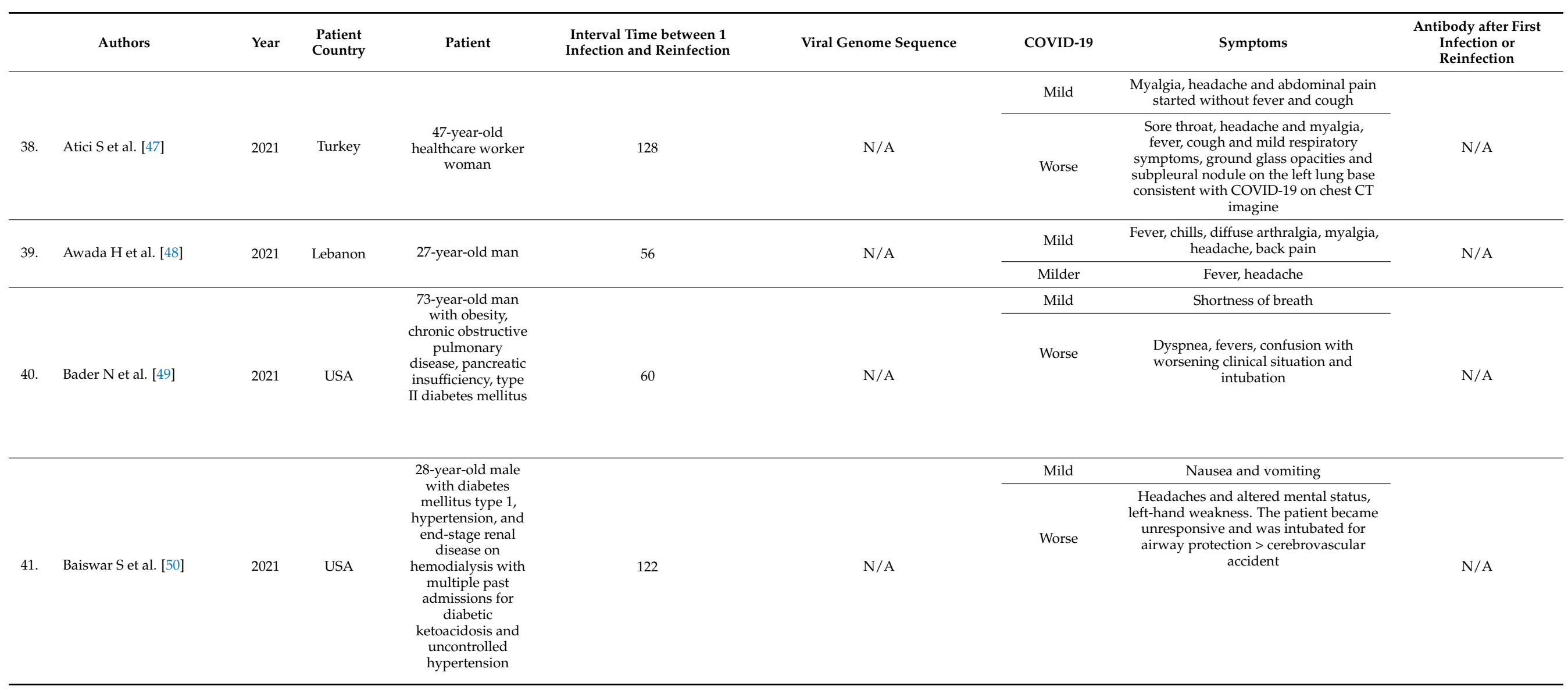


Table 2. Cont.

\begin{tabular}{|c|c|c|c|c|c|c|c|c|c|}
\hline & Authors & Year & $\begin{array}{l}\text { Patient } \\
\text { Country }\end{array}$ & Patient & $\begin{array}{l}\text { Interval Time between } 1 \\
\text { Infection and Reinfection }\end{array}$ & Viral Genome Sequence & COVID-19 & Symptoms & $\begin{array}{l}\text { Antibody after First } \\
\text { Infection or } \\
\text { Reinfection }\end{array}$ \\
\hline \multirow[b]{2}{*}{42.} & \multirow[b]{2}{*}{ Bellesso M et al. [51] } & \multirow[b]{2}{*}{2021} & \multirow[b]{2}{*}{ Brazil } & \multirow{2}{*}{$\begin{array}{l}\text { 76-year-old female } \\
\text { with end-stage } \\
\text { kidney disease } \\
\text { related to lambda } \\
\text { light chain } \\
\text { multiple myeloma }\end{array}$} & & \multirow[b]{2}{*}{$\mathrm{N} / \mathrm{A}$} & Moderate & Hip pain, confusion, respiratory distress & \multirow[b]{2}{*}{$\mathrm{N} / \mathrm{A}$} \\
\hline & & & & & 126 & & Worse & $\begin{array}{l}\text { Dyspnea, acute respiratory failure, } \\
\text { hypoxemia }>\text { death }\end{array}$ & \\
\hline \multirow[t]{2}{*}{43.} & \multirow[t]{2}{*}{ Bongiovanni M. [52] } & \multirow[t]{2}{*}{2020} & \multirow[t]{2}{*}{ Italy } & \multirow{2}{*}{$\begin{array}{l}\text { 48-year-old nurse } \\
\text { female }\end{array}$} & \multirow[t]{2}{*}{90} & \multirow[t]{2}{*}{$\mathrm{N} / \mathrm{A}$} & Mild & Dry cough, mild fever & $\begin{array}{l}\text { LIASON }^{\circledR} \text { SARS-CoV-2 } \\
\text { S1/S2 IgG+ } 30 \mathrm{Au} / \mathrm{mL}\end{array}$ \\
\hline & & & & & & & Asymptomatic & Asymptomatic & $\mathrm{IgG}+102.9 \mathrm{Au} / \mathrm{mL}$ \\
\hline \multirow[b]{2}{*}{44.} & \multirow[b]{2}{*}{ Bonifacio LP et al. [53] } & \multirow[b]{2}{*}{2020} & \multirow[b]{2}{*}{ Brazil } & \multirow[b]{2}{*}{$\begin{array}{l}\text { 24-year-old white } \\
\text { female without } \\
\text { comorbidities }\end{array}$} & \multirow[b]{2}{*}{76} & \multirow[b]{2}{*}{$\mathrm{N} / \mathrm{A}$} & $\begin{array}{l}\text { Mild with } \\
\text { complete } \\
\text { resolution at } \\
\text { home within } \\
10 \text { days }\end{array}$ & $\begin{array}{l}\text { Headache, malaise, adynamia, feverish } \\
\text { sensation, sore throat, nasal congestion }\end{array}$ & $\mathrm{N} / \mathrm{A}$ \\
\hline & & & & & & & $\begin{array}{l}\text { Worse with } \\
\text { home } \\
\text { resolution in } \\
12 \text { days, } \\
\text { headache and } \\
\text { hyposmia for } \\
63 \text { days }\end{array}$ & $\begin{array}{l}\text { Malaise, myalgia, severe headache, } \\
\text { fatigue, weakness, feverish sensation, } \\
\text { sore throat, anosmia, dysgeusia, } \\
\text { diarrhea, coughing }\end{array}$ & $\begin{array}{c}\mathrm{IgG} / \mathrm{IgM}-\text { at } \\
\text { NAAT+IgG/IgM+ } 28 \\
\text { days after NAAT+ }\end{array}$ \\
\hline \multirow[b]{2}{*}{45.} & \multirow[b]{2}{*}{ Borgogna C et al. [54] } & \multirow[b]{2}{*}{2021} & \multirow[b]{2}{*}{ Italy } & \multirow[b]{2}{*}{$\begin{array}{l}\text { 52-year-old man } \\
\text { with transitional } \\
\text { cell carcinoma of } \\
\text { the renal pelvis }\end{array}$} & \multirow[b]{2}{*}{110} & $\begin{array}{c}\text { Clade 20B and Pangolin lineage } \\
\text { B.1.1 }\end{array}$ & Mild & Cough, fever & \\
\hline & & & & & & Clade 20A and Pangolin lineage B.1 & Milder & Fever & $\begin{array}{c}\text { Very low levels of IgG } \\
\text { anti-SARS-CoV-2 Spike } \\
\text { protein, positive IgG } \\
\text { anti-SARS-CoV-2 N } \\
\text { protein }\end{array}$ \\
\hline
\end{tabular}


Table 2. Cont.

\begin{tabular}{|c|c|c|c|c|c|c|c|c|c|}
\hline & Authors & Year & $\begin{array}{l}\text { Patient } \\
\text { Country }\end{array}$ & Patient & $\begin{array}{c}\text { Interval Time between } 1 \\
\text { Infection and Reinfection }\end{array}$ & Viral Genome Sequence & COVID-19 & Symptoms & $\begin{array}{l}\text { Antibody after First } \\
\text { Infection or } \\
\text { Reinfection }\end{array}$ \\
\hline \multirow{2}{*}{46.} & \multirow{2}{*}{ Brehm TT et al. [55] } & \multirow{2}{*}{2021} & \multirow{2}{*}{ Germany } & \multirow{2}{*}{$\begin{array}{l}\text { 27-year-old } \\
\text { female nurse }\end{array}$} & \multirow{2}{*}{282} & $\begin{array}{l}\text { HH-24.I } \\
(19 \mathrm{~A})\end{array}$ & Mild & Fever, chills, dyspnea & $\begin{array}{c}\text { IgG } \\
\text { anti-SARS-CoV-2 } \\
\text { Spike protein: } 40 \\
\text { AU/mL in July 2020, } \\
15 \mathrm{AU} / \mathrm{mL} \text { in } \\
\text { September } 2020\end{array}$ \\
\hline & & & & & & $\begin{array}{c}\text { HH-24.II (20EU1) with } \\
\text { differences in } 21 \text { positions, } \\
\text { including } 2 \text { typical variations } \\
\text { in spike proteins A222V and } \\
\text { D614G }\end{array}$ & Milder & Dry cough, mild rhinorrhea & $\begin{array}{c}\text { IgG } \\
\text { anti-SARS-CoV-2 } \\
\text { Spike protein: } 97 \\
\text { AU/mL on } 29 \\
\text { December }\end{array}$ \\
\hline \multirow[t]{2}{*}{47.} & \multirow[t]{2}{*}{ Buddingh EP et al. [56] } & \multirow[t]{2}{*}{2021} & \multirow[t]{2}{*}{$\begin{array}{l}\text { The } \\
\text { Netherlands }\end{array}$} & \multirow[t]{2}{*}{ 16-year-old girl } & \multirow[t]{2}{*}{390} & Classic & Moderate & $\begin{array}{c}\text { High fever, mild conjunctivitis, } \\
\text { malaise, chest pain, coughing, } \\
\text { abdominal pain and diarrhea. She } \\
\text { was diagnosed with myocarditis, } \\
\text { shock and had high inflammatory } \\
\text { parameters. }\end{array}$ & \multirow[t]{2}{*}{$\begin{array}{l}\text { IgG SARS-CoV-2 } \\
\text { was negative (Abbott } \\
\text { SARS-CoV-2 IgG; } \\
\text { Abbott Laboratories) }\end{array}$} \\
\hline & & & & & & B.1.1.7 variant (UK variant), & Mild & Mild respiratory symptoms & \\
\hline \multirow{2}{*}{48.} & \multirow{2}{*}{ Caralis P. [57] } & \multirow{2}{*}{2021} & \multirow{2}{*}{ USA } & \multirow{2}{*}{60 with diabetes } & \multirow{2}{*}{72} & \multirow{2}{*}{$\mathrm{N} / \mathrm{A}$} & Mild & Acute renal failure & \\
\hline & & & & & & & Milder & Fatigue & \\
\hline \multirow{2}{*}{49.} & \multirow{2}{*}{ Caralis P. [57] } & \multirow{2}{*}{2021} & \multirow{2}{*}{ USA } & \multirow{2}{*}{$\begin{array}{l}27 \text { with psoriatic } \\
\text { arthritis }\end{array}$} & \multirow{2}{*}{79} & \multirow{2}{*}{ N/A } & Mild & Fever, flu-like & \multirow{2}{*}{ IgG+ } \\
\hline & & & & & & & Milder & Fatigue, loss taste & \\
\hline \multirow{2}{*}{50.} & \multirow{2}{*}{ Caralis P. [57] } & \multirow{2}{*}{2021} & \multirow{2}{*}{ USA } & \multirow{2}{*}{$\begin{array}{c}33 \text { year-old } \\
\text { woman with } \\
\text { allergic rhinitis }\end{array}$} & \multirow{2}{*}{172} & \multirow{2}{*}{ N/A } & Mild & Fever, cough, diarrhea & \multirow{2}{*}{$\operatorname{IgG}+$} \\
\hline & & & & & & & Milder & Fever headache & \\
\hline 51. & Caralis P. [57] & 2021 & USA & $\begin{array}{l}71 \text { with } \\
\text { renal/liver }\end{array}$ & 93 & N/A & Moderate & $\begin{array}{l}\text { Fever, pneumonia, respiratory } \\
\text { insufficiency }\end{array}$ & \\
\hline & & & & $\begin{array}{l}\text { transplant HIV, } \\
\text { diabetes }\end{array}$ & & & Asymptomatic & Asymptomatic & \\
\hline 52 & Caralis P [57] & 2021 & USA & 72 with pul- & 111 & $\mathrm{~N} / \mathrm{A}$ & Mild & Dyspnea, fatigue, headache & \\
\hline . & ] & 2021 & USA & $\begin{array}{c}\text { monary / cardiac } \\
\text { sarcoidosis }\end{array}$ & 111 & N/R & Milder & Fatigue & \\
\hline 53. & Cavanagaugh AM et al. & & & M (80-89 vears & & & Asymptomatic & asymptomatic & \\
\hline & [58] & 2021 & USA & old) & 101 & $\mathrm{~N} / \mathrm{A}$ & Mild & $\begin{array}{l}\text { Lethargy, decreased appetite, dry } \\
\text { cough for } 14 \text { days }\end{array}$ & N/A \\
\hline
\end{tabular}


Table 2. Cont.

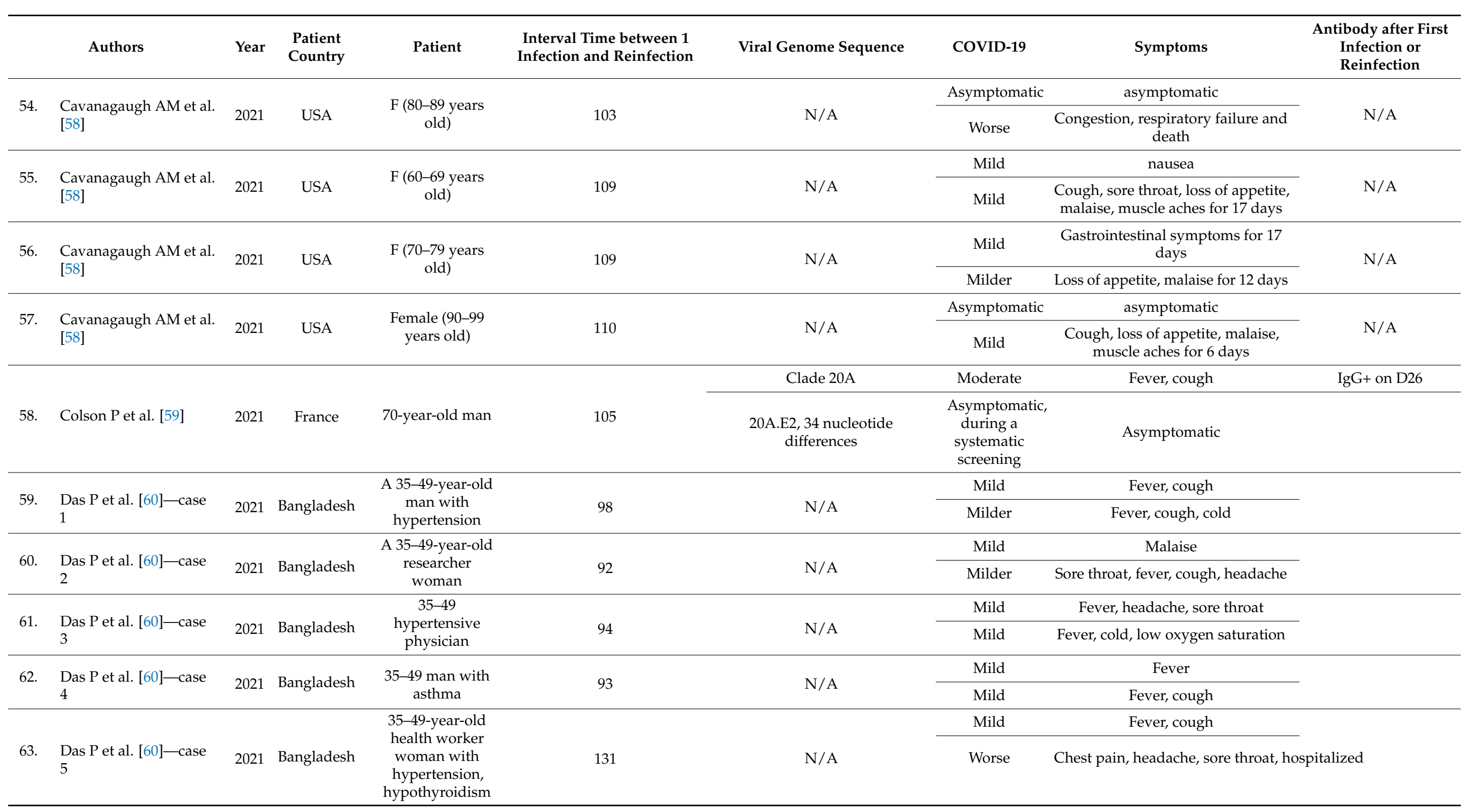


Table 2. Cont.

\begin{tabular}{|c|c|c|c|c|c|c|c|c|c|}
\hline & Authors & Year & $\begin{array}{l}\text { Patient } \\
\text { Country }\end{array}$ & Patient & $\begin{array}{l}\text { Interval Time between } 1 \\
\text { Infection and Reinfection }\end{array}$ & Viral Genome Sequence & COVID-19 & Symptoms & $\begin{array}{l}\text { Antibody after First } \\
\text { Infection or } \\
\text { Reinfection } \\
\end{array}$ \\
\hline \multirow{2}{*}{64.} & \multirow{2}{*}{ Daw MA et al. [61] } & \multirow{2}{*}{2021} & \multirow{2}{*}{ Libya } & \multirow{2}{*}{$\begin{array}{l}\text { 52-year-old } \\
\text { healthy male }\end{array}$} & \multirow{2}{*}{72} & \multirow{2}{*}{$\mathrm{N} / \mathrm{A}$} & Mild & $\begin{array}{l}\text { Cough, sore throat, fever, myalgias, } \\
\text { headache }\end{array}$ & \multirow{2}{*}{$\mathrm{N} / \mathrm{A}$} \\
\hline & & & & & & & Worse & $\begin{array}{l}\text { Fever, cough, shortness of breath, } \\
\text { gastrointestinal symptoms }\end{array}$ & \\
\hline \multirow{2}{*}{65.} & \multirow{2}{*}{ De Brito C. et al. [62] } & \multirow{2}{*}{2020} & \multirow{2}{*}{ Brazil } & \multirow{2}{*}{$\begin{array}{l}\text { 40-year-old male } \\
\text { doctor }\end{array}$} & \multirow{2}{*}{46} & \multirow{2}{*}{$\mathrm{N} / \mathrm{A}$} & Moderate & $\begin{array}{l}\text { Fever, cough, sore throat, fatigue, } \\
\text { myalgia, headache, diarrhea }\end{array}$ & $\begin{array}{l}\text { IgG and IgM- } 42 \\
\text { days after } 1 \text { infection }\end{array}$ \\
\hline & & & & & & & & anosmia and dysgeusia & \\
\hline \multirow{2}{*}{66.} & \multirow{2}{*}{ Diaz Y et al. [63] } & \multirow{2}{*}{2021} & \multirow{2}{*}{ Panama } & \multirow{2}{*}{$\begin{array}{l}\text { 36-year-old man } \\
\text { without } \\
\text { comorbidities }\end{array}$} & \multirow{2}{*}{181} & A. 2.4 & Mild & $\begin{array}{l}\text { Myalgia, chest pain, fever, cephalea, } \\
\text { rhinorrhea, hyposmia, ageusia }\end{array}$ & \\
\hline & & & & & & $\begin{array}{c}\text { A.2.5 containing Spike } \\
\text { mutations D614G and L452R }\end{array}$ & Milder & Cephalea, myalgia, rhinorrhea & \\
\hline \multirow[b]{2}{*}{67.} & \multirow[b]{2}{*}{ Dimeglio C et al. [64] } & \multirow[b]{2}{*}{2021} & \multirow[b]{2}{*}{ France } & \multirow{2}{*}{$\begin{array}{l}\text { 25-year-old } \\
\text { female } \\
\text { healthcare } \\
\text { worker }\end{array}$} & \multirow[b]{2}{*}{$>90$} & \multirow[b]{2}{*}{$\mathrm{N} / \mathrm{A}$} & Asymptomatic & Asymptomatic & $\begin{array}{l}\text { No neutralizing } \\
\text { antibodies }\end{array}$ \\
\hline & & & & & & & Moderate & $\begin{array}{l}\text { Fever, rhinorrhea, dyspnea, chest } \\
\text { pain, dysgeusia, anosmia, asthenia, } \\
\text { myalgia, eye pain, pharyngitis; not } \\
\text { hospitalized }\end{array}$ & $\begin{array}{l}\text { Yes, neutralizing } \\
\text { antibodies }\end{array}$ \\
\hline \multirow{2}{*}{68.} & \multirow{2}{*}{ Dimeglio C et al. [64] } & \multirow{2}{*}{2021} & \multirow{2}{*}{ France } & \multirow{2}{*}{$\begin{array}{l}\text { 40-year-old } \\
\text { female } \\
\text { healthcare } \\
\text { worker }\end{array}$} & \multirow{2}{*}{$>90$} & \multirow{2}{*}{$\mathrm{N} / \mathrm{A}$} & Asymptomatic & Asymptomatic & $\begin{array}{l}\text { No neutralizing } \\
\text { antibodies }\end{array}$ \\
\hline & & & & & & & Asymptomatic & Asymptomatic & $\begin{array}{l}\text { No neutralizing } \\
\text { antibodies }\end{array}$ \\
\hline \multirow[t]{2}{*}{69.} & Dimeglio C et al. [64] & 2021 & France & $\begin{array}{l}\text { 46-year-old } \\
\text { female }\end{array}$ & $>90$ & $\mathrm{~N} / \mathrm{A}$ & Moderate & $\begin{array}{l}\text { Fever, rhinorrhea, cough, dyspnea, } \\
\text { chest pain, intestinal disorders, } \\
\text { dysgeusia, anosmia, asthenia, } \\
\text { headache, myalgia, not hospitalized }\end{array}$ & $\begin{array}{l}\text { Yes, neutralizing } \\
\text { antibodies }\end{array}$ \\
\hline & & & & $\begin{array}{l}\text { nealthcare } \\
\text { worker }\end{array}$ & & & Mild & $\begin{array}{l}\text { Fever, cough, dyspnea, chest pain, } \\
\text { headache, asthenia, myalgia, } \\
\text { pharyngitis; not hospitalized }\end{array}$ & $\begin{array}{l}\text { Yes, neutralizing } \\
\text { antibodies }\end{array}$ \\
\hline 70. & Dimeglio C et al. [64] & 2021 & France & $\begin{array}{l}\text { 31-year-old male } \\
\text { healthcare }\end{array}$ & $>90$ & $\mathrm{~N} / \mathrm{A}$ & Mild & Anosmia; not hospitalized & $\begin{array}{l}\text { Yes, neutralizing } \\
\text { antibodies }\end{array}$ \\
\hline & & & (10. & worker & 然 & & Asymptomatic & Asymptomatic & $\begin{array}{l}\text { Yes, neutralizing } \\
\text { antibodies }\end{array}$ \\
\hline
\end{tabular}


Table 2. Cont.

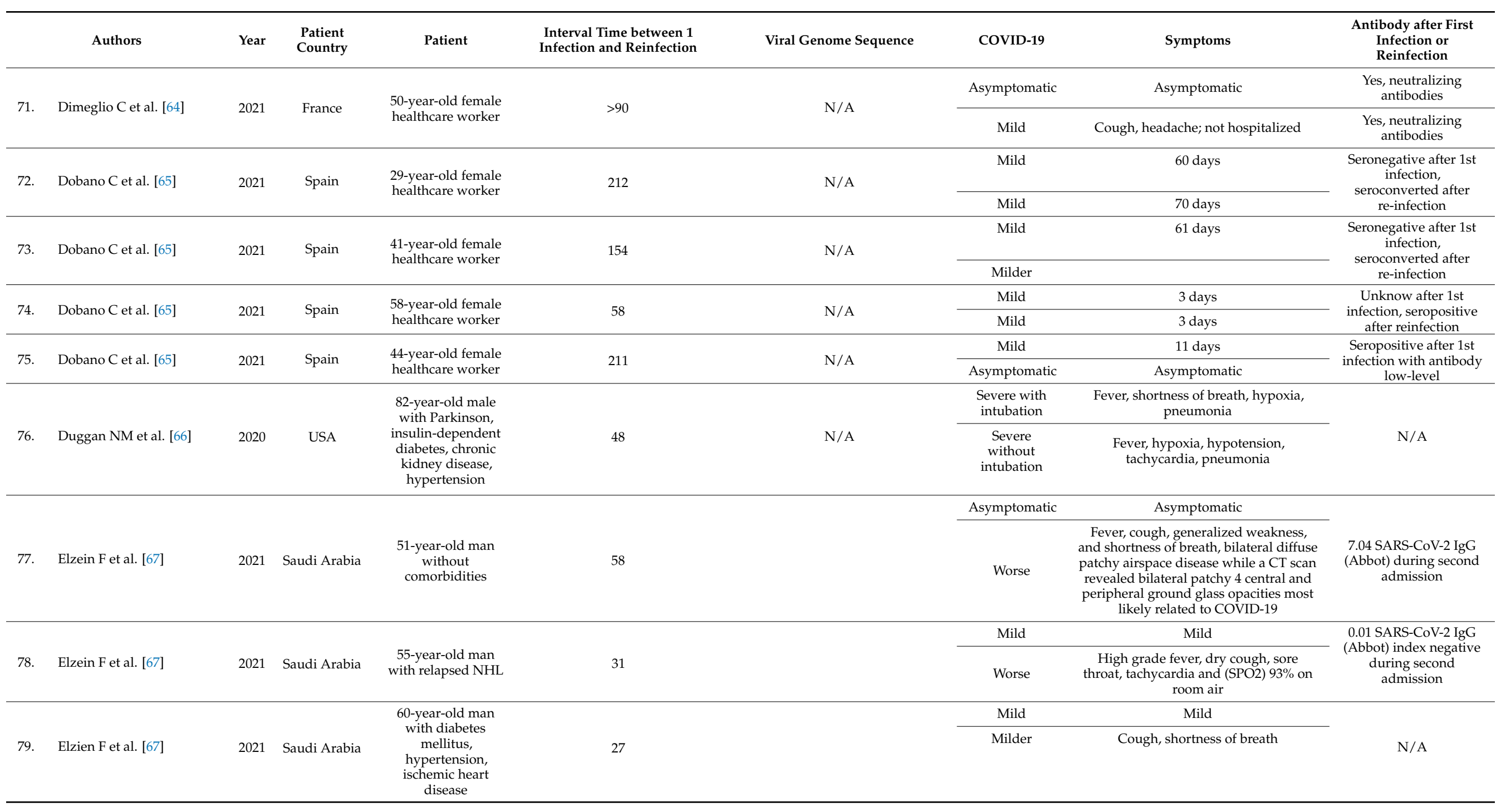


Table 2. Cont.

\begin{tabular}{|c|c|c|c|c|c|c|c|c|c|}
\hline & Authors & Year & $\begin{array}{l}\text { Patient } \\
\text { Country }\end{array}$ & Patient & $\begin{array}{l}\text { Interval Time between } 1 \\
\text { Infection and Reinfection }\end{array}$ & Viral Genome Sequence & COVID-19 & Symptoms & $\begin{array}{c}\text { Antibody after First } \\
\text { Infection or } \\
\text { Reinfection } \\
\end{array}$ \\
\hline \multirow[b]{2}{*}{80.} & \multirow[b]{2}{*}{ Elzein F et al. [67] } & \multirow[b]{2}{*}{2021} & \multirow[b]{2}{*}{ Saudi Arabia } & \multirow{2}{*}{$\begin{array}{c}\text { 48-year-old } \\
\text { woman with } \\
\text { metastatic breast } \\
\text { cancer }\end{array}$} & \multirow[b]{2}{*}{85} & & Moderate & Pneumonia & \multirow[b]{2}{*}{$\mathrm{N} / \mathrm{A}$} \\
\hline & & & & & & & Mild & Fever, shortness of breath & \\
\hline \multirow[t]{2}{*}{81.} & \multirow[t]{2}{*}{ Fageeh H et al. [68] } & \multirow[t]{2}{*}{2021} & \multirow[t]{2}{*}{ Saudi Arabia } & \multirow{2}{*}{$\begin{array}{l}\text { 24-year-old male } \\
\text { dental student }\end{array}$} & \multirow[t]{2}{*}{90} & \multirow[t]{2}{*}{ N/A } & Mild & $\begin{array}{l}\text { Sore throat, cough, headache, nausea, } \\
\text { diarrhea, loss of taste and smell, } \\
\text { insomnia, loss of appetite, and fatigue, } \\
\text { fear and anxiety, increased insomnia, } \\
\text { and increased body ache }\end{array}$ & \multirow[t]{2}{*}{ N/A } \\
\hline & & & & & & & Mild & $\begin{array}{l}\text { Coughing, body ache, loss of taste and } \\
\text { smell, and diarrhea symptoms were } \\
\text { slightly less severe, the patient was less } \\
\text { anxious and slept well. Fever }\end{array}$ & \\
\hline \multirow[t]{2}{*}{82.} & \multirow{2}{*}{$\begin{array}{l}\text { Fabianova K et al. } \\
\text { [69]—case } 1\end{array}$} & \multirow{2}{*}{2021} & \multirow{2}{*}{$\begin{array}{l}\text { Czech } \\
\text { Republic }\end{array}$} & \multirow{2}{*}{$\begin{array}{l}\text { 60-year-old man } \\
\text { with diabetes }\end{array}$} & \multirow{2}{*}{177} & \multirow{2}{*}{ N/A } & Mild & Mild-long term care facility & \multirow{2}{*}{$\mathrm{N} / \mathrm{A}$} \\
\hline & & & & & & & Moderate & Mild-hospitalized & \\
\hline \multirow{2}{*}{83.} & \multirow[b]{2}{*}{$\begin{array}{l}\text { Fabianova K et al. } \\
\text { [69]—-case } 2\end{array}$} & \multirow[b]{2}{*}{2021} & \multirow[b]{2}{*}{$\begin{array}{l}\text { Czech } \\
\text { Republic }\end{array}$} & \multirow{2}{*}{$\begin{array}{l}75 \text {-year-old man } \\
\text { with diabetes, } \\
\text { cardiovascular } \\
\text { disease }\end{array}$} & \multirow[b]{2}{*}{102} & \multirow[b]{2}{*}{$\mathrm{N} / \mathrm{A}$} & Mild & Mild—long term care facility & \multirow[b]{2}{*}{$\mathrm{N} / \mathrm{A}$} \\
\hline & & & & & & & Severe & Mild-hospitalized & \\
\hline 84. & [69]—case 3 & 2021 & Republic & with malignity & 200 & 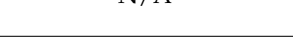 & Mild & Mild-home & 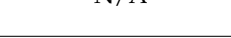 \\
\hline 85. & Fabianova K et al. & & Czech & 62-year-old & & & Mild & Mild-home & $N / A$ \\
\hline & [69]—case 4 & 2021 & Republic & $\begin{array}{l}\text { womann with } \\
\text { asthma }\end{array}$ & 137 & N/A & Mild & Mild-home & N/A \\
\hline 86. & Fabianova K et al. & & Czech & $\begin{array}{l}\text { 57-year-old } \\
\text { woman without }\end{array}$ & & & Mild & Mild-home & \\
\hline & [69]—case 5 & 2021 & Republic & $\begin{array}{l}\text { woman without } \\
\text { comorbidities }\end{array}$ & 203 & $\mathrm{~N} / \mathrm{A}$ & Mild & Mild-home & $\mathrm{N} / \mathrm{A}$ \\
\hline 87. & Fabianova K et al. & & Czech & 56-year-old & & $N / A$ & Mild & Mild-home & $\mathrm{N} / \mathrm{A}$ \\
\hline & {$[69]$ - case 6} & 2021 & Republic & $\begin{array}{l}\text { Woman without } \\
\text { comorbidities }\end{array}$ & 216 & N/A & Mild & Mild-home & N/A \\
\hline 88. & Fabianova K et al. & 2021 & Czech & 55-year-old man & & & Mild & Mild-home & \\
\hline & [69]—case 7 & 2021 & Republic & $\begin{array}{c}\text { without } \\
\text { comorbidities }\end{array}$ & 212 & $\mathrm{~N} / \mathrm{A}$ & Mild & Mild-home & $\mathrm{N} / \mathrm{A}$ \\
\hline 89. & Fabianova K et al. & 2021 & Czech & 53-year-old man & 214 & & Mild & Mild-home & \\
\hline & [69]—case 8 & 2021 & Republic & comorbidities & 214 & $\mathrm{~N} / \mathrm{A}$ & Mild & Mild-home & N/A \\
\hline 90. & Fabianova K et al. & 2021 & Czech & 50-year-old & 197 & $N / A$ & Mild & Mild-home & $N / A$ \\
\hline & [69]—case 9 & 2021 & Republic & malignity & 197 & $1 \mathrm{~N} / \mathrm{A}$ & Mild & Mild-home & $1 \mathrm{~N} / \mathrm{A}$ \\
\hline 91. & Fabianova K et al. & 2021 & Czech & $\begin{array}{c}\text { 49-year-old } \\
\text { woman without }\end{array}$ & 195 & $\mathrm{~N} / \mathrm{A}$ & Mild & Mild-home & $\mathrm{N} / \mathrm{A}$ \\
\hline & [69]—case 10 & 2021 & Republic & comorbidities & 190 & N $/ \mathrm{A}$ & Mild & Mild-home & $\mathrm{N} / \mathrm{A}$ \\
\hline
\end{tabular}


Table 2. Cont

\begin{tabular}{|c|c|c|c|c|c|c|c|c|c|}
\hline & Authors & Year & $\begin{array}{l}\text { Patient } \\
\text { Country }\end{array}$ & Patient & $\begin{array}{l}\text { Interval Time between } 1 \\
\text { Infection and Reinfection }\end{array}$ & Viral Genome Sequence & COVID-19 & Symptoms & $\begin{array}{l}\text { Antibody after First } \\
\text { Infection or } \\
\text { Reinfection }\end{array}$ \\
\hline \multirow[t]{2}{*}{92.} & \multirow{2}{*}{$\begin{array}{l}\text { Fabianova K et al. } \\
\text { [69]—case } 11\end{array}$} & \multirow{2}{*}{2021} & \multirow{2}{*}{$\begin{array}{l}\text { Czech } \\
\text { Republic }\end{array}$} & \multirow{2}{*}{$\begin{array}{c}\text { 49-year-old } \\
\text { woman without } \\
\text { comorbidities }\end{array}$} & \multirow{2}{*}{200} & \multirow{2}{*}{ N/A } & Mild & Mild_home & \multirow{2}{*}{$\mathrm{N} / \mathrm{A}$} \\
\hline & & & & & & & Mild & Mild-home & \\
\hline \multirow[t]{2}{*}{93.} & \multirow{2}{*}{$\begin{array}{l}\text { Fabianova K et al. } \\
\text { [69]—case } 12\end{array}$} & \multirow{2}{*}{2021} & \multirow{2}{*}{$\begin{array}{l}\text { Czech } \\
\text { Republic }\end{array}$} & 47-year-old man & \multirow{2}{*}{141} & \multirow{2}{*}{$\mathrm{N} / \mathrm{A}$} & Mild & Mild-home & \multirow{2}{*}{$\mathrm{N} / \mathrm{A}$} \\
\hline & & & & $\begin{array}{c}\text { without } \\
\text { comorbidities }\end{array}$ & & & Moderate & Mild-home & \\
\hline \multirow{2}{*}{94.} & \multirow{2}{*}{$\begin{array}{l}\text { Fabianova K et al. } \\
\text { [69]—case } 13\end{array}$} & \multirow{2}{*}{2021} & \multirow{2}{*}{$\begin{array}{l}\text { Czech } \\
\text { Republic }\end{array}$} & 47-year-old man & \multirow{2}{*}{206} & \multirow{2}{*}{ N/A } & Mild & Mild-home & \multirow{2}{*}{ N/A } \\
\hline & & & & $\begin{array}{l}\text { Without } \\
\text { comorbidities } \\
\end{array}$ & & & Mild & Mild-home & \\
\hline 95. & $\begin{array}{l}\text { Fabianova K et al. } \\
\text { [69]—case } 14\end{array}$ & 2021 & $\begin{array}{l}\text { Czech } \\
\text { Republic }\end{array}$ & $\begin{array}{l}\text { Without } \\
\text { comorbidities }\end{array}$ & 154 & N/A & Mild & Mild-home & N/A \\
\hline \multirow[t]{2}{*}{96.} & Fabianova $\mathrm{K}$ et al. & & Czech & 46-year-old & & & Mild & Mild-home & \\
\hline & [69]-case 15 & 2021 & Republic & $\begin{array}{l}\text { woman without } \\
\text { comorbidities }\end{array}$ & 231 & N/A & Mild & Mild-home & N/A \\
\hline 97. & Fabianova $\mathrm{K}$ et al. & & Czech & 45-year-old & & & Mild & Mild-home & \\
\hline & [69] — case 16 & 2021 & Republic & $\begin{array}{l}\text { woman without } \\
\text { comorbidities }\end{array}$ & 101 & N/A & Mild & Mild-home & $\mathrm{N} / \mathrm{A}$ \\
\hline & & & & 45-year-old & & & Mild & Mild-home & \\
\hline 98. & $\begin{array}{l}\text { Fabianova K et al. } \\
\text { [69]—case } 17\end{array}$ & 2021 & $\begin{array}{l}\text { Czech } \\
\text { Republic }\end{array}$ & $\begin{array}{l}\text { woman with } \\
\text { diabetes, chronic } \\
\text { pulmonary } \\
\text { disease, allergy }\end{array}$ & 196 & N/A & Mild & Mild-home & N/A \\
\hline & & & & 45-year-old & & & Mild & Mild-home & \\
\hline 99. & $\begin{array}{l}\text { Fabianova K et al. } \\
\text { [69]-case } 18\end{array}$ & 2021 & $\begin{array}{l}\text { Czech } \\
\text { Republic }\end{array}$ & $\begin{array}{l}\text { woman with } \\
\text { cardiovascular } \\
\text { disease }\end{array}$ & 211 & $\mathrm{~N} / \mathrm{A}$ & Mild & Mild-home & N/A \\
\hline 100. & Fabianova K et al. & & Czech & 44-year-old & & & Mild & Mild-home & N/A \\
\hline & [69]-case 19 & 2021 & Republic & $\begin{array}{l}\text { woman with } \\
\text { hypertension }\end{array}$ & 169 & $\mathrm{~N} / \mathrm{A}$ & Mild & Mild-home & N/A \\
\hline 101. & Fabianova Ket al. & 2021 & Czech & 44-year-old man & 224 & N/A & Mild & Mild-home & $\mathrm{N} / \mathrm{A}$ \\
\hline & [69]—case 20 & & Republic & $\begin{array}{c}\text { Without } \\
\text { comorbidities }\end{array}$ & & & Mild & Mild—home & \\
\hline 102. & Fabianova $\mathrm{K}$ et al. & 2021 & Czech & 42-year-old & 206 & $N / A$ & Mild & Mild-home & N/A \\
\hline & [69]—case 21 & 2021 & Republic & $\begin{array}{l}\text { woman without } \\
\text { comorbidities }\end{array}$ & 206 & N/A & Mild & Mild-home & N/A \\
\hline 103. & Fabianova K et al. & & Czech & 39-year-old & 229 & & Mild & Mild-home & \\
\hline & [69] - case 22 & 2021 & Republic & $\begin{array}{l}\text { woman without } \\
\text { comorbidities }\end{array}$ & 229 & N/A & Mild & Mild-home & $\mathrm{N} / \mathrm{A}$ \\
\hline 104. & Fabianova $\mathrm{K}$ et al. & & Czech & 34-year-old man & & & Mild & Mild-home & \\
\hline & [69]—case 23 & 2021 & Republic & $\begin{array}{l}\text { without } \\
\text { comorbidities }\end{array}$ & 158 & N/A & Mild & Mild-home & N/A \\
\hline 105. & Fabianova $\mathrm{K}$ et al. & 2021 & Czech & 30-year-old & 219 & $N / A$ & Mild & Mild-home & N/A \\
\hline & [69]—case 24 & 2021 & Republic & $\begin{array}{l}\text { woman without } \\
\text { comorbidities }\end{array}$ & 219 & N/A & Mild & Mild-home & $\mathrm{N} / \mathrm{A}$ \\
\hline
\end{tabular}


Table 2. Cont.

\begin{tabular}{|c|c|c|c|c|c|c|c|c|c|}
\hline & Authors & Year & $\begin{array}{l}\text { Patient } \\
\text { Country }\end{array}$ & Patient & $\begin{array}{l}\text { Interval Time between } 1 \\
\text { Infection and Reinfection }\end{array}$ & Viral Genome Sequence & COVID-19 & Symptoms & $\begin{array}{l}\text { Antibody after First } \\
\text { Infection or } \\
\text { Reinfection } \\
\end{array}$ \\
\hline \multirow{2}{*}{106.} & \multirow{2}{*}{$\begin{array}{l}\text { Fabianova K et al. } \\
\text { [69]—-ase } 25\end{array}$} & \multirow{2}{*}{2021} & \multirow{2}{*}{$\begin{array}{l}\text { Czech } \\
\text { Republic }\end{array}$} & \multirow{2}{*}{$\begin{array}{c}\text { 29-year-old } \\
\text { woman without } \\
\text { comorbidities }\end{array}$} & \multirow{2}{*}{139} & \multirow{2}{*}{$\mathrm{N} / \mathrm{A}$} & Mild & Mild-home & \multirow{2}{*}{$\mathrm{N} / \mathrm{A}$} \\
\hline & & & & & & & Mild & Mild-home & \\
\hline \multirow{2}{*}{107.} & \multirow{2}{*}{$\begin{array}{l}\text { Fabianova K et al. } \\
\text { [69]—case } 26\end{array}$} & \multirow{2}{*}{2021} & \multirow{2}{*}{$\begin{array}{l}\text { Czech } \\
\text { Republic }\end{array}$} & 27-year-old & \multirow{2}{*}{172} & \multirow{2}{*}{ N/A } & Mild & Mild-home & \multirow{2}{*}{$\mathrm{N} / \mathrm{A}$} \\
\hline & & & & $\begin{array}{l}\text { Woman witnout } \\
\text { comorbidities }\end{array}$ & & & Mild & Mild-home & \\
\hline \multirow[t]{2}{*}{108.} & \multirow{2}{*}{$\begin{array}{l}\text { Fabianova K et al. } \\
\text { [69]—case } 27\end{array}$} & \multirow{2}{*}{2021} & \multirow{2}{*}{$\begin{array}{l}\text { Czech } \\
\text { Republic }\end{array}$} & $\begin{array}{l}\text { 27-year-old } \\
\end{array}$ & \multirow{2}{*}{215} & \multirow{2}{*}{$\mathrm{N} / \mathrm{A}$} & Mild & Mild-home & \multirow{2}{*}{$\mathrm{N} / \mathrm{A}$} \\
\hline & & & & $\begin{array}{l}\text { woman without } \\
\text { comorbidities }\end{array}$ & & & Mild & Mild-home & \\
\hline 109. & $\begin{array}{l}\text { Fabianova K et al. } \\
\text { [69]—case } 28\end{array}$ & 2021 & $\begin{array}{l}\text { Czech } \\
\text { Republic }\end{array}$ & $\begin{array}{l}\text { Without } \\
\text { comorbidities }\end{array}$ & 222 & $\mathrm{~N} / \mathrm{A}$ & Mild & Mild-home & $\mathrm{N} / \mathrm{A}$ \\
\hline \multirow[b]{2}{*}{110.} & \multirow[b]{2}{*}{ Fernandez AC et al. [70] } & \multirow[b]{2}{*}{2021} & \multirow[b]{2}{*}{ Portugal } & \multirow[b]{2}{*}{$\begin{array}{l}\text { 28-year-old man } \\
\text { with asthma }\end{array}$} & & & Mild & Fever, chills, sneezing & \\
\hline & & & & & 285 & $\mathrm{~N} / \mathrm{A}$ & Worse & $\begin{array}{c}\text { Fever, tiredness, productive cough, } \\
\text { frontal headache, dizziness, dark urine, } \\
\text { dysuria }\end{array}$ & $\mathrm{N} / \mathrm{A}$ \\
\hline & & & & 24-vear-old & & N/A & Asymptomatic & Asymptomatic & $\begin{array}{l}\text { No IgG antibodies after } \\
\text { first infection }\end{array}$ \\
\hline 111. & Ferrante L et al. [71] & 2021 & Brazil & $\begin{array}{l}\text { woman without } \\
\text { comorbidities }\end{array}$ & 109 & P1 variant & Worse & $\begin{array}{l}\text { Headache, sore throat, odynophagia, } \\
\text { nasal congestion, tiredness, fatigue, } \\
\text { chest pain, lack of appetite, } \\
\text { hypertension, tachycardia }\end{array}$ & \\
\hline 112. & Fintelman-Rodrigues N & & & 54-year-old man & & $\mathrm{N} / \mathrm{A}$ & Mild & Headache & $\begin{array}{c}\text { IgM, IgA, IgG detected } \\
<1: 4\end{array}$ \\
\hline & et al. [72] & 2021 & Brazil & $\begin{array}{l}\text { without } \\
\text { comorbidities }\end{array}$ & 65 & Clade 20B & Worse & $\begin{array}{l}\text { Fever, dry cough, tiredness, body ache, } \\
\text { anosmia, ageusia }\end{array}$ & $\begin{array}{c}\text { IgM, IgA, IgG detected } \\
1: 128\end{array}$ \\
\hline 113. & Fintelman-Rodrigues N & & & $\begin{array}{l}57 \text {-year-old } \\
\text { woman with }\end{array}$ & & Clade 19A & Mild & Mild diarrhea & $\begin{array}{c}\operatorname{IgM}, \operatorname{IgA}, \operatorname{IgG} \text { detected } \\
<1: 4\end{array}$ \\
\hline & et al. [72] & 2021 & Brazil & $\begin{array}{l}\text { discoid lupus } \\
\text { erythematous }\end{array}$ & 61 & Clade 20B & Worse & $\begin{array}{l}\text { Fever, diarrhea, headache, body ache, } \\
\text { anosmia, ageusia }\end{array}$ & $\begin{array}{c}\text { IgM, IgA, IgG detected } \\
1: 32\end{array}$ \\
\hline 114. & Fintelman-Rodrigues N & & & 34-year-old man & & Clade 20B & Mild & Asymptomatic & $\begin{array}{c}\text { IgM, IgA, IgG detected } \\
<1: 4\end{array}$ \\
\hline & et al. [72] & 2021 & Brazil & $\begin{array}{l}\text { without } \\
\text { comorbidities }\end{array}$ & 64 & Clade 20B & Worse & $\begin{array}{l}\text { Fever, nausea, tiredness, headache, } \\
\text { body ache }\end{array}$ & $\begin{array}{c}\text { IgM, IgA, IgG detected } \\
1.64\end{array}$ \\
\hline 115. & Fintelman-Rodrigues N & & & 34-year-old & & $\mathrm{N} / \mathrm{A}$ & Mild & Mild diarrhea & $\begin{array}{c}\text { IgM, IgA, IgG detected } \\
<1: 4\end{array}$ \\
\hline & et al. [72] & 2021 & Brazil & $\begin{array}{l}\text { woman without } \\
\text { comorbidities }\end{array}$ & 60 & Clade 20B & Worse & $\begin{array}{l}\text { Dry cough, diarrhea, tiredness, } \\
\text { headache, body ache, anosmia, ageusia }\end{array}$ & $\underset{1: 64}{\operatorname{IgM}, \text { IgA, IgG detected }}$ \\
\hline
\end{tabular}


Table 2. Cont.

\begin{tabular}{|c|c|c|c|c|c|c|c|c|c|}
\hline & Authors & Year & $\begin{array}{l}\text { Patient } \\
\text { Country }\end{array}$ & Patient & $\begin{array}{l}\text { Interval Time between } 1 \\
\text { Infection and Reinfection }\end{array}$ & Viral Genome Sequence & COVID-19 & Symptoms & $\begin{array}{l}\text { Antibody after First } \\
\text { Infection or } \\
\text { Reinfection } \\
\end{array}$ \\
\hline 116. & Fonseca $\mathrm{V}$ et al. [73] & 2021 & Brazil & $\begin{array}{l}\text { 29-year-old health } \\
\text { care worker man } \\
\text { without } \\
\text { comorbidities }\end{array}$ & 225 & $\begin{array}{c}\text { B.1.1.28 } \\
\text { Spike D614G }\end{array}$ & Mild & $\begin{array}{l}\text { Fever, myalgia cough, sore throat, } \\
\text { diarrhea }\end{array}$ & $\begin{array}{l}\text { IgG negative } 180 \text { days } \\
\text { after the } 1 \text { st infection }\end{array}$ \\
\hline \multirow[t]{2}{*}{117.} & \multirow[t]{2}{*}{ Garduno-Orbe B et al. [74] } & \multirow[t]{2}{*}{2021} & \multirow[t]{2}{*}{ Mexico } & \multirow{2}{*}{$\begin{array}{l}\text { 40-year-old } \\
\text { healthcare worker } \\
\text { woman with } \\
\text { hypertension, } \\
\text { smoking }\end{array}$} & \multirow[t]{2}{*}{134} & \multirow[t]{2}{*}{$\mathrm{N} / \mathrm{A}$} & Moderate & $\begin{array}{c}\text { Fever, dry cough, nasal drainage, } \\
\text { dyspnea, myalgia, arthralgia, headache, } \\
\text { anosmia, dysgeusia, decreased oxygen } \\
\text { saturation up to } 84 \% \text {, maculopapular } \\
\text { rash on the upper and lower limbs, } \\
\text { chest, face, neck }\end{array}$ & \\
\hline & & & & & & & Worse & $\begin{array}{l}\text { Sneezing, runny nose, myalgia, } \\
\text { arthralgia, fever, dry cough, headache, } \\
\text { dyspnea, emphysema of the right lung }\end{array}$ & \\
\hline \multirow{2}{*}{118.} & \multirow{2}{*}{ Garduno-Orbe B et al. [74] } & \multirow{2}{*}{2021} & \multirow{2}{*}{ Mexico } & \multirow{2}{*}{$\begin{array}{l}\text { 49-year-old health } \\
\text { care worker } \\
\text { woman with } \\
\text { hypothyroidism }\end{array}$} & \multirow{2}{*}{129} & \multirow{2}{*}{ N/A } & Mild & $\begin{array}{l}\text { Nasal congestion, myalgia, arthralgia, } \\
\text { chills, headache, dry cough, dysgeusia, } \\
\text { anosmia, maculopapular exanthema, } \\
\text { insomnia }\end{array}$ & \\
\hline & & & & & & & Mild & $\begin{array}{l}\text { Headache, dry cough, odynophagia, } \\
\text { myalgia, dyspnea, conjunctivitis }\end{array}$ & \\
\hline 119. & Garduno-Orbe B et al. [74] & 2021 & Mexico & $\begin{array}{l}\text { 53-year-old health } \\
\text { care worker man } \\
\text { without } \\
\text { comorbidities }\end{array}$ & 107 & $\mathrm{~N} / \mathrm{A}$ & Mild & $\begin{array}{l}\text { Fever, chills, anosmia, dysgeusia dry } \\
\text { cough, rhinorrhea, general malaise, } \\
\text { chest pain, }\end{array}$ & \\
\hline \multirow{2}{*}{120.} & \multirow{2}{*}{ Garduno-Orbe B et al. [74] } & \multirow[b]{2}{*}{2021} & \multirow[b]{2}{*}{ Mexico } & \multirow{2}{*}{$\begin{array}{l}\text { 52-year-old health } \\
\text { care worker man } \\
\text { without } \\
\text { comorbidities }\end{array}$} & \multirow[b]{2}{*}{82} & \multirow[b]{2}{*}{ N/A } & Mild & $\begin{array}{l}\text { Odynophagia, dry cough, } \\
\text { nasopharyngeal exudate }\end{array}$ & \\
\hline & & & & & & & Worse & $\begin{array}{c}\text { Myalgias, arthralgias, dry cough, } \\
\text { dyspnea, odynophagia, pneumonia> } \\
\text { intensive care for hypoxia }\end{array}$ & \\
\hline \multirow{2}{*}{121.} & \multirow{2}{*}{ Garg J et al. [75] } & \multirow{2}{*}{2021} & \multirow{2}{*}{ India } & $\begin{array}{l}\text { 30-year-old health } \\
\text { care worker man }\end{array}$ & 90 & $\mathrm{~N} / \mathrm{A}$ & Mild & Fever & $\begin{array}{c}30 \text { days after initial } \\
\text { diagnosis IgG antibody } \\
\text { negativity }\end{array}$ \\
\hline & & & & $\begin{array}{l}\text { without } \\
\text { comorbidities }\end{array}$ & ( & 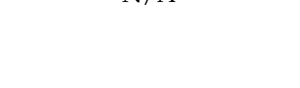 & Worse & $\begin{array}{l}\text { Fever, severe myalgia, anosmia, loss of } \\
\text { taste }\end{array}$ & $\begin{array}{l}30 \text { days after } \\
\text { reinfection diagnosis } \\
\text { IgG antibody positivity }\end{array}$ \\
\hline
\end{tabular}


Table 2. Cont.

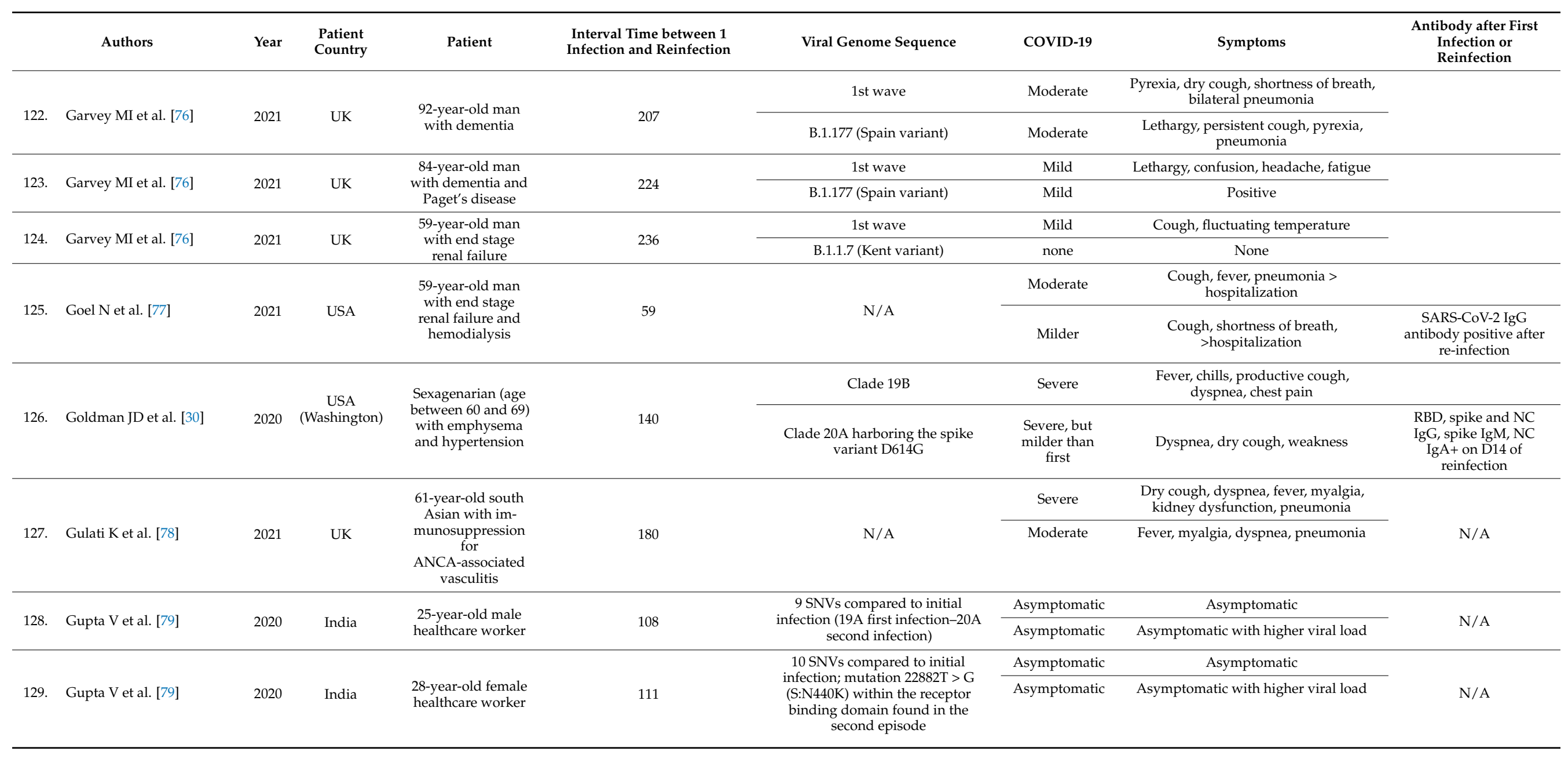


Table 2. Cont

\begin{tabular}{|c|c|c|c|c|c|c|c|c|c|}
\hline & Authors & Year & $\begin{array}{l}\text { Patient } \\
\text { Country }\end{array}$ & Patient & $\begin{array}{l}\text { Interval Time between } 1 \\
\text { Infection and Reinfection }\end{array}$ & Viral Genome Sequence & COVID-19 & Symptoms & $\begin{array}{l}\text { Antibody after First } \\
\text { Infection or } \\
\text { Reinfection }\end{array}$ \\
\hline \multirow[b]{2}{*}{130.} & \multirow[b]{2}{*}{ Habadi MI et al. [80] } & \multirow[b]{2}{*}{2021} & \multirow[b]{2}{*}{ SAU } & \multirow[b]{2}{*}{$\begin{array}{l}\text { 44-year-old } \\
\text { woman healthcare } \\
\text { worker }\end{array}$} & \multirow[b]{2}{*}{108} & \multirow[b]{2}{*}{$\mathrm{N} / \mathrm{A}$} & Moderate & Fever, chills, severe sore throat, fatigue & \multirow[b]{2}{*}{$\mathrm{N} / \mathrm{A}$} \\
\hline & & & & & & & Moderate & $\begin{array}{l}\text { Severe persistent productive cough, } \\
\text { runny nose, loss of smell, partial loss of } \\
\text { taste }\end{array}$ & \\
\hline \multirow[b]{2}{*}{131.} & \multirow[b]{2}{*}{ Habadi MI et al. [80] } & \multirow[b]{2}{*}{2021} & \multirow[b]{2}{*}{ SAU } & \multirow[b]{2}{*}{$\begin{array}{l}\text { 35-year-old heavy } \\
\text { male smoker }\end{array}$} & \multirow[b]{2}{*}{94} & \multirow[b]{2}{*}{$\mathrm{N} / \mathrm{A}$} & Asymptomatic & Asymptomatic & \multirow[b]{2}{*}{ N/A } \\
\hline & & & & & & & Worse & $\begin{array}{l}\text { Fever, cough, body ache, abdominal } \\
\text { pain, loss of taste }\end{array}$ & \\
\hline 132. & Hanif $\mathrm{M}$ et al. [81] & 2020 & Pakistan & $\begin{array}{l}\text { 58-year-old cardiac } \\
\text { surgeon male } \\
\text { without } \\
\text { comorbidities }\end{array}$ & 55 & N/A & $\begin{array}{l}\text { Hospitalized } \\
\text { for } 14 \text { days }\end{array}$ & Fever $>39^{\circ} \mathrm{C}$, headache, muscle aches & $\mathrm{N} / \mathrm{A}$ \\
\hline \multirow[b]{2}{*}{133.} & \multirow[b]{2}{*}{ Harrington D et al. [82] } & \multirow[b]{2}{*}{2021} & \multirow[b]{2}{*}{ UK } & \multirow[b]{2}{*}{$\begin{array}{l}\text { 78-year-old man } \\
\text { with type } 2 \\
\text { diabetes mellitus, } \\
\text { diabetic } \\
\text { nephropathy, } \\
\text { chronic obstructive } \\
\text { pulmonary } \\
\text { diseases, sleep } \\
\text { apnea, ischemic } \\
\text { heart disease }\end{array}$} & \multirow[b]{2}{*}{250} & $\begin{array}{l}\text { Lineage } \mathrm{B} .2 \text { with no mutations in } \\
\text { the } \mathrm{S} \text { region }\end{array}$ & $\begin{array}{l}\text { Discharged } \\
\text { home }\end{array}$ & Mild illness & \multirow[b]{2}{*}{$\begin{array}{l}\text { SARS-CoV-2 antibodies } \\
\text { (using the Roche } \\
\text { anti-SARS-CoV-2 } \\
\text { IgM/IgG assay } \\
\text { detecting antibodies } \\
\text { targeting viral } \\
\text { nucleocapsid "N" } \\
\text { antigen) were } \\
\text { detectable on } 6 \\
\text { occasions between } 4 \\
\text { June } 2020 \text { and } 13 \\
\text { November } 2020 \text { with } \\
\text { no evidence of } \\
\text { antibody waning seen }\end{array}$} \\
\hline & & & & & & $\begin{array}{l}\text { Variant VOC-20201/01 of lineage } \\
\text { B.1.1.7 with } 18 \text { amino acid } \\
\text { replacement and deletions in the S } \\
\text { region }\end{array}$ & $\begin{array}{l}\text { Emergency } \\
\text { intubation, } \\
\text { worse }\end{array}$ & $\begin{array}{l}\text { Shortness breath, severe hypoxia, } \\
\text { pneumonia, myocardial infarction }\end{array}$ & \\
\hline \multirow[b]{2}{*}{134.} & \multirow[b]{2}{*}{ Hayes B et al. [83] } & \multirow[b]{2}{*}{2021} & \multirow[b]{2}{*}{ USA } & \multirow{2}{*}{$\begin{array}{c}\text { 30-year-old female } \\
\text { healthcare worker } \\
\text { with idiopathic } \\
\text { thrombocytopenic } \\
\text { purpura, } \\
\text { pancreatitis, } \\
\text { GERD, anxiety, } \\
\text { recurrent } \\
\text { pneumonia }\end{array}$} & \multirow[b]{2}{*}{183} & & Mild & $\begin{array}{l}\text { Fever, fatigue, sore throat, nasal } \\
\text { congestion, dry cough, chest tightness }\end{array}$ & $\begin{array}{l}\text { After 1st infection } \\
\text { anti-SARS-CoV-2 IgG } \\
\text { were negative }\end{array}$ \\
\hline & & & & & & $\mathrm{N} / \mathrm{A}$ & Mild & Headaches, fever, sinus congestion & $\begin{array}{l}\text { After } 2 \text { nd infection } \\
\text { anti-SARS-CoV-2 IgG } \\
\text { were positive }\end{array}$ \\
\hline & & & & 81-year-old & & & Mild & Altered mental status, & \\
\hline 135. & Hunsinger HP et al. [84] & 2021 & USA & $\begin{array}{l}\text { woman with im- } \\
\text { munosuppression } \\
\text { for rheumatoid } \\
\text { arthritis }\end{array}$ & 62 & N/A & Moderate & $\begin{array}{l}\text { Cough, shortness of breath, oxygen } \\
\text { requirement }\end{array}$ & $\mathrm{N} / \mathrm{A}$ \\
\hline 136. & Hussein NR, Musa DH & 2027 & Irag & 39-year-old man & 112 & $N / A$ & Moderate & Fever, dry cough, hypoxemia & SARS-CoV-2 2 months \\
\hline & et al. [85] & 2021 & & with hypertension & 112 & N/A & Mild & Fever, not hypoxemia & after discharge \\
\hline
\end{tabular}


Table 2. Cont.

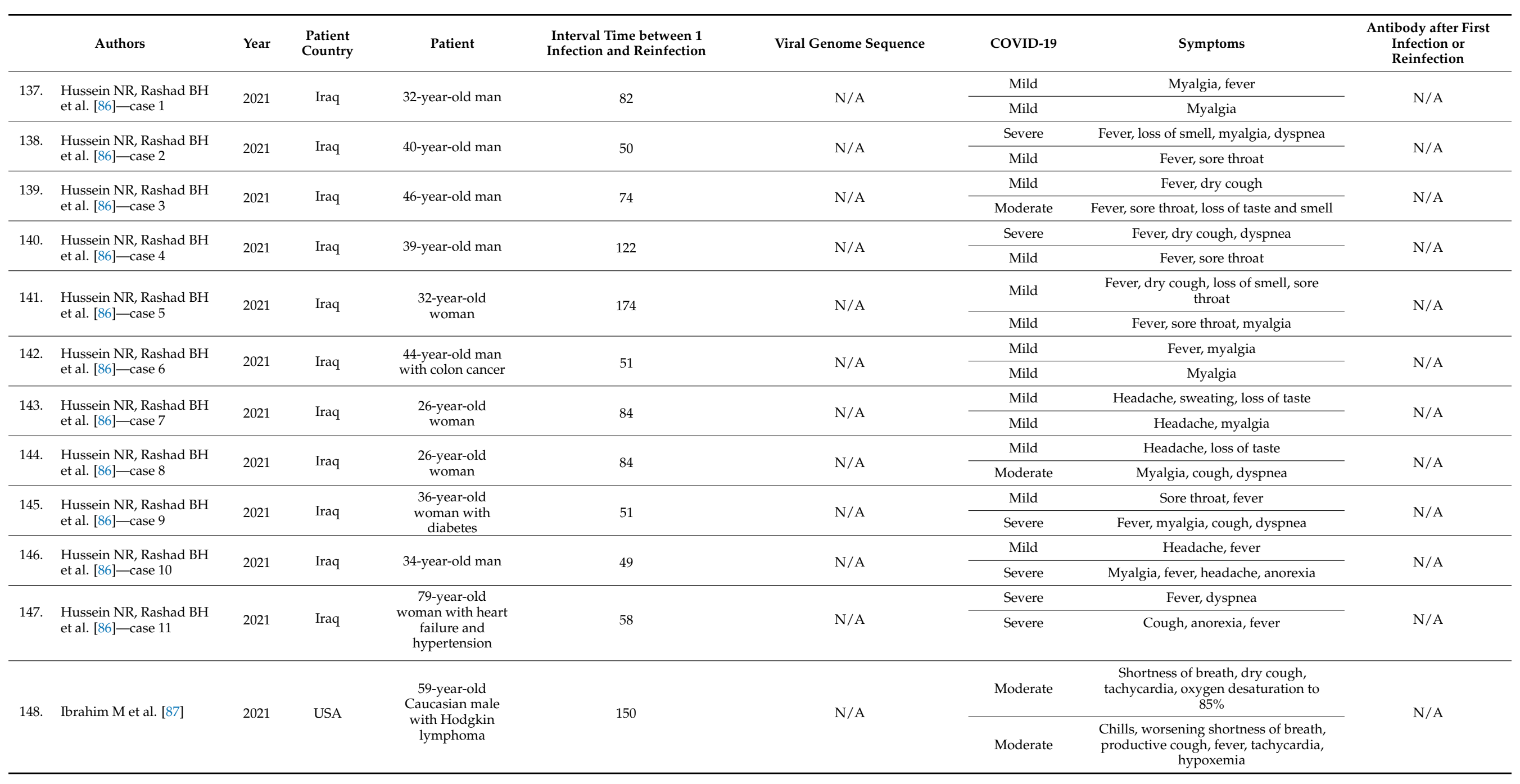


Table 2. Cont.

\begin{tabular}{|c|c|c|c|c|c|c|c|c|c|}
\hline & Authors & Year & $\begin{array}{l}\text { Patient } \\
\text { Country }\end{array}$ & Patient & $\begin{array}{l}\text { Interval Time between } 1 \\
\text { Infection and Reinfection }\end{array}$ & Viral Genome Sequence & COVID-19 & Symptoms & $\begin{array}{l}\text { Antibody after First } \\
\text { Infection or } \\
\text { Reinfection }\end{array}$ \\
\hline \multirow[b]{2}{*}{149.} & \multirow[b]{2}{*}{ Inada $\mathrm{M}$ et al. [88] } & \multirow[b]{2}{*}{2021} & \multirow[b]{2}{*}{ Japan } & \multirow[b]{2}{*}{$\begin{array}{l}\text { 58-year-old with } \\
\text { mild dyslipidemia }\end{array}$} & \multirow[b]{2}{*}{105} & \multirow[b]{2}{*}{$\mathrm{N} / \mathrm{A}$} & Moderate & Fever, bilateral pneumonia & $\begin{array}{c}\text { After 1st episode IC50 } \\
\text { of neutralizing } \\
\text { antibodies } \\
\text { anti-SARS-CoV-2 was } \\
50.0 \text { microg } / \mathrm{mL}\end{array}$ \\
\hline & & & & & & & Asymptomatic & Asymptomatic & $\begin{array}{l}\text { After 2nd episode IC50 } \\
\text { of neutralizing } \\
\text { antibodies } \\
\text { anti-SARS-CoV-2 was } \\
14.8 \text { microg } / \mathrm{mL}\end{array}$ \\
\hline \multirow{2}{*}{150.} & \multirow{2}{*}{ Jain A et al. [89] } & \multirow{2}{*}{2020} & \multirow{2}{*}{ India } & \multirow{2}{*}{ 21-year-old female } & \multirow{2}{*}{50} & \multirow{2}{*}{ N/A } & Asymptomatic & Asymptomatic & \multirow{2}{*}{ N/A } \\
\hline & & & & & & & mild & Complete loss of smell for 2 weeks & \\
\hline & \multirow[b]{2}{*}{ Kapoor R et al. [90] } & \multirow[b]{2}{*}{2021} & \multirow[b]{2}{*}{ India } & \multirow{2}{*}{$\begin{array}{l}\text { 39-year-old male } \\
\text { with multiple } \\
\text { myeloma }\end{array}$} & \multirow[b]{2}{*}{84} & \multirow[b]{2}{*}{ N/A } & Asymptomatic & Asymptomatic & \multirow[b]{2}{*}{ N/A } \\
\hline & & & & & & & Severe & $\begin{array}{l}\text { High grade fever, chills, shortness of } \\
\text { breath, bilateral pneunomia }\end{array}$ & \\
\hline \multirow[b]{2}{*}{152.} & \multirow[b]{2}{*}{ Kapoor R et al. [90] } & \multirow[b]{2}{*}{2021} & \multirow[b]{2}{*}{ India } & \multirow{2}{*}{$\begin{array}{c}\text { 33-year-old male } \\
\text { with T cell acute } \\
\text { lymphoblastic } \\
\text { leukemia }\end{array}$} & \multirow[b]{2}{*}{60} & \multirow[b]{2}{*}{ N/A } & Severe & Fever, cough, pneumonia & \multirow[b]{2}{*}{$\mathrm{N} / \mathrm{A}$} \\
\hline & & & & & & & Severe & $\begin{array}{c}\text { Headache, vomiting, high grade fever, } \\
\text { pneumonia }\end{array}$ & \\
\hline & Kapoor R et al. [90] & 2021 & India & $\begin{array}{c}\text { 26-year-old male } \\
\text { with Philadelphia } \\
\text { chromosome } \\
\text { positive acute } \\
\text { lymphoblastic } \\
\text { leukemia }\end{array}$ & 91 & N/A & Moderate & Fever & N/A \\
\hline & & & & $\begin{array}{l}\text { 70-year-old man } \\
\text { with }\end{array}$ & & & Asymptomatic & Asymptomatic & \\
\hline 154. & Krishna VN et al. [91] & 2021 & USA & $\begin{array}{c}\text { with hypertension, } \\
\text { diabetes mellitus, } \\
\text { coronary artery } \\
\text { disease }\end{array}$ & 45 & N/A & Worse & $\begin{array}{l}\text { Shortness of breath, cough, chest pain, } \\
\text { myalgias }\end{array}$ & $\begin{array}{l}\text { COVID-19 IgG positive } \\
\text { after 1st infection }\end{array}$ \\
\hline & & & & Late 50s woman & & & Asymptomatic & Asymptomatic & \\
\hline 155. & Krishna VN et al. [91] & 2021 & USA & $\begin{array}{l}\text { with hypertension, } \\
\text { hepatitis } C \text {, heart } \\
\text { failure }\end{array}$ & 75 & N/A & Worse & Fever, myalgias, sore throat & $\mathrm{N} / \mathrm{A}$ \\
\hline & & & & 66-year-old man & & Clade B.1 & Mild & Fever, fatigue, dry cough & Failure of humoral \\
\hline 156. & Klein J et al. [31] * & 2021 & USA & $\begin{array}{l}\text { disorder, end-stage } \\
\text { renal disease due } \\
\text { to lithium toxicity } \\
\text { and renal } \\
\text { transplantation }\end{array}$ & 210 & Clade B.1.280 & Milder & Fatigue and nonproductive cough & $\begin{array}{l}\text { immunity with } \\
\text { defective response of } \\
\text { the neutralizing } \\
\text { antibodies after } \\
\text { primary infection }\end{array}$ \\
\hline
\end{tabular}


Table 2. Cont.

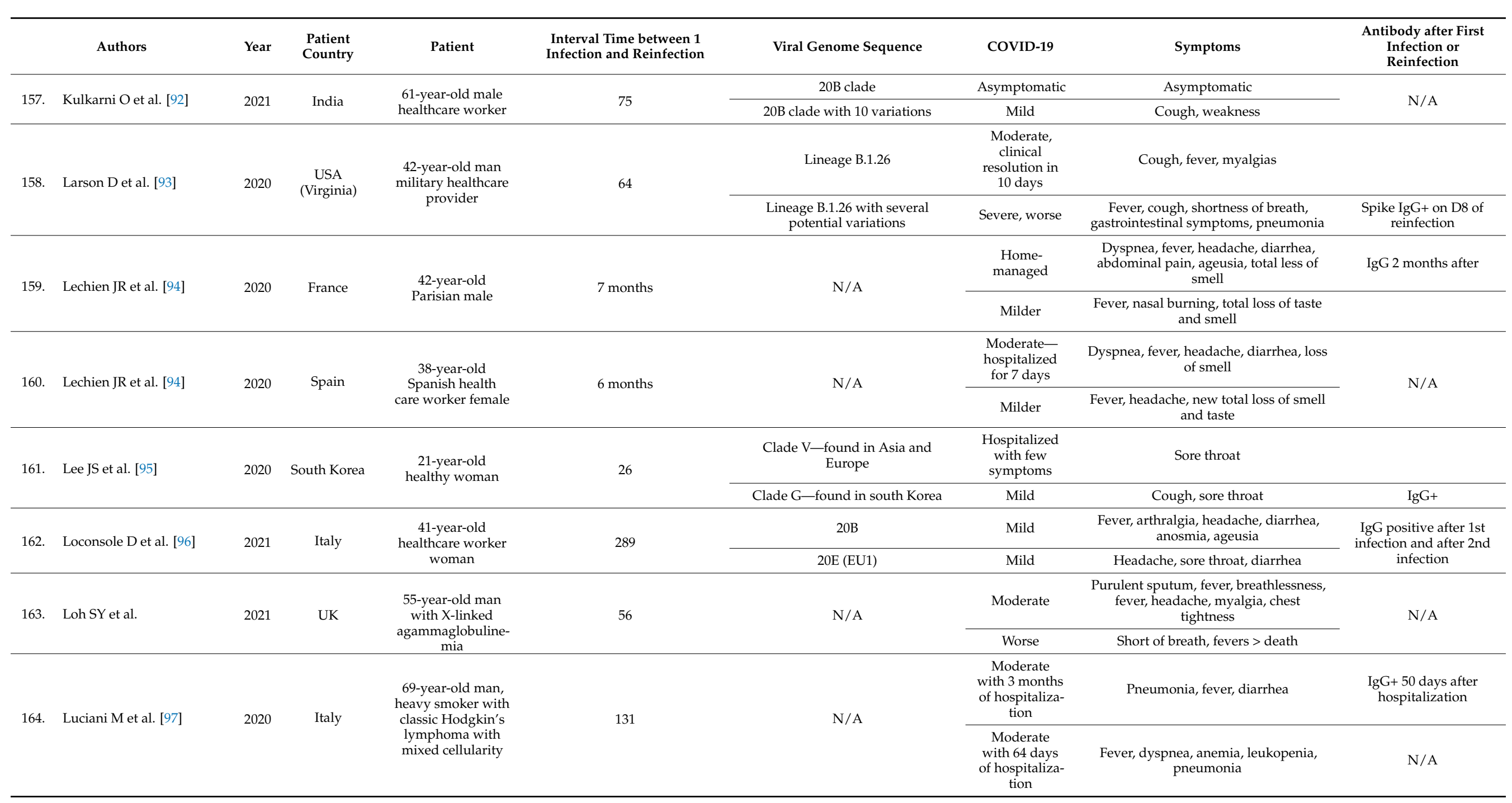


Table 2. Cont.

\begin{tabular}{|c|c|c|c|c|c|c|c|c|c|}
\hline & Authors & Year & $\begin{array}{l}\text { Patient } \\
\text { Country }\end{array}$ & Patient & $\begin{array}{l}\text { Interval Time between } 1 \\
\text { Infection and Reinfection }\end{array}$ & Viral Genome Sequence & COVID-19 & Symptoms & $\begin{array}{l}\text { Antibody after First } \\
\text { Infection or } \\
\text { Reinfection } \\
\end{array}$ \\
\hline \multirow[b]{2}{*}{165.} & \multirow[b]{2}{*}{$\begin{array}{l}\text { Mahajan NN et al. } \\
{[98] \text {-Case } 2}\end{array}$} & \multirow[b]{2}{*}{2021} & \multirow[b]{2}{*}{ India } & \multirow[b]{2}{*}{ 33-year-old man } & \multirow[b]{2}{*}{90} & \multirow[b]{2}{*}{ N/A } & Mild & Sore throat & \multirow[b]{2}{*}{ N/A } \\
\hline & & & & & & & Worse & $\begin{array}{c}\text { Influenza like Illness symptoms with } \\
\text { breathing difficulty }\end{array}$ & \\
\hline \multirow{2}{*}{166.} & \multirow{2}{*}{$\begin{array}{l}\text { Mahajan NN et al. } \\
\text { [98]-Case } 3\end{array}$} & \multirow{2}{*}{2021} & \multirow{2}{*}{ India } & \multirow{2}{*}{ 27-year-old man } & \multirow{2}{*}{69} & \multirow{2}{*}{$\mathrm{N} / \mathrm{A}$} & Asymptomatic & Asymptomatic & \multirow{2}{*}{$\mathrm{N} / \mathrm{A}$} \\
\hline & & & & & & & Worse & Fever, cough, myalgia & \\
\hline 167. & $\begin{array}{l}\text { Mahajan NN et al. } \\
\text { [98]-Case } 4\end{array}$ & 2021 & India & $\begin{array}{l}\text { 48-year-old } \\
\text { woman }\end{array}$ & 97 & N/A & Mild & Myalgia & N/A \\
\hline \multirow{2}{*}{168.} & \multirow{2}{*}{$\begin{array}{l}\text { Mahajan NN et al. } \\
\text { [98]-Case } 5\end{array}$} & \multirow{2}{*}{2021} & \multirow{2}{*}{ India } & \multirow{2}{*}{$\begin{array}{l}\text { 26-year-old } \\
\text { woman }\end{array}$} & \multirow{2}{*}{55} & \multirow{2}{*}{ N/A } & Mild & Fever, myalgia & \multirow{2}{*}{$\mathrm{N} / \mathrm{A}$} \\
\hline & & & & & & & Mild & Fever, sore throat, myalgia & \\
\hline \multirow[t]{2}{*}{169.} & \multirow{2}{*}{$\begin{array}{l}\text { Mahajan NN et al. } \\
\text { [98]—Case } 6\end{array}$} & \multirow{2}{*}{2021} & India & 25-year-old man & 89 & N/A & Mild & $\begin{array}{l}\text { Fever, sore throat, myalgia and loss of } \\
\text { smell and taste }\end{array}$ & N/A \\
\hline & & & & & & & Mild & Fever & \\
\hline 170. & Mahajan NN et al. & 2021 & India & 31-vear-old man & 70 & & Asymptomatic & Asymptomatic & \\
\hline & [98]-Case 7 & 2021 & India & 3it-y ear-orid mant & 10 & N/A & Worse & Myalgia & N/A \\
\hline 171 & Mahaian NN et al & & & 51-vear-old & & & Asymptomatic & Asymptomatic & \\
\hline 172. & Marquez L et al. [99] & 2021 & USA & $\begin{array}{l}\text { 16-year-old } \\
\text { woman with }\end{array}$ & 90 & B.1.2 & Mild & $\begin{array}{l}\text { Sore throat, fatigue, nasal congestion, } \\
\text { rhinorrhea, dry cough }\end{array}$ & IgM+ and IgG - after \\
\hline & & 2021 & ( & $\begin{array}{l}\text { end-stage renal } \\
\text { disease }\end{array}$ & (5) & B.1.1.7 & Milder & Leg pain, fatigue, swelling leg, fever & the 2nd infection \\
\hline & & & & $\begin{array}{l}\text { 62-year-old male } \\
\text { healthcare worker }\end{array}$ & & & Mild & $\begin{array}{l}\text { Fever of } 38^{\circ} \mathrm{C} \text {, diarrhea, anosmia, } \\
\text { dysgeusia, cough, intense asthenia, and } \\
\text { arthromyalgia }\end{array}$ & $\begin{array}{l}\text { After reinfection weak } \\
\text { immune response, with }\end{array}$ \\
\hline 173. & Massanella M et al. [100] & 2021 & Spain & $\begin{array}{l}\text { with previous } \\
\text { history of mild } \\
\text { asthma, } \\
\text { hypertension, } \\
\text { dyslipidemia, liver } \\
\text { steatosis, } \\
\text { hyperuricemia, } \\
\text { and overweight } \\
\text { (body mass index } \\
\geq 30 \mathrm{~kg} / \mathrm{m}^{2} \text { ) }\end{array}$ & 158 & B.1.79 (G) & Worse & $\begin{array}{l}\text { Intense arthromyalgias, headache, fever, } \\
\text { cough, and dyspnea }>\text { admitted to the } \\
\text { emergency room for worsening } \\
\text { dyspnea, cough, chills, fever } 39^{\circ} \mathrm{C}, \\
\text { myalgias, anosmia, and ageusia. His } \\
\text { respiratory rate was } 36 \text { breaths/minute, } \\
\text { his heart rate was } 100 \text { beats/minute, } \\
\text { and he had bilateral inspiratory } \\
\text { crackles. The chest radiograph showed } \\
\text { bilateral alveolar-interstitial infiltrates }\end{array}$ & $\begin{array}{l}\text { specific T-cell responses } \\
\text { against SARS-CoV-2. } \\
\text { All antibody isotypes } \\
\text { tested as well as } \\
\text { SARS-CoV-2 } \\
\text { neutralizing antibodies } \\
\text { increased sharply after } \\
\text { day } 8 \text { post symptoms. } \\
\text { A slight increase of } \\
\text { T-cell responses was } \\
\text { observed at day } 19 \text { after } \\
\text { symptom onset }\end{array}$ \\
\hline
\end{tabular}


Table 2. Cont.

\begin{tabular}{|c|c|c|c|c|c|c|c|c|c|}
\hline & Authors & Year & $\begin{array}{l}\text { Patient } \\
\text { Country }\end{array}$ & Patient & $\begin{array}{l}\text { Interval Time between } 1 \\
\text { Infection and Reinfection }\end{array}$ & Viral Genome Sequence & COVID-19 & Symptoms & $\begin{array}{l}\text { Antibody after First } \\
\text { Infection or } \\
\text { Reinfection }\end{array}$ \\
\hline & & & & 53-year-old female & & & Severe & Encephalopathy due to her COVID-19 & \\
\hline 174. & Mohseni M et al. [101] & 2021 & USA & $\begin{array}{c}\text { with liver } \\
\text { transplant in } 2010 \\
\text { due to alcoholic } \\
\text { cirrhosis, } \\
\text { hypertension, } \\
\text { hypothyroidism, } \\
\text { anxiety, and } \\
\text { chronic kidney } \\
\text { disease }\end{array}$ & 90 & N/A & Mild & $\begin{array}{c}\text { Nausea, vomiting, diarrhea, and } \\
\text { myalgias }\end{array}$ & $\mathrm{N} / \mathrm{A}$ \\
\hline \multirow[b]{2}{*}{175.} & \multirow[b]{2}{*}{ Mulder et al. [102] } & \multirow[b]{2}{*}{2020} & \multirow[b]{2}{*}{ Denmark } & \multirow{2}{*}{$\begin{array}{l}\text { 89-year-old } \\
\text { immunocompro- } \\
\text { mised woman } \\
\text { (Waldestrom } \\
\text { macroglobuline- } \\
\text { mia) }\end{array}$} & \multirow[b]{2}{*}{59} & \multirow{2}{*}{$\begin{array}{c}\text { The } 2 \text { strains differed at } 10 \\
\text { nucleotide positions in ORF1a (4), } \\
\text { ORF1b (2), spike (2), ORF3A (1), M } \\
\text { (1) genes }\end{array}$} & $\begin{array}{l}\text { Hospitalized } \\
\text { for } 5 \text { days }\end{array}$ & Fever, severe cough, persisting fatigue & IgM- \\
\hline & & & & & & & Worse & $\begin{array}{c}\text { Fever, cough, dyspnea }>\text { death after } 2 \\
\text { weeks }\end{array}$ & N/A \\
\hline \multirow[b]{2}{*}{176.} & \multirow[b]{2}{*}{$\begin{array}{l}\text { Munos Mendoza J et al. } \\
\text { [103] }\end{array}$} & \multirow[b]{2}{*}{2020} & \multirow[b]{2}{*}{ USA } & \multirow[b]{2}{*}{$\begin{array}{c}51-\text { year-old } \\
\text { African American } \\
\text { male with } \\
\text { hypertension and } \\
\text { hemodialysis } \\
\text { history }\end{array}$} & \multirow[b]{2}{*}{2 months } & \multirow[b]{2}{*}{$\mathrm{N} / \mathrm{A}$} & Asymptomatic & $\begin{array}{l}\text { Positive for NAAT and IgG at a routine } \\
\text { control during hemodialysis }\end{array}$ & $\operatorname{IgM}-, \operatorname{IgG}+$ \\
\hline & & & & & & & $\begin{array}{c}\text { Severe, } \\
\text { hospitalized } \\
\text { with } \\
\text { non-invasive } \\
\text { positive } \\
\text { pressure } \\
\text { mechanical } \\
\text { ventilation }\end{array}$ & $\begin{array}{l}\text { Fever } 38.3^{\circ} \mathrm{C} \text {, severe dyspnea, } \\
\text { pneumonia }\end{array}$ & $\operatorname{IgG}+, \operatorname{IgM}+, \operatorname{IgA}+$ \\
\hline \multirow[t]{2}{*}{177.} & \multirow[t]{2}{*}{ Nachmias V. et al. [104] } & \multirow[t]{2}{*}{2020} & \multirow[t]{2}{*}{ Israel } & \multirow{2}{*}{$\begin{array}{l}\text { 22-year-old } \\
\text { woman without } \\
\text { comorbidities }\end{array}$} & \multirow[t]{2}{*}{111} & \multirow[t]{2}{*}{ N/A } & $\begin{array}{l}\text { Mild with } \\
\text { home back } \\
\text { after } 23 \text { days }\end{array}$ & Fever, cough & \\
\hline & & & & & & & Asymptomatic & Tachycardia & $\operatorname{IgG}+$ \\
\hline \multirow{2}{*}{178.} & \multirow{2}{*}{$\begin{array}{l}\text { Naveca F et al._case } 1 \\
{[105]^{*}}\end{array}$} & \multirow[b]{2}{*}{2021} & \multirow[b]{2}{*}{ Brazil } & \multirow[b]{2}{*}{ 29-year-old } & \multirow[b]{2}{*}{281} & $20 \mathrm{~A}$ & Mild & $\begin{array}{c}\text { Fever, myalgia, cough, sore throat, } \\
\text { nausea, and back pain }\end{array}$ & \\
\hline & & & & & & 20J (P.1) & Mild & $\begin{array}{l}\text { Fever, cough, sore throat, diarrhea, } \\
\text { anosmia, ageusia, headache, runny } \\
\text { nose, and resting pulse oximetry of } 97 \%\end{array}$ & \\
\hline \multirow{2}{*}{179.} & \multirow{2}{*}{$\begin{array}{l}\text { Naveca F et al.—case } 2 \\
{[105]^{*}}\end{array}$} & \multirow{2}{*}{2021} & \multirow{2}{*}{ Brazil } & \multirow{2}{*}{ 50-year-old } & \multirow{2}{*}{153} & $20 \mathrm{~B}$ & Mild & Fever, cough, and tiredness & \\
\hline & & & & & & 20J (P.1) & Mild & Cough, headache, and runny nose & \\
\hline \multirow[t]{2}{*}{180.} & \multirow{2}{*}{$\begin{array}{l}\text { Naveca F et al._case } 3 \\
{[105]^{*}}\end{array}$} & \multirow{2}{*}{2021} & \multirow{2}{*}{ Brazil } & 40-year-old & 282 & $20 \mathrm{~A}$ & Mild & $\begin{array}{l}\text { Fever, headache, chest pain, and } \\
\text { weakness }\end{array}$ & \\
\hline & & & & woman & & 20J (P.1) & Mild & Sore throat and running nose & \\
\hline
\end{tabular}


Table 2. Cont.

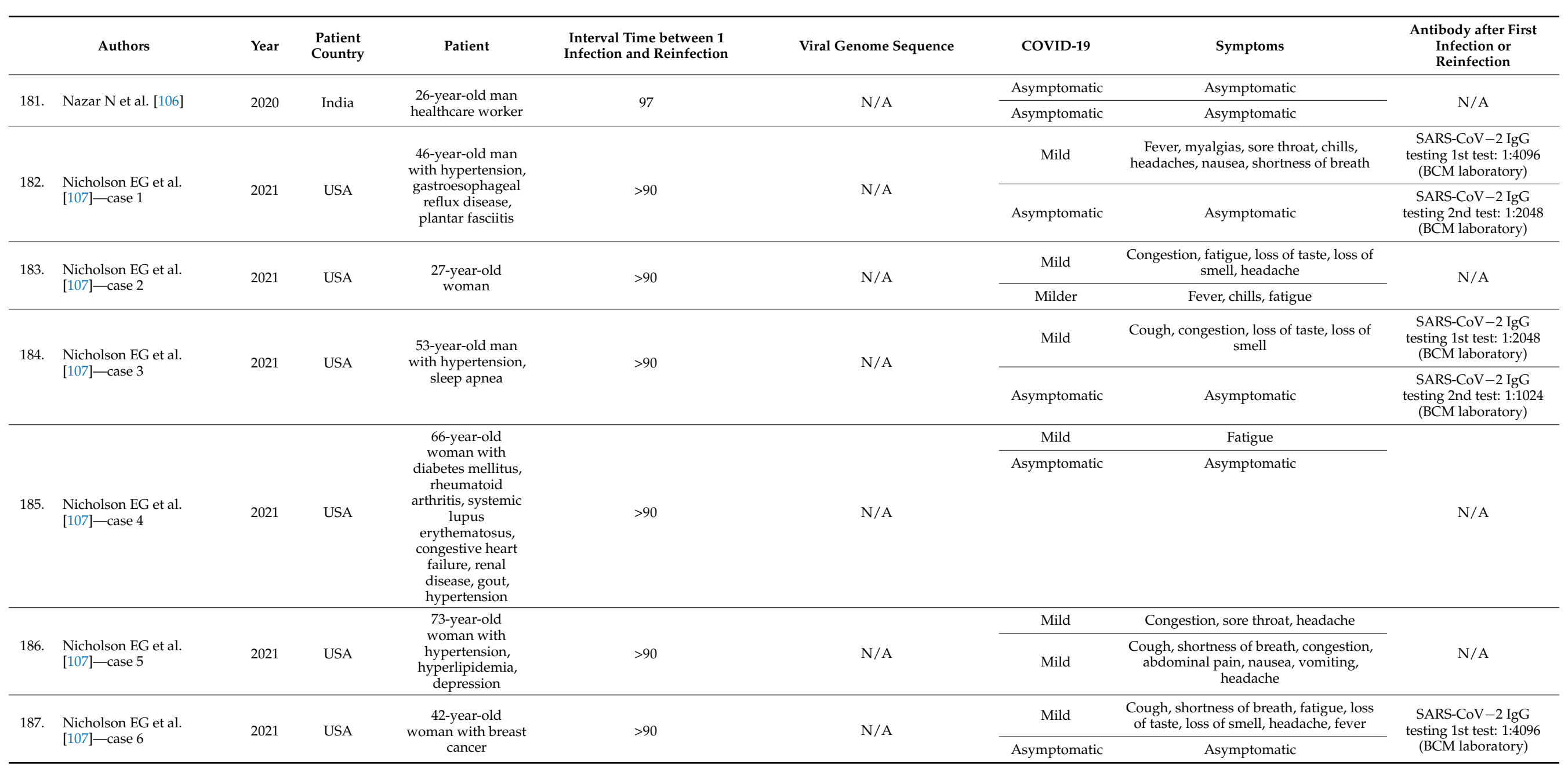


Table 2. Cont.

\begin{tabular}{|c|c|c|c|c|c|c|c|c|c|}
\hline & Authors & Year & $\begin{array}{l}\text { Patient } \\
\text { Country }\end{array}$ & Patient & $\begin{array}{l}\text { Interval Time between } 1 \\
\text { Infection and Reinfection }\end{array}$ & Viral Genome Sequence & COVID-19 & Symptoms & $\begin{array}{l}\text { Antibody after First } \\
\text { Infection or } \\
\text { Reinfection }\end{array}$ \\
\hline \multirow[t]{2}{*}{188.} & \multirow[t]{2}{*}{$\begin{array}{l}\text { Nicholson EG et al. } \\
{[107] \text { - case } 7}\end{array}$} & \multirow[t]{2}{*}{2021} & \multirow[t]{2}{*}{ USA } & \multirow[t]{2}{*}{ 36-year-old man } & \multirow[t]{2}{*}{$>90$} & \multirow[t]{2}{*}{$\mathrm{N} / \mathrm{A}$} & Mild & $\begin{array}{l}\text { Cough, fatigue, nausea, loss of smell, } \\
\text { fever }\end{array}$ & $\begin{array}{c}\text { SARS-CoV-2 IgG } \\
\text { testing 1st test: 1:4096 } \\
\text { (BCM laboratory), 2nd } \\
\text { test: 1:4096 (BCM } \\
\text { laboratory) }\end{array}$ \\
\hline & & & & & & & Asymptomatic & Asymptomatic & \\
\hline 189. & Nonaka CKV et al. [108] & 2021 & Brazil & $\begin{array}{l}\text { 45-year-old } \\
\text { woman }\end{array}$ & 147 & $\begin{array}{l}\text { Lineage B.1.1.33 with S:G1219C } \\
\text { mutation }\end{array}$ & Mild & $\begin{array}{l}\text { Diarrhea, myalgia, asthenia, } \\
\text { odynophagia for } 7 \text { days }\end{array}$ & N/A \\
\hline \multirow[b]{2}{*}{190.} & \multirow{2}{*}{ Novoa W et al. [109] } & \multirow[b]{2}{*}{2021} & \multirow[b]{2}{*}{ Colombia } & \multirow{2}{*}{$\begin{array}{l}\text { 44-year-old male, } \\
\text { healthcare worker }\end{array}$} & \multirow[b]{2}{*}{103} & \multirow[b]{2}{*}{$\mathrm{N} / \mathrm{A}$} & Asymptomatic & Asymptomatic & \multirow[b]{2}{*}{$\mathrm{N} / \mathrm{A}$} \\
\hline & & & & & & & Moderate & $\begin{array}{l}\text { Malaise, chills, headache, fever, } \\
\text { odynophagia }\end{array}$ & \\
\hline \multirow{2}{*}{191.} & \multirow{2}{*}{ Ozaras R et al. [110] } & \multirow{2}{*}{2020} & \multirow{2}{*}{ Turkey } & \multirow{2}{*}{$\begin{array}{l}\text { 23-year-old } \\
\text { woman }\end{array}$} & \multirow{2}{*}{116} & \multirow{2}{*}{$\mathrm{N} / \mathrm{A}$} & Hospitalized & $\begin{array}{c}\text { Fever }>39^{\circ} \mathrm{C} \text {, chills, fatigue, cough, } \\
\text { headache, sore throat, muscle and joint } \\
\text { pain }\end{array}$ & $\mathrm{N} / \mathrm{A}$ \\
\hline & & & & & & & $\begin{array}{l}\text { Recovered in } \\
10 \text { days }\end{array}$ & $\begin{array}{l}\text { Fever } 28.7^{\circ} \mathrm{C} \text {, chills, fatigue, loss of } \\
\text { appetite, taste and smell loss, muscle } \\
\text { and joint pain }\end{array}$ & IgG slightly positive \\
\hline \multirow{2}{*}{192.} & \multirow{2}{*}{ Pow T et al. [111] } & \multirow{2}{*}{2021} & \multirow{2}{*}{ USA } & \multirow{2}{*}{ 40-year-old man } & \multirow{2}{*}{89} & \multirow{2}{*}{$\mathrm{N} / \mathrm{A}$} & Mild & Fever, cough & $N / A$ \\
\hline & & & & & & & Worse & Dyspnea, tachycardia > death & $\mathrm{N} / \mathrm{A}$ \\
\hline & & & & & & $\begin{array}{l}\text { Nextstrain 20A/GISAID B1.p9 } \\
\text { lineage }\end{array}$ & Mild & Intense headache, drowsiness & $\begin{array}{l}\text { IgM+ IgG- on D7 of } \\
\text { initial infection }\end{array}$ \\
\hline 193. & Prado-Vivar B et al. [28] & 2020 & Ecuador & 46-year-old man & 63 & $\begin{array}{l}\text { Nextstrain 19B/GISAID A.1.1 } \\
\text { lineage; } 18 \text { mutations difference }\end{array}$ & Moderate & $\begin{array}{l}\text { Odynophagia, nasal congestion, fever } \\
39^{\circ} \mathrm{C} \text {, back pain, productive cough, } \\
\text { dyspnea }\end{array}$ & $\operatorname{IgM}+\operatorname{IgG}+$ on $\mathrm{D} 28$ \\
\hline & & & & 60-year-old male, & & & Mild & Cough and low-grade fever & \\
\hline 194. & Quiroga B et al. [112] & 2021 & Spain & $\begin{array}{l}\text { With chronic } \\
\text { kidney disease } \\
\text { (CKD) } \\
\text { due to focal and } \\
\text { segmental } \\
\text { glomerulosclerosis } \\
\text { that received his } \\
\text { first kidney } \\
\text { transplant } 2004 \\
\end{array}$ & 149 & N/A & Worse & $\begin{array}{l}\text { Respiratory fever and acute injury of } \\
\text { the allograft function. A chest X-ray } \\
\text { showed bilateral infiltrates with } \\
\text { unilateral pleural effusion }>\text { death }\end{array}$ & $\begin{array}{l}\text { Antibodies (IgM and } \\
\text { IgG) for SARS-CoV2 } \\
\text { resulted negative after } \\
\text { reinfection }\end{array}$ \\
\hline & & & & 54-year-old & & B.1 & Mild & Fever, cough, odynophagia, fatigue & \\
\hline 195. & $\begin{array}{l}\text { Ramirez ]D et al. } \\
\text { [113]-case } 3\end{array}$ & 2021 & Colombia & $\begin{array}{l}\text { woman with } \\
\text { hypertension, } \\
\text { gastritis, arthrosis }\end{array}$ & 33 & B.1.1.269 & Milder & Fever, odynophagia & $\mathrm{N} / \mathrm{A}$ \\
\hline
\end{tabular}


Table 2. Cont.

\begin{tabular}{|c|c|c|c|c|c|c|c|c|c|}
\hline & Authors & Year & $\begin{array}{l}\text { Patient } \\
\text { Country }\end{array}$ & Patient & $\begin{array}{l}\text { Interval Time between } 1 \\
\text { Infection and Reinfection }\end{array}$ & Viral Genome Sequence & COVID-19 & Symptoms & $\begin{array}{c}\text { Antibody after First } \\
\text { Infection or } \\
\text { Reinfection } \\
\end{array}$ \\
\hline 196. & Rani PR et al. [114] & 2021 & India & 47-year-old man & 46 & $\begin{array}{c}15 \text { genetic variants with 22882T > G } \\
\text { (Spike N440K) }\end{array}$ & Asymptomatic & Asymptomatic & N/A \\
\hline \multirow[t]{2}{*}{197.} & \multirow[t]{2}{*}{ Resende PC et al. [115] } & \multirow[t]{2}{*}{2021} & \multirow[t]{2}{*}{ Brazil } & \multirow{2}{*}{$\begin{array}{l}\text { 37-year-old } \\
\text { healthcare worker } \\
\text { woman }\end{array}$} & \multirow[t]{2}{*}{116} & B.1.1.33 & Mild & $\begin{array}{l}\text { Headache, runny nose, diarrhea, } \\
\text { myalgia }\end{array}$ & \multirow[t]{2}{*}{ IgG+ after re-infection } \\
\hline & & & & & & VOI P.2 with mutation S-E484K & Mild & Headache, ageusia, anosmia, fatigue & \\
\hline 198. & $\begin{array}{l}\text { Rodríguez-Espinosa D } \\
\text { et al. [116] }\end{array}$ & 2021 & Spain & $\begin{array}{l}\text { 76-year-old man } \\
\text { with hypertension, } \\
\text { biological aortic } \\
\text { heart valve } \\
\text { replacement, and } \\
\text { end-stage kidney } \\
\text { disease secondary } \\
\text { to autosomal } \\
\text { dominant } \\
\text { polycystic kidney } \\
\text { disease }\end{array}$ & 58 & & Worse & $\begin{array}{l}\text { Fever, cough, and shortness of breath, } \\
\text { bilateral pneumonia > death } 18 \text { days } \\
\text { after admission }\end{array}$ & $\begin{array}{l}\text { IgG and IgM to } \\
\text { SARS-CoV-2 tested } \\
\text { negative after 1st and } \\
\text { 2nd episode }\end{array}$ \\
\hline \multirow{2}{*}{199.} & \multirow{2}{*}{ Romano CM et al. [117] } & \multirow{2}{*}{2021} & \multirow{2}{*}{ Brazil } & \multirow{2}{*}{$\begin{array}{l}\text { 26-year-old } \\
\text { woman }\end{array}$} & \multirow{2}{*}{128} & Non-VOC virus & Mild & $\begin{array}{l}\text { Dry cough, dizziness, headache, fatigue, } \\
\text { stuffy nose, back pain, loss of taste, } \\
\text { nausea, diarrhea }\end{array}$ & \\
\hline & & & & & & VOC-virus P.1 variant & Mild & $\begin{array}{l}\text { Dry cough, dizziness, headache, fatigue, } \\
\text { diarrhea, joint pain legs, difficult } \\
\text { breathing }\end{array}$ & \\
\hline \multirow[b]{2}{*}{200.} & \multirow[b]{2}{*}{ Salcin S et al. [118] } & \multirow[b]{2}{*}{2021} & \multirow[b]{2}{*}{ USA } & \multirow{2}{*}{$\begin{array}{c}\text { 62-year-old } \\
\text { womann with } \\
\text { hypertension, } \\
\text { hypothyroidism, } \\
\text { chronic lower back } \\
\text { pain } \\
\end{array}$} & \multirow[b]{2}{*}{90} & & Hospitalized & $\begin{array}{l}\text { Worsening shortness of breath, cough, } \\
\text { hypoxia }\end{array}$ & \multirow[b]{2}{*}{$\mathrm{N} / \mathrm{A}$} \\
\hline & & & & & & N/A & $\begin{array}{l}\text { Worse with } \\
\text { intubation } \\
\text { twice }\end{array}$ & Tachypnea, hypoxia, pneumonia & \\
\hline \multirow[b]{2}{*}{201.} & \multirow[b]{2}{*}{ Salehi-Vaziri M et al. [119] } & \multirow[b]{2}{*}{2021} & \multirow[b]{2}{*}{ Iran } & & & 20G with 11 mutations & Mild & Cough, headache, severe diarrhea & IgG and IgM negative \\
\hline & & & & 42-year-old man & 128 & $20 \mathrm{G}$ with 17 mutations & Mild & $\begin{array}{l}\text { Body pain, shortness of breath, } \\
\text { headache, anosmia }\end{array}$ & IgG and IgM negative \\
\hline
\end{tabular}


Table 2. Cont.

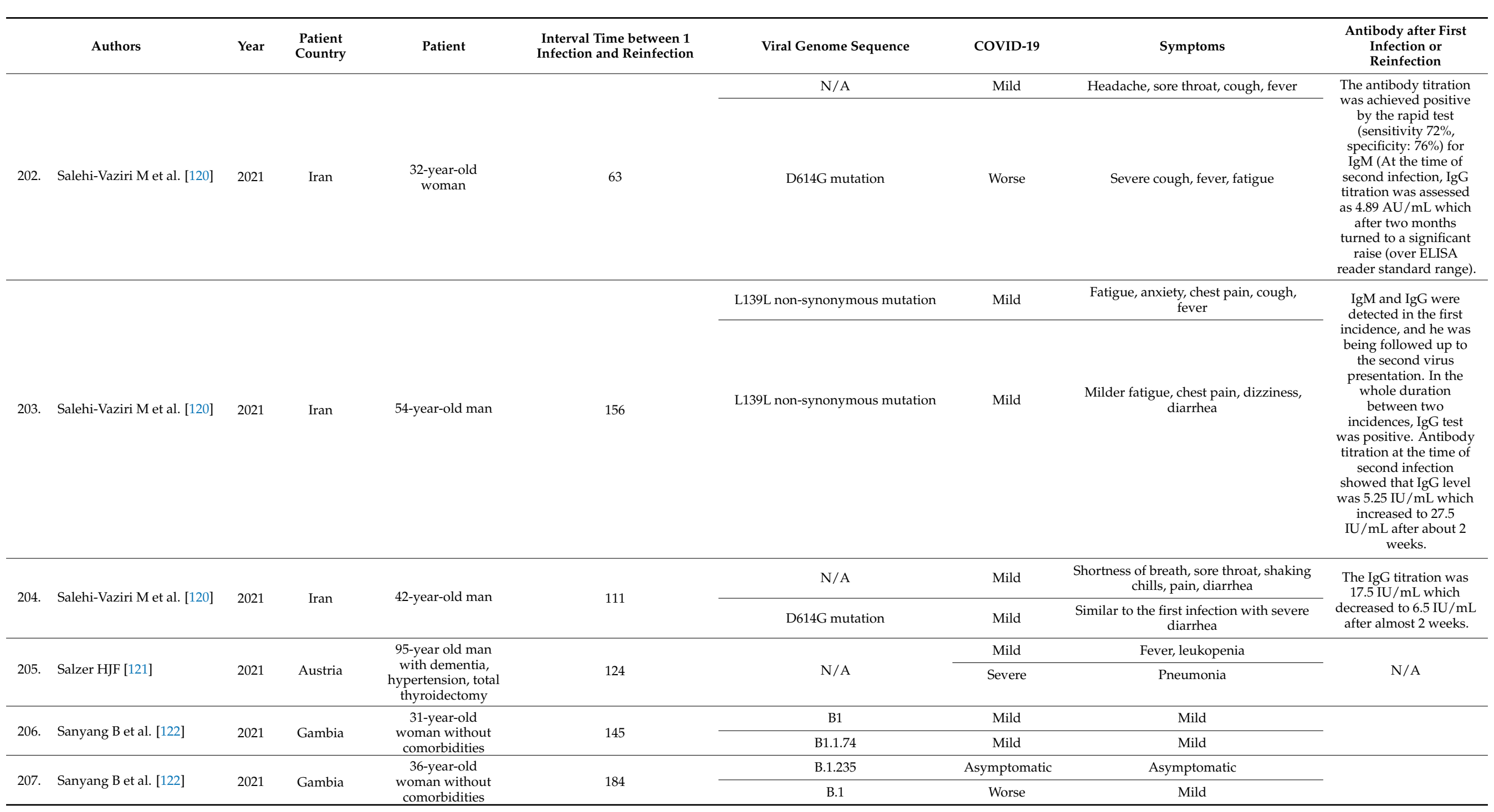


Table 2. Cont.

\begin{tabular}{|c|c|c|c|c|c|c|c|c|c|}
\hline & Authors & Year & $\begin{array}{l}\text { Patient } \\
\text { Country }\end{array}$ & Patient & $\begin{array}{l}\text { Interval Time between } 1 \\
\text { Infection and Reinfection }\end{array}$ & Viral Genome Sequence & COVID-19 & Symptoms & $\begin{array}{l}\text { Antibody after First } \\
\text { Infection or } \\
\text { Reinfection } \\
\end{array}$ \\
\hline \multirow[b]{2}{*}{208.} & \multirow[b]{2}{*}{ Scarpati G et al. [123] } & \multirow[b]{2}{*}{2021} & \multirow[b]{2}{*}{ Italy } & \multirow{2}{*}{$\begin{array}{c}\text { 63-year-old } \\
\text { healthcare man } \\
\text { with type II } \\
\text { diabetes, atrial } \\
\text { fibrillation, chronic } \\
\text { obstructive } \\
\text { pulmonary disease }\end{array}$} & \multirow[b]{2}{*}{299} & Clade 20A & Asymptomatic & Asymptomatic & \\
\hline & & & & & & Clade 20E & Worse & $\begin{array}{l}\text { Shortness of breath with rapid } \\
\text { worsening of clinical presentation and } \\
\text { recovering in intensive care unit }>\text { death }\end{array}$ & \\
\hline \multirow[t]{2}{*}{209.} & \multirow{2}{*}{ Selhorst P et al. [124] } & \multirow{2}{*}{2020} & \multirow{2}{*}{ Belgium } & \multirow{2}{*}{$\begin{array}{l}\text { 39-year-old female } \\
\text { immunocompetent } \\
\text { healthcare worker }\end{array}$} & \multirow{2}{*}{185} & Different clades: 19A & Mild & $\begin{array}{l}\text { Cough, dyspnea, headache, fever, } \\
\text { general malaise }\end{array}$ & IgG+ \\
\hline & & & & & & $20 \mathrm{~A}$ & Milder & Dyspnea & IgM and IgG+ \\
\hline \multirow[b]{2}{*}{210.} & \multirow[b]{2}{*}{ Selvaraj V. et al. [125] } & \multirow[b]{2}{*}{2020} & \multirow[b]{2}{*}{ USA } & \multirow{2}{*}{$\begin{array}{c}\text { 70-year-old male } \\
\text { with obesity, } \\
\text { neuropathy, } \\
\text { asthma, } \\
\text { obstructive sleep } \\
\text { apnea, } \\
\text { hypertension }\end{array}$} & \multirow[b]{2}{*}{7 months } & \multirow[b]{2}{*}{ N/A } & Hospitalized & $\begin{array}{l}\text { Worsening shortness of breath, } \\
\text { tachypneic, mild, patchy mid and lower } \\
\text { lung airspace disease bilaterally }\end{array}$ & SARS-CoV-2 IgG- \\
\hline & & & & & & & Hospitalized & $\begin{array}{l}\text { Shortness of breath, fever, body aches, } \\
\text { nausea, malaise }\end{array}$ & \\
\hline \multirow{2}{*}{211.} & \multirow{2}{*}{ Sen MK et al. [126] } & \multirow{2}{*}{2020} & \multirow{2}{*}{ India } & \multirow{2}{*}{$\begin{array}{l}\text { 78-year-old man } \\
\text { with coronary } \\
\text { artery disease }\end{array}$} & \multirow{2}{*}{57} & \multirow{2}{*}{$\mathrm{N} / \mathrm{A}$} & Mild & Fever, cough for 2 days & \multirow{2}{*}{ N/A } \\
\hline & & & & & & & Mild & Fever, cough, dyspnea for 1 day & \\
\hline 212. & Sevillano G et al. [127] & 2021 & Ecuador & 28-year-old man & 102 & Different in 27 nucleotides & Mild & Anosmia, ageusia, fever, headache & $\begin{array}{l}\text { IgM and IgG negative } \\
\text { after 2nd infection }\end{array}$ \\
\hline \multirow[t]{2}{*}{213.} & \multirow[t]{2}{*}{ Sharma R et al. [13] } & \multirow[t]{2}{*}{2020} & Qatar & $\begin{array}{l}\text { 57-year-old male } \\
\text { with diabetes }\end{array}$ & 86 & N/A & Asymptomatic & $\begin{array}{l}\text { Asymptomatic, screening for exposition } \\
\text { to an infected work colleague }\end{array}$ & $\mathrm{N} / \mathrm{A}$ \\
\hline & & & & mellitus & 00 & 10/ & Symptomatic & $\begin{array}{l}\text { Fever, myalgia, headache, productive } \\
\text { cough }\end{array}$ & IgM and IgG+ \\
\hline & & & & & & Lineage B.1 & $\begin{array}{l}\text { Mild, } 2 \text { days } \\
\text { of symptoms }\end{array}$ & Sore throat, nasal congestion, rhinitis & N/A \\
\hline 214. & $\begin{array}{l}\text { Shastri ] et al. [128]-Case } \\
\text { A }\end{array}$ & 2021 & India & $\begin{array}{l}\text { 27-year-old male } \\
\text { doctor }\end{array}$ & 66 & Lineage B with 7 differences & $\begin{array}{l}\text { Mild, worse } \\
\text { than initial (1 } \\
\text { week) }\end{array}$ & $\begin{array}{l}\text { Myalgia, fever, non-productive cough, } \\
\text { fatigue }\end{array}$ & $\begin{array}{l}\text { Abbott anti-NC IgG- } \\
\text { on D5 of reinfection }\end{array}$ \\
\hline & & & & & & Lineage B.1.1 & Asymptomatic & Nothing & N/A \\
\hline 215. & $\begin{array}{l}\text { Shastri J et al. [128]—Case } \\
\text { B }\end{array}$ & 2021 & India & $\begin{array}{l}\text { 31-year-old male } \\
\text { doctor }\end{array}$ & 65 & $\begin{array}{l}\text { Lineage B.1.1 with 8SPSs in initial } \\
\text { strain compared to reference not } \\
\text { present in reinfection strain } \\
\text { including D614G }\end{array}$ & $\begin{array}{l}\text { Mild, worse } \\
\text { than initial (2 } \\
\text { days) }\end{array}$ & Myalgia, malaise & $\begin{array}{l}\text { Abbott NC IgG- on D7 } \\
\text { of reinfection }\end{array}$ \\
\hline
\end{tabular}


Table 2. Cont.

\begin{tabular}{|c|c|c|c|c|c|c|c|c|c|}
\hline & Authors & Year & $\begin{array}{l}\text { Patient } \\
\text { Country }\end{array}$ & Patient & $\begin{array}{l}\text { Interval Time between } 1 \\
\text { Infection and Reinfection }\end{array}$ & Viral Genome Sequence & COVID-19 & Symptoms & $\begin{array}{l}\text { Antibody after First } \\
\text { Infection or } \\
\text { Reinfection } \\
\end{array}$ \\
\hline 216. & $\begin{array}{l}\text { Shastri J et al. [128]—Case } \\
\text { C }\end{array}$ & 2021 & India & $\begin{array}{l}\text { 27-year-old male } \\
\text { doctor }\end{array}$ & 19 & Lineage B.1.1 & Asymptomatic & $\begin{array}{l}\text { Asymptomatic-screening prior going } \\
\text { home to visit parents }\end{array}$ & $\mathrm{N} / \mathrm{A}$ \\
\hline \multirow[b]{2}{*}{217.} & \multirow[b]{2}{*}{$\begin{array}{l}\text { Shastri J et al. [128]—Case } \\
\text { D }\end{array}$} & \multirow[b]{2}{*}{2021} & \multirow[b]{2}{*}{ India } & \multirow[b]{2}{*}{$\begin{array}{l}\text { 24-year-old } \\
\text { woman nurse }\end{array}$} & \multirow[b]{2}{*}{55} & Lineage B.1.1 & Mild, 5 days & Sore throat, rhinitis, myalgia & N/A \\
\hline & & & & & & $\begin{array}{l}\text { Lineage B.1.1 with 10SNPs } \\
\text { compared to reference not present } \\
\text { in initial infection strain including } \\
\text { D614G }\end{array}$ & $\begin{array}{l}\text { Mild, worse } \\
\text { than initial-3 } \\
\text { weeks }\end{array}$ & $\begin{array}{l}\text { Fever, myalgia, rhinitis, sore throat, not } \\
\text { productive cough, fatigue }\end{array}$ & $\operatorname{IgG} / \operatorname{IgM} / \operatorname{Ig} \mathrm{A}-$ \\
\hline \multirow[b]{2}{*}{218.} & \multirow{2}{*}{ Shoar S et al. [129] } & \multirow[b]{2}{*}{2021} & \multirow[b]{2}{*}{ USA } & \multirow{2}{*}{$\begin{array}{l}\text { 31-year-old } \\
\text { healthcare worker } \\
\text { man }\end{array}$} & \multirow[b]{2}{*}{79} & \multirow{2}{*}{$\mathrm{N} / \mathrm{A}$} & Severe & $\begin{array}{c}\text { Malaise, cough, shortness of breath, } \\
\text { anosmia, }=2 \text { saturation to } 88 \%, \\
\text { pneumonia }\end{array}$ & \multirow{2}{*}{ N/A } \\
\hline & & & & & & & Milder & $\begin{array}{l}\text { Malaise, aphthous gingival ulcer, } \\
\text { desquamating palmar lesion, fever, } \\
\text { myalgia }\end{array}$ & \\
\hline 219. & Sicsic I et al. [130] & 2021 & USA & $\begin{array}{c}\text { 69-year-old } \\
\text { woman with } \\
\text { asthma, hyperc- } \\
\text { holesteremia, } \\
\text { hypertension, OSA } \\
\text { (obstructive sleep } \\
\text { apnea) }\end{array}$ & 70 & N/A & Mild & $\begin{array}{l}\text { Shortness of breath, dry cough, } \\
\text { headache, fatigue, fevers }\end{array}$ & $\mathrm{N} / \mathrm{A}$ \\
\hline \multirow[b]{2}{*}{220.} & \multirow[b]{2}{*}{ Siqueira JD et al. [131] } & \multirow[b]{2}{*}{2021} & \multirow[b]{2}{*}{ Brazil } & \multirow{2}{*}{$\begin{array}{l}\text { 76-year-old } \\
\text { woman with } \\
\text { chronic renal } \\
\text { failure and renal } \\
\text { squamous cell } \\
\text { carcinoma }\end{array}$} & \multirow[b]{2}{*}{104} & & Severe & Cough, fever, pneumonia & \multirow[b]{2}{*}{$\mathrm{N} / \mathrm{A}$} \\
\hline & & & & & & $\begin{array}{l}9 \text { single nucleotide variations } \\
\text { (SNVs) }\end{array}$ & Worse & Cough, fever, pneumonia > death & \\
\hline \multirow[b]{2}{*}{221.} & & & & 39-year-old man & & P.1 & Not reported & Not reported & \\
\hline & Soares da Silva et al. [132] & 2021 & Brazil & $\begin{array}{c}\text { cardiovascular } \\
\text { disease, diabetes } \\
\text { mellitus }\end{array}$ & 101 & P.2 & Worse & $\begin{array}{c}\text { Dyspnea, fatigue, respiratory distress > } \\
\text { intubated > death } 12 \text { days after the } \\
\text { onset of symptoms }\end{array}$ & N/A \\
\hline & & & & Mid-20s healthcare & & November N/A & Asymptomatic & Asymptomatic & \\
\hline 222. & Staub T et al. [133] - case 1 & 2021 & France & $\begin{array}{c}\text { worker man } \\
\text { without } \\
\text { comorbidities }\end{array}$ & $>83$ & $\begin{array}{l}\text { B1.351-identified in December } \\
2020 \text { in South Africa }\end{array}$ & Worse & Cough & N/A \\
\hline 223. & Staub Tet al. [133]—case 2 & 2021 & France & $\begin{array}{l}\text { Mid-20s healthcare } \\
\text { worker woman }\end{array}$ & 288 & April 2020-N/A & Mild & $\begin{array}{l}\text { Fever, headache, chills, diarrhea, loss of } \\
\text { taste and smell }\end{array}$ & N/A \\
\hline & 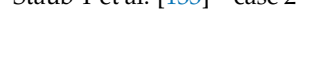 & 2021 & France & $\begin{array}{c}\text { without } \\
\text { comorbidities }\end{array}$ & 200 & B1.351 & Milder & Fever, headache, chills & $1 \mathrm{~V} / \mathrm{R}$ \\
\hline
\end{tabular}


Table 2. Cont.

\begin{tabular}{|c|c|c|c|c|c|c|c|c|}
\hline Authors & Year & $\begin{array}{l}\text { Patient } \\
\text { Country }\end{array}$ & Patient & $\begin{array}{l}\text { Interval Time between } 1 \\
\text { Infection and Reinfection }\end{array}$ & Viral Genome Sequence & COVID-19 & Symptoms & $\begin{array}{l}\text { Antibody after First } \\
\text { Infection or } \\
\text { Reinfection }\end{array}$ \\
\hline 224. Staub $\mathrm{T}$ et al. [133]—case 4 & 2021 & France & $\begin{array}{l}\text { Late-20s healthcare } \\
\text { worker woman } \\
\text { without } \\
\text { comorbidities }\end{array}$ & 90 & November $2020-\mathrm{N} / \mathrm{A}$ & Mild & $\begin{array}{l}\text { Fever, muscle pain, headache, loss of } \\
\text { taste and smell }\end{array}$ & N/A \\
\hline \multirow[b]{2}{*}{$\begin{array}{l}\text { 225. Takeda C et al. [134] } \\
\text { Patient } 1\end{array}$} & \multirow[b]{2}{*}{2020} & \multirow[b]{2}{*}{ Brazil } & \multirow{2}{*}{$\begin{array}{c}\text { 29-year-old man } \\
\text { healthcare } \\
\text { professional } \\
\text { without } \\
\text { comorbidities }\end{array}$} & \multirow[b]{2}{*}{53} & \multirow[b]{2}{*}{$\mathrm{N} / \mathrm{A}$} & Mild & Myalgia, fever & \multirow[b]{2}{*}{$\mathrm{N} / \mathrm{A}$} \\
\hline & & & & & & Mild & Fever, anosmia, loss of taste & \\
\hline \multirow[b]{2}{*}{$\begin{array}{l}\text { 226. Takeda C et al. [134] } \\
\text { Patient } 2\end{array}$} & \multirow[b]{2}{*}{2020} & \multirow[b]{2}{*}{ Brazil } & \multirow{2}{*}{$\begin{array}{c}\text { 63-year-old man } \\
\text { healthcare } \\
\text { professional } \\
\text { without } \\
\text { comorbidities } \\
\end{array}$} & \multirow[b]{2}{*}{58} & \multirow[b]{2}{*}{$\mathrm{N} / \mathrm{A}$} & Mild & Diarrhea, fever & \multirow[b]{2}{*}{$\mathrm{N} / \mathrm{A}$} \\
\hline & & & & & & Mild & Hypoxemia, fever & \\
\hline \multirow[b]{2}{*}{$\begin{array}{l}\text { 227. Takeda C et al. [134] } \\
\text { Patient } 3\end{array}$} & \multirow[b]{2}{*}{2020} & \multirow[b]{2}{*}{ Brazil } & \multirow[b]{2}{*}{$\begin{array}{c}\text { 40-year-old } \\
\text { woman healthcare } \\
\text { professional with } \\
\text { ankylosing } \\
\text { spondylitis and } \\
\text { asthma }\end{array}$} & \multirow[b]{2}{*}{70} & \multirow[b]{2}{*}{$\mathrm{N} / \mathrm{A}$} & Moderate & Fever, Pneumonia, myalgia & \multirow[b]{2}{*}{ Not specified } \\
\hline & & & & & & Mild & Anosmia, fever & \\
\hline $\begin{array}{l}\text { 228. Takeda C et al. [134] } \\
\text { Patient } 4\end{array}$ & 2020 & Brazil & $\begin{array}{l}\text { 67-year-old man } \\
\text { healthcare } \\
\text { professional with } \\
\text { obesity, apnea } \\
\text { syndrome, rhinitis }\end{array}$ & 54 & N/A & Mild & Coryza, arthralgia & Not specified \\
\hline \multirow[b]{2}{*}{$\begin{array}{l}\text { 229. Takeda C et al. [134] } \\
\text { Patient } 5\end{array}$} & \multirow[b]{2}{*}{2020} & & 47-year-old man & & & Mild & Myalgia, fever & \\
\hline & & Brazil & $\begin{array}{l}\text { healthcare } \\
\text { professional } \\
\text { without } \\
\text { comorbidities }\end{array}$ & 56 & N/A & Mild & Fever & Not specified \\
\hline & & & 31-year-old man & & & Moderate & Hypoxemia, myalgia, diarrhea, fever & \\
\hline $\begin{array}{l}\text { 230. Takeda C et al. [134] } \\
\text { Patient } 6\end{array}$ & 2020 & Brazil & $\begin{array}{l}\text { hearthcare } \\
\text { professional } \\
\text { without } \\
\text { comorbidities }\end{array}$ & 57 & N/A & Moderate & Hypoxemia, fever & Not specified \\
\hline & & & & & PANGOLIN A.3 lineage & Mild & Cough, chills, exertional dyspnea, sore & \\
\hline 231. Tang CY et al. [135] & 2021 & USA & $\begin{array}{l}\text { Female in 20s with } \\
\text { asthma, obesity, }\end{array}$ & 19 & PANGOLIN B.1.1 lineage & Milder & throat, dizziness, rhinorrhea, fever & N/A \\
\hline & & & anxiety, depression & & & & Cough, fatigue, dyspnea & \\
\hline
\end{tabular}


Table 2. Cont.

\begin{tabular}{|c|c|c|c|c|c|c|c|c|c|}
\hline & Authors & Year & $\begin{array}{l}\text { Patient } \\
\text { Country }\end{array}$ & Patient & $\begin{array}{l}\text { Interval Time between } 1 \\
\text { Infection and Reinfection }\end{array}$ & Viral Genome Sequence & COVID-19 & Symptoms & $\begin{array}{c}\text { Antibody after First } \\
\text { Infection or } \\
\text { Reinfection } \\
\end{array}$ \\
\hline 232. & Tehrani HA et al. [136] & 2021 & Iran & $\begin{array}{l}\text { 15-year-old boy } \\
\text { with acute myeloid } \\
\text { leukemia M3 }\end{array}$ & 43 & $\mathrm{~N} / \mathrm{A}$ & Moderate & $\begin{array}{l}\text { Cough, dyspnea, patchy infiltration in } \\
\text { the left lung }\end{array}$ & $\operatorname{IgG}+\operatorname{IgM}-$ \\
\hline \multirow{2}{*}{233.} & \multirow{2}{*}{ Teka IA et al. [137] } & \multirow{2}{*}{2021} & \multirow{2}{*}{ Libya } & \multirow{2}{*}{ 18-year-old man } & \multirow{2}{*}{80} & \multirow{2}{*}{$\mathrm{N} / \mathrm{A}$} & Mild & $\begin{array}{l}\text { Fever, headache, sore throat, cough, } \\
\text { shortness of breath, anosmia }\end{array}$ & \multirow{2}{*}{$\begin{array}{l}\text { IgG positive after } \\
\text { re-infection }\end{array}$} \\
\hline & & & & & & & Worse & $\begin{array}{l}\text { Fever, cough, muscle pain, dyspnea, } \\
\text { hypoxia }\end{array}$ & \\
\hline \multirow[b]{2}{*}{234.} & \multirow[b]{2}{*}{ Tillett RL et al. [27] } & \multirow[b]{2}{*}{2020} & \multirow[b]{2}{*}{ USA (Nevada) } & \multirow{2}{*}{$\begin{array}{l}\text { 25-year-old man } \\
\text { without } \\
\text { comorbidities }\end{array}$} & \multirow[b]{2}{*}{48} & Clade 20C & Mild & $\begin{array}{l}\text { Sore throat, cough, headache, nausea, } \\
\text { diarrhea }\end{array}$ & $\mathrm{N} / \mathrm{A}$ \\
\hline & & & & & & Clade $20 \mathrm{C}$ with $11 \mathrm{SNP}$ mutation & $\begin{array}{l}\text { Severe with } \\
\text { hospitaliza- } \\
\quad \text { tion }\end{array}$ & $\begin{array}{c}\text { Fever, headache, dizziness, cough, } \\
\text { nausea, diarrhea, hypoxia, shortness of } \\
\text { breath }\end{array}$ & $\begin{array}{l}\text { Roche Elecsys } \\
\text { Anrti-SARS-CoV-2 } \\
\text { IgM/IgG+ on D8 of } \\
\text { reinfection }\end{array}$ \\
\hline
\end{tabular}


Table 2. Cont.

\begin{tabular}{|c|c|c|c|c|c|c|c|c|c|}
\hline & Authors & Year & $\begin{array}{l}\text { Patient } \\
\text { Country }\end{array}$ & Patient & $\begin{array}{l}\text { Interval Time between } 1 \\
\text { Infection and Reinfection }\end{array}$ & Viral Genome Sequence & COVID-19 & Symptoms & $\begin{array}{l}\text { Antibody after First } \\
\text { Infection or } \\
\text { Reinfection }\end{array}$ \\
\hline \multirow{2}{*}{235.} & \multirow{2}{*}{ To KK et al. $[5,138,139]$} & \multirow{2}{*}{2020} & \multirow{2}{*}{ Hong Kong } & \multirow{2}{*}{ A 33-year-old male } & \multirow{2}{*}{142} & $\begin{array}{l}\text { Nextstrain 19A/GISAID } \\
\text { V/Pangolin lineage B.2 }\end{array}$ & $\begin{array}{l}\text { Mild-- } \\
\text { hospitalized }\end{array}$ & Fever, headache, cough, sore throat & $\begin{array}{c}\text { IgG negativity by } \\
\text { ELISA or microsphere } \\
\text { based antibody assay } \\
10 \text { days post symptom } \\
\text { onset; IgG positivity } \\
\text { but IgM negativity by } \\
\text { indirect } \\
\text { immunofluoresence } \\
\text { assay; neutralizing } \\
\text { antibody presence } 10 \\
\text { days post-symptom } \\
\text { onset with } \\
\text { conventional and } \\
\text { pseudovirus-based } \\
\text { neutralization tests } \\
\text { (VNTs) }\end{array}$ \\
\hline & & & & & & $\begin{array}{c}\text { Nextstrain 20A/GISAID } \\
\text { G/Rambout B.1.79; } 24 \text { nucleotides } \\
\text { difference }\end{array}$ & $\begin{array}{l}\text { Asymptomatic, } \\
\text { systematic } \\
\text { screening }\end{array}$ & Asymptomatic & $\begin{array}{c}\text { IgG negativity by } \\
\text { ELISA or microsphere } \\
\text { based antibody assay } 1 \\
\text { day } \\
\text { post-hospitalization, } \\
\text { but positivity at day 5; } \\
\text { absence of neutralizing } \\
\text { antibodies by VNTs } \\
\text { and IgM negativity by } \\
\text { IFI assay and CLIA 1 } \\
\text { day } \\
\text { post-hospitalization; } \\
\text { then positivation on } \\
\text { day 3; neutralizing } \\
\text { antibody detection on } \\
\text { day 3; IgG detection by } \\
\text { IFon day 3; high affinity } \\
\text { IgG }\end{array}$ \\
\hline \multirow[b]{2}{*}{236.} & \multirow[b]{2}{*}{$\begin{array}{l}\text { Tomkins-Tinch C-H et al. } \\
\text { [140] }\end{array}$} & \multirow[b]{2}{*}{2021} & \multirow[b]{2}{*}{ USA } & \multirow{2}{*}{$\begin{array}{l}\text { 61-year-old man } \\
\text { with liver } \\
\text { transplant due to } \\
\text { chronic hepatitis B } \\
\text { and C infections }\end{array}$} & \multirow[b]{2}{*}{111} & \multirow[b]{2}{*}{$\begin{array}{l}\text { Genome of } 2 \text { nd episode differed by } \\
11 \text { to } 12 \text { single base substitutions }\end{array}$} & Mild & Fever, nausea, vomiting, cough & \\
\hline & & & & & & & Worse & $\begin{array}{l}\text { Confusion, hallucination, lethargy, } \\
\text { hypoxia }\end{array}$ & $\begin{array}{l}\text { Anti-SARS-CoV-2 assay } \\
\text { positive after 2nd } \\
\text { episode }\end{array}$ \\
\hline \multirow{2}{*}{237.} & \multirow{2}{*}{$\begin{array}{l}\text { Tomassini S et al. case } 9 \\
\text { [141] }\end{array}$} & \multirow[b]{2}{*}{2021} & \multirow[b]{2}{*}{ UK } & \multirow{2}{*}{$\begin{array}{c}\text { 93-year-old British } \\
\text { male with multiple } \\
\text { myeloma, } \\
\text { cognitive } \\
\text { impairment }\end{array}$} & \multirow[b]{2}{*}{55} & \multirow[b]{2}{*}{$\mathrm{N} / \mathrm{A}$} & $\begin{array}{c}14 \text { days- } \\
\text { hospitalized }\end{array}$ & Lethargy, reduced appetite, diarrhea & \\
\hline & & & & & & & & Cough, fever, dyspnea & $\begin{array}{c}\text { Abbott Architect } \\
\text { SARS-CoV-2 IgG+ on } \\
\text { D58 }\end{array}$ \\
\hline
\end{tabular}


Table 2. Cont.

\begin{tabular}{|c|c|c|c|c|c|c|c|c|c|}
\hline & Authors & Year & $\begin{array}{l}\text { Patient } \\
\text { Country }\end{array}$ & Patient & $\begin{array}{l}\text { Interval Time between } 1 \\
\text { Infection and Reinfection }\end{array}$ & Viral Genome Sequence & COVID-19 & Symptoms & $\begin{array}{l}\text { Antibody after First } \\
\text { Infection or } \\
\text { Reinfection }\end{array}$ \\
\hline \multirow[b]{2}{*}{238.} & \multirow[b]{2}{*}{$\begin{array}{l}\text { Tomassini S et al. case } 24 \\
\text { [141] }\end{array}$} & \multirow[b]{2}{*}{2021} & \multirow[b]{2}{*}{ UK } & \multirow{2}{*}{$\begin{array}{l}\text { 82-year-old British } \\
\text { male with atrial } \\
\text { fibrillation, } \\
\text { congestive cardiac } \\
\text { failure, abdominal } \\
\text { aortic aneurism, } \\
\text { lung cancer, } \\
\text { diabetes }\end{array}$} & \multirow[b]{2}{*}{87} & \multirow[b]{2}{*}{ N/A } & $\begin{array}{c}\text { Mild-- } \\
\text { hospitalized }\end{array}$ & $\begin{array}{l}\text { Fever, cough, sore throat, dyspnea, } \\
\text { hemoptysis, hypoxia }\end{array}$ & \\
\hline & & & & & & & Milder & Fever, cough, dyspnea & $\begin{array}{c}\text { Abbott Architect } \\
\text { SARS-CoV-2 IgG+ on } \\
\text { D88. } 92\end{array}$ \\
\hline 239. & Torres DA et al. [142] & 2020 & Brazil & $\begin{array}{l}\text { 36-year-old female } \\
\text { medical doctor } \\
\text { without } \\
\text { comorbidities }\end{array}$ & 87 & N/A & Worse & $\begin{array}{l}\text { Nasal obstruction, hyaline rhinorrhea, } \\
\text { sudden and complete anosmia and } \\
\text { ageusia, frontal headache and asthenia, } \\
\text { pneumonia }\end{array}$ & IgG+ at the 20th day \\
\hline \multirow{2}{*}{240.} & \multirow{2}{*}{ Tuan J et al. [136] } & \multirow{2}{*}{2021} & \multirow{2}{*}{ USA } & \multirow{2}{*}{$\begin{array}{l}\text { 44-year-old } \\
\text { Hispanic man with } \\
\text { type } 2 \text { diabetes } \\
\text { mellitus, obesity } \\
\end{array}$} & \multirow{2}{*}{4 months } & \multirow{2}{*}{$\mathrm{N} / \mathrm{A}$} & $\begin{array}{c}\text { Severe with } \\
\text { tracheostomy }\end{array}$ & Dyspnea, stridor, difficulty at breath, & \multirow{2}{*}{$\operatorname{IgG}+$} \\
\hline & & & & & & & Mild & Fever, respiratory decompensation & \\
\hline 241. & Ul-Haq Z et al. [143] & 2020 & Pakistan & $\begin{array}{l}\text { 41-year-old } \\
\text { healthcare worker } \\
\text { man }\end{array}$ & 133 & N/A & Milder & $\begin{array}{l}\text { Fever, moderate shortness of breath, } \\
\text { loss of smell, moderate restlessness, } \\
\text { insomnia, body aches }\end{array}$ & $\begin{array}{c}\text { SARS-CoV-2 antibodies: } \\
0.08\end{array}$ \\
\hline \multirow[t]{2}{*}{242.} & \multirow[t]{2}{*}{ Van Elsland J et al. [29] } & \multirow{2}{*}{2020} & \multirow[t]{2}{*}{ Belgium } & \multirow{2}{*}{$\begin{array}{l}\text { 51-year-old } \\
\text { woman with } \\
\text { asthma }\end{array}$} & \multirow[t]{2}{*}{93} & Pangolin Lineage B.1.1 & $\begin{array}{l}\text { Moderate } \\
\text { with self- } \\
\text { quarantine for } \\
2 \text { weeks } \\
\end{array}$ & $\begin{array}{l}\text { Headache, myalgia, fever, cough, chest } \\
\text { pain, dyspnea; some persisting } \\
\text { symptoms for } 5 \text { weeks }\end{array}$ & N/A \\
\hline & & & & & & $\begin{array}{l}\text { Lineage } \mathrm{A} ; 11 \text { nucleotide } \\
\text { differences }\end{array}$ & $\begin{array}{l}\text { Milder with } \\
\text { resolution in } 1 \\
\text { week }\end{array}$ & Headache, cough, fatigue, rhinitis & $\begin{array}{l}\text { Roche nucleocapsid } \\
\text { IgG+ on D7 of } \\
\text { reinfection }\end{array}$ \\
\hline \multirow{2}{*}{243.} & \multirow{2}{*}{ Vetter P et al. [144] } & \multirow{2}{*}{2021} & c-it ollo & 36-year-old female & 205 & Clade 20A & Mild & Asthenia, headache, slight memory loss & $\begin{array}{l}\text { Positivity for anti-S1 } \\
\text { IgG and anti-N Ig at } \\
\text { 14th and at 30th days }\end{array}$ \\
\hline & & & Switzerrana & physician & 205 & $\begin{array}{l}\text { Clade 20A.EU2 with } \\
\text { non-synonymous mutation in the S } \\
\text { (S477N) }\end{array}$ & Mild & $\begin{array}{l}\text { Asthenia, shivering, rhinorrhea, } \\
\text { anosmia, arthralgia, headache, } \\
\text { exertional dyspnea for } 10 \text { days }\end{array}$ & $\begin{array}{l}\text { Positivity for anti-S1 } \\
\text { IgG and anti-N Ig }\end{array}$ \\
\hline
\end{tabular}


Table 2. Cont

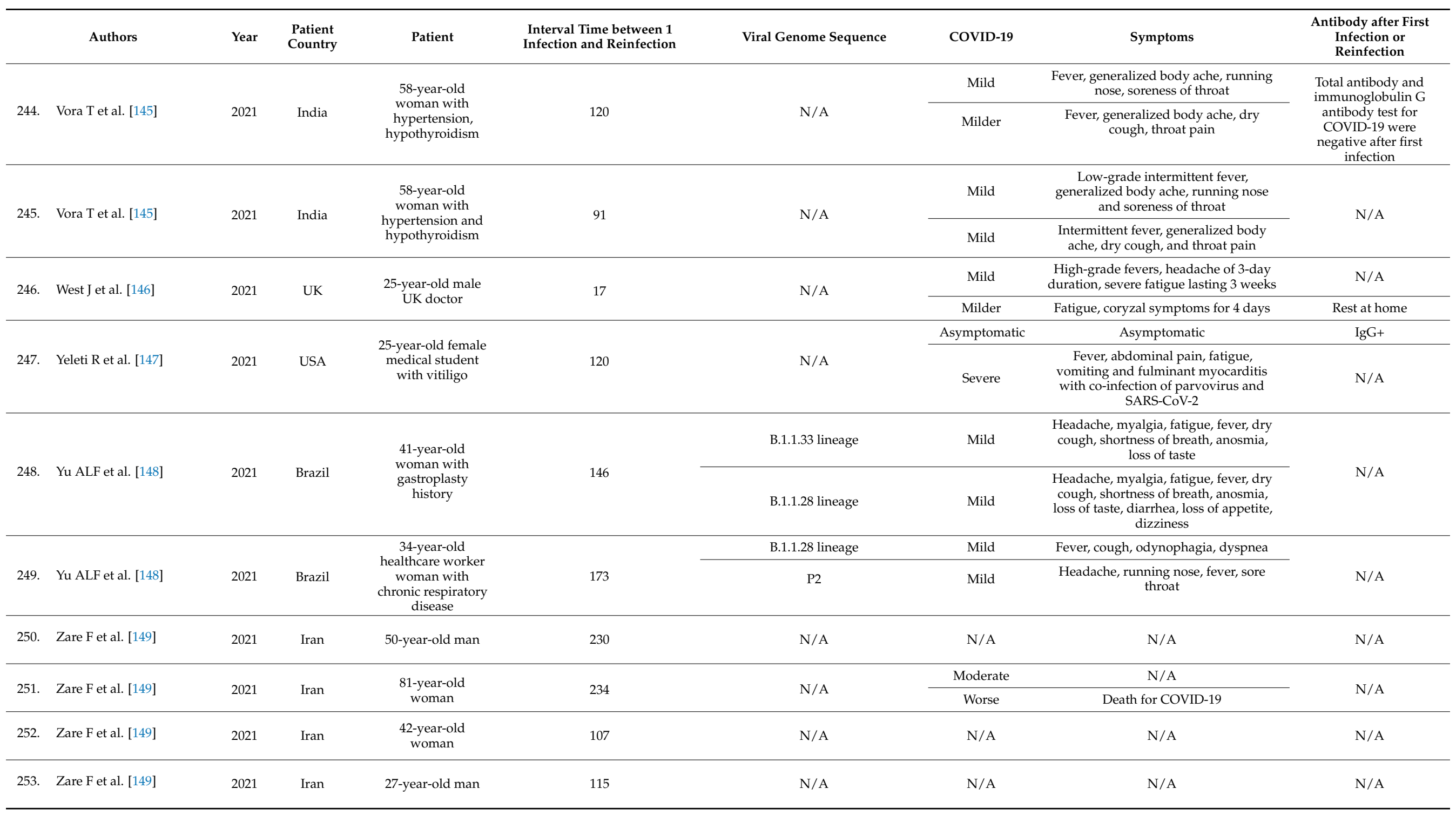


Table 2. Cont.

\begin{tabular}{|c|c|c|c|c|c|c|c|c|c|}
\hline & Authors & Year & $\begin{array}{l}\text { Patient } \\
\text { Country }\end{array}$ & Patient & $\begin{array}{l}\text { Interval Time between } 1 \\
\text { Infection and Reinfection }\end{array}$ & Viral Genome Sequence & COVID-19 & Symptoms & $\begin{array}{l}\text { Antibody after First } \\
\text { Infection or } \\
\text { Reinfection } \\
\end{array}$ \\
\hline \multirow{2}{*}{254.} & \multirow{2}{*}{ Zare F et al. [149] } & \multirow{2}{*}{2021} & \multirow{2}{*}{ Iran } & \multirow{2}{*}{ 79-year-old man } & \multirow{2}{*}{150} & \multirow{2}{*}{ N/A } & Moderate & $\mathrm{N} / \mathrm{A}$ & \multirow{2}{*}{ N/A } \\
\hline & & & & & & & Worse & Death for COVID-19 & \\
\hline \multirow{2}{*}{255.} & \multirow{2}{*}{ Zare F et al. [149] } & \multirow{2}{*}{2021} & \multirow{2}{*}{ Iran } & \multirow{2}{*}{ 86-year-old man } & \multirow{2}{*}{164} & \multirow{2}{*}{ N/A } & Moderate & $\mathrm{N} / \mathrm{A}$ & \multirow{2}{*}{$\mathrm{N} / \mathrm{A}$} \\
\hline & & & & & & & Worse & Death for COVID-19 & \\
\hline 256. & Zare F et al. [149] & 2021 & Iran & $\begin{array}{l}\text { 90-year-old } \\
\text { woman }\end{array}$ & 130 & N/A & $\mathrm{N} / \mathrm{A}$ & $\mathrm{N} / \mathrm{A}$ & N/A \\
\hline \multirow[t]{2}{*}{258.} & \multirow[t]{2}{*}{ Zhang K et al. [150] } & \multirow[t]{2}{*}{2020} & \multirow[t]{2}{*}{ China } & \multirow[t]{2}{*}{ 33-year-old female } & \multirow[t]{2}{*}{59} & \multirow[t]{2}{*}{ N/A } & $\begin{array}{l}\text { Moderate- } \\
\text { hospitalized } \\
\text { for } 16 \text { days }\end{array}$ & & Reduction of IgG+ to - \\
\hline & & & & & & & Moderate & & IgG+ \\
\hline \multirow[t]{2}{*}{259.} & \multirow[t]{2}{*}{ Zhang K et al. [150] } & \multirow[t]{2}{*}{2020} & \multirow[t]{2}{*}{ China } & \multirow[t]{2}{*}{ 33-year-old female } & \multirow[t]{2}{*}{86} & \multirow[t]{2}{*}{ N/A } & $\begin{array}{c}\text { Severe- } \\
\text { hospitalized } \\
\text { for } 38 \text { days }\end{array}$ & & $\begin{array}{l}\text { Reduction of IgG+ to } \\
\text { weak+ }\end{array}$ \\
\hline & & & & & & & Moderate & & IgM+ and IgG+ \\
\hline 260. & Zucman N et al. [151] & 2021 & South African & $\begin{array}{l}\text { 58-year-old male } \\
\text { with asthma }\end{array}$ & 120 & South African variant 501Y.V2 & $\begin{array}{l}\text { Severe with } \\
\text { intubation } \\
\text { and } \\
\text { mechanical } \\
\text { ventilation }\end{array}$ & $\begin{array}{l}\text { Dyspnea, fever, severe acute respiratory } \\
\text { distress syndrome }\end{array}$ & IgG+ \\
\hline
\end{tabular}

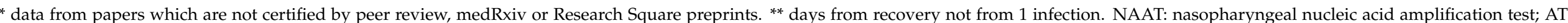
antibody test. 


\subsection{Demographic and Clinical Features of Reinfection Cases}

Reinfection occurred across the world: 1 case from Austria, 1 from Bahrain, 5 from Bangladesh, 2 from Belgium, 31 from Brazil, 3 from China including 1 from Hong Kong, 2 from Colombia, 28 from the Czech Republic, 1 from Denmark, 2 from Ecuador, 10 from France, 2 from Gambia, 1 from Germany, 24 from India, 31 from Iran, 12 from Iraq, 1 from Israel, 5 from Italy, 1 from Japan, 1 from Lebanon, 1 from Libya, 4 from Mexico, 5 from Pakistan, 1 from Panama, 1 from Peru, 1 from Portugal, 6 from Qatar, 1 from South Korea, 1 from Switzerland, 8 from Saudi Arabia, 1 from South Africa, 9 from Spain, 1 from the Netherlands, 4 from Turkey, 9 from the United Kingdom, 42 from the United States of America (Figure 2).

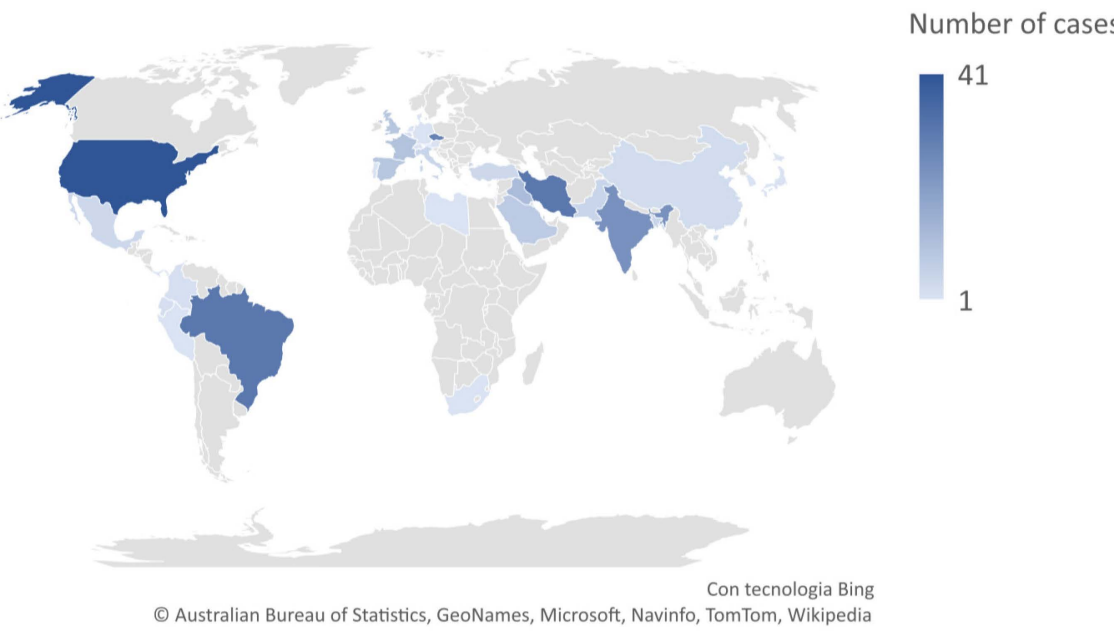

Figure 2. Distribution of cases worldwide.

Age was reported in 237 cases: 5/237 patients (2.1\%) were between 0 and 20 years old, 95/237 (40\%) between 21 and 40 years old, 83/237 (35\%) between 41 and 60, 42/237 (17\%) between 61 and 80, and 12/237 (5\%) > 80 years old (Figure 3 ).

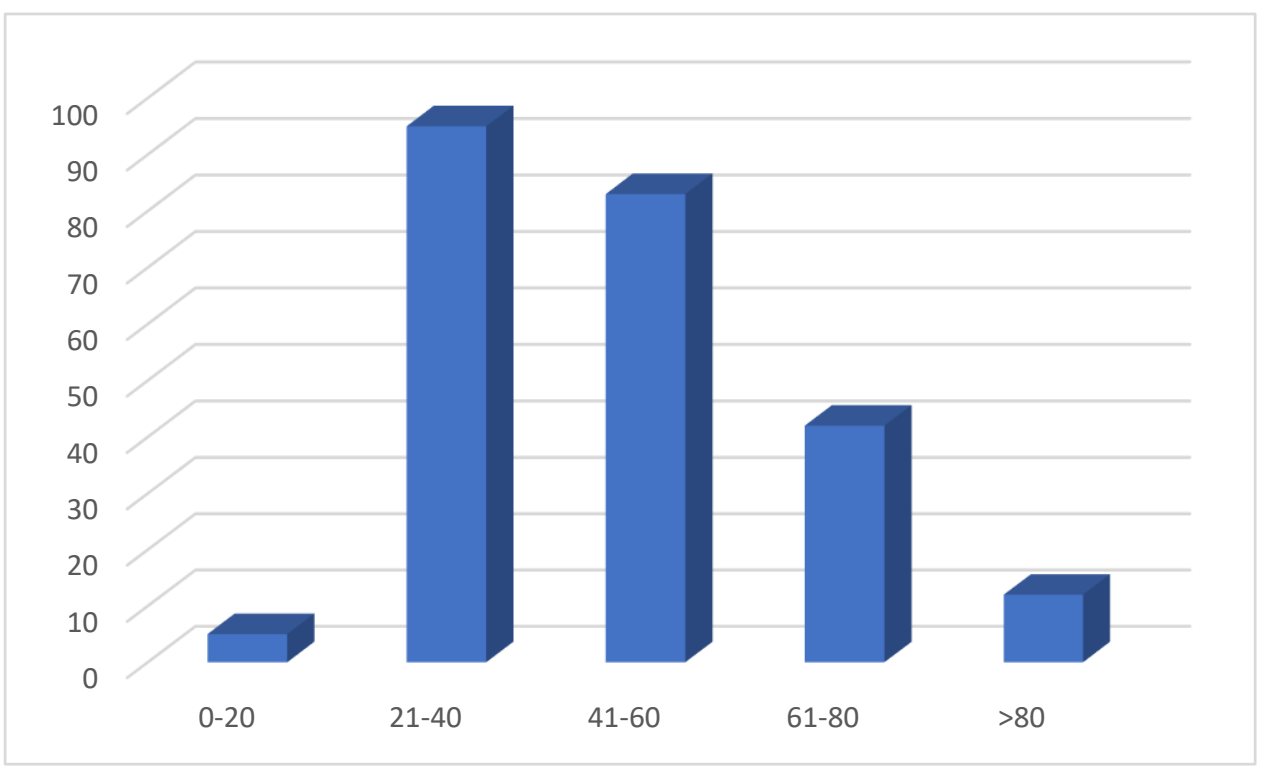

Figure 3. Distribution of cases according age.

Gender was reported in $251 / 260$ cases, among which $115 / 251$ patients ( $45.8 \%$ ) were female and 136/251 (54.2\%) were male (Figure 4). 


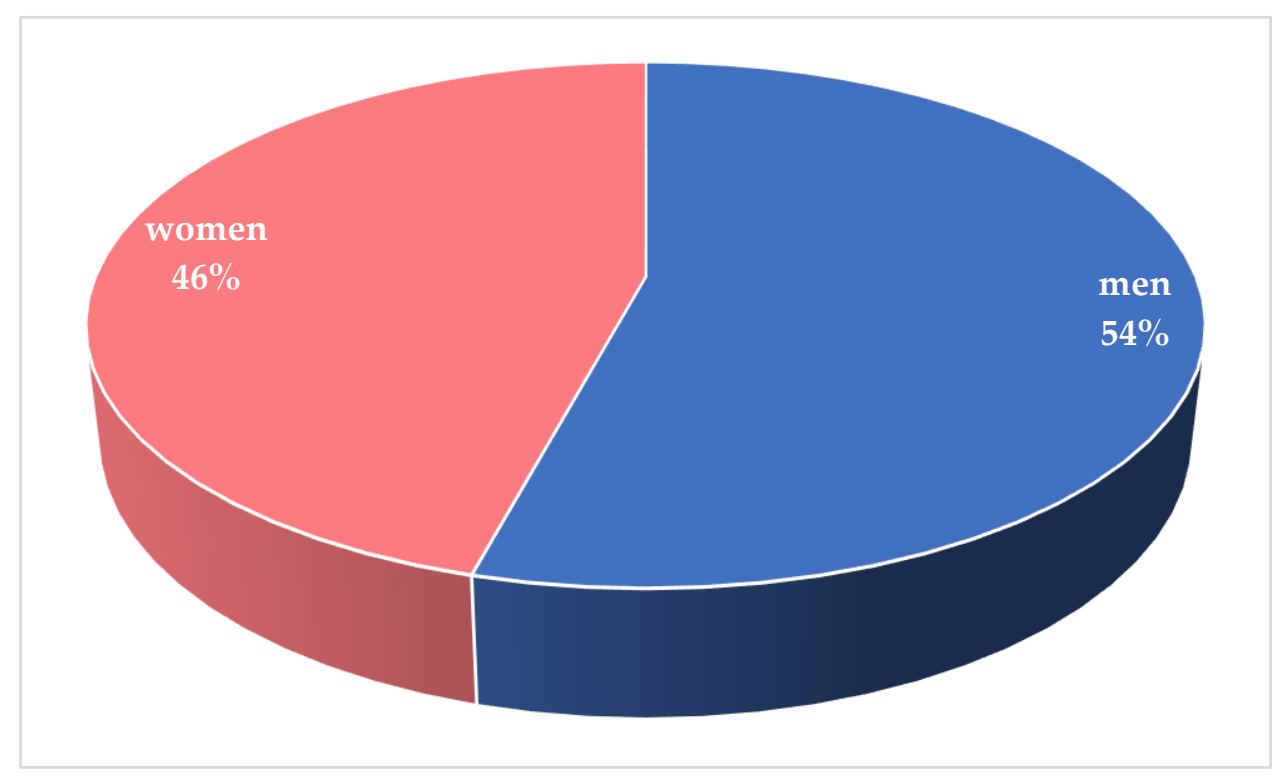

Figure 4. Distribution of cases according sex.

The main risk groups were healthcare workers and patients with comorbidities. In total, $66 / 260$ cases $(2.3 \%)$ occurred among high risk groups, including healthcare workers (HCWs), doctors, students and nursing resident. A total of 91 cases (35\%) occurred among patients with comorbidities, 48 in men and 38 in woman (Figure 5).

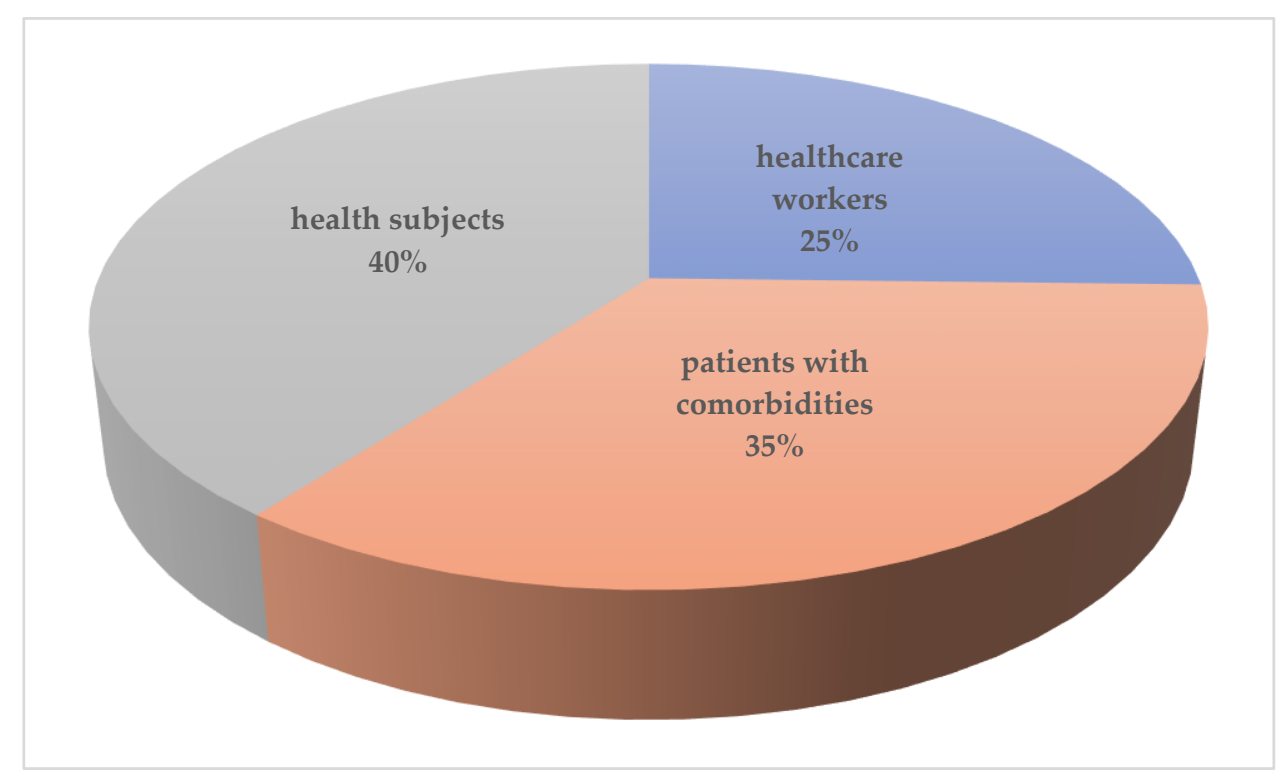

Figure 5. In total, $60 \%$ of reinfection involved patients in risk groups.

The evolution of the reinfection episode itself was more severe in $92 / 260(35.3 \%)$ cases with the death only in $14 / 260$ cases $(5.3 \%), 7 / 260$ male $(2.65 \%)$ and $7 / 260$ females $(2.65 \%)$; 8 of these had a neoplastic immune system diseases, or transplant or other important comorbidities and 3 were over 80 years old (Figure 6). 


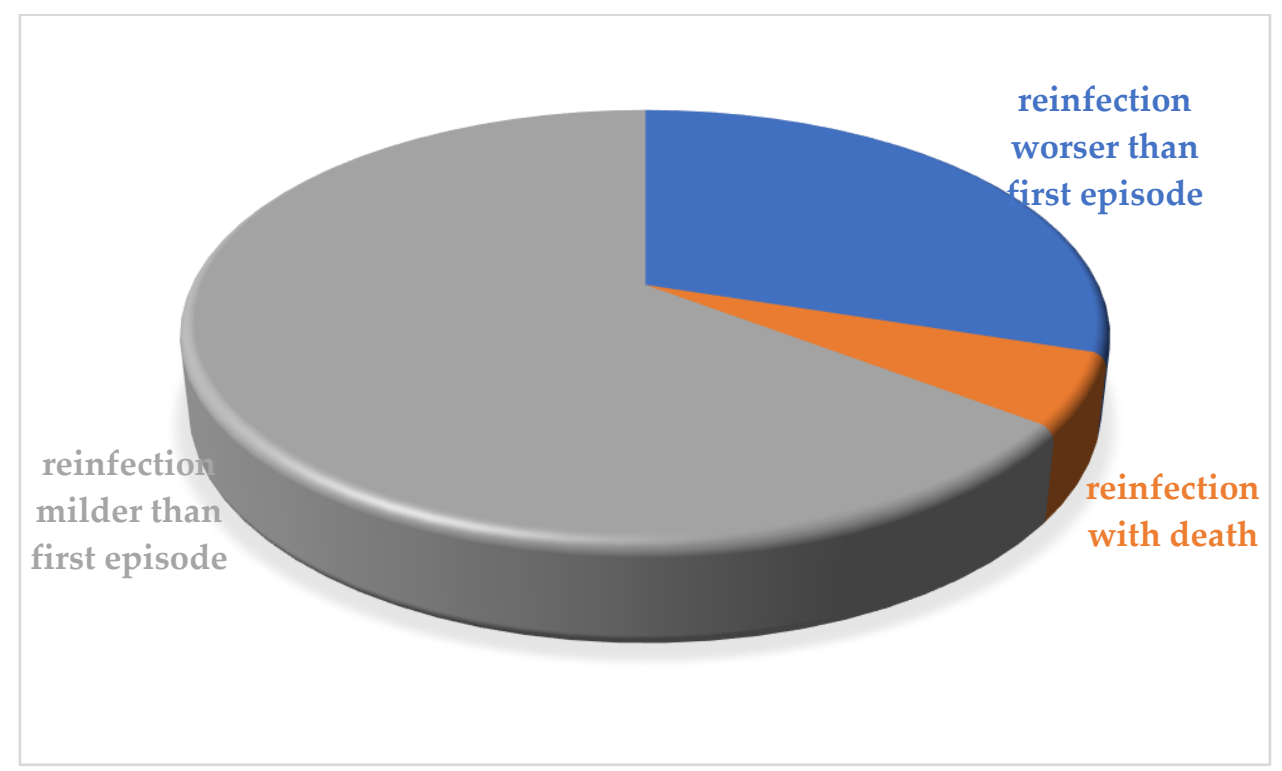

Figure 6. The evolution of the reinfection episode was more severe in $35.3 \%$ of cases.

Notably, reinfection occurred among patients whose initial infections were both asymptomatic/mild, 80\% (207/260), and moderate/severe, 20\% (53/260). The demonstration that moderate/severe initial infections do not necessarily provide enhanced protection against reinfection is important because patients with more severe infection have been found to have higher neutralizing antibody titers, which may be expected to confer protection. Additionally of note, the severity of the reinfection episode itself was less in 21/53 cases $(40 \%)$. The observation that many reinfection cases were less severe than initial cases is interesting because it may suggest partial protection from disease [152] and argues against antibody-dependent immune enhancement, which can be seen with other viral pathogens. In the absence of routine surveillance, we would have expected a bias toward detection of symptomatic reinfection, underscoring the importance of prospective screening.

Another interesting datapoint is the detection of different clades or lineages detected by genome sequencing between initial infection and reinfection in 52/260 cases (20\%). The current gold standard for identifying reinfection is detection of a distinct virus by genome sequencing. Detection of reinfection is most straightforward when viruses belong to a different clade or lineage, as this provides clear evidence of infection by a different virus [6]. Although reinfection is most apparent when viruses are different enough to distinguish by genome sequencing, it remains unclear whether these viral genomic differences play a causative role in reinfection. That is, does reinfection occur when viral genomic differences permit escape from an existing, but narrow, immune response to the initial infection? Answering this question will require detailed mapping of the relationship between virus substitutions and immune escape.

\subsection{Quality and Risk of Bias Assessment}

Briefly, only 14 studies fulfilled the quality checklist. "Selection-Does the patient(s) represent(s) the whole experience of the investigator (center) or is the selection method unclear to the extent that other patients with similar presentation may not have been reported?" checklist resulted unclear in most of the studies, because the patient selection method was unclear. In general, overall quality was satisfactory in all included studies.

\section{Discussion}

Since the first cases, a question has haunted all researchers: can a patient recovered from COVID-19 get sick again? The first confirmed case of reinfection occurred in a 33year-old Caucasian man of Hong Kong, that was admitted to the hospital for COVID-19 
on 23 March 2020 [5]. After two negative tests by RT-PCR on days 21 and 22 he was discharged from the hospital and resumed his usual work [5]. Serological controls after the first infection showed that he did not produce virus neutralizing antibodies [139]. On 15 August 2020 after a 1-week trip in Spain, the patient returned to Hong Kong and was submitted to a collection of a deep throat saliva sample for RT-PCR as border surveillance and resulted positive [5]. The patient was asymptomatic until the new negative test. The viruses from the first and the second infection were phylogenetically distinct and the virus of first infection had a truncation in the 58AA open reading frame 8 gene, that could be responsible immune evasion [138]. However T cells and mucosal immunity might have played an important role in resolving the second infection, even if there was the absence of primary neutralizing antibodies [139].

In October 2020, Tillett et al. reported the first confirmed case of SARS-CoV-2 reinfection in the USA [27]. A 25-year-old man from Nevada, without known immune disorders, had PCR-confirmed SARS-CoV-2 infection in April, 2020 (cycle threshold (Ct) value 35.24; specimen A) [27]. He recovered in quarantine, testing negative by RT-PCR at two consecutive timepoints thereafter [27]. However, 48 days after the initial test, the patient tested positive again by RT-PCR (Ct value 35.31; specimen B) [27]. Viral genome sequencing showed that both specimens A and B belonged to clade 20C, a predominant clade seen in northern Nevada [27]. The genome sequences of isolates from the first infection (specimen A) and reinfection (specimen B) differed significantly, making the chance of the virus being from the same infection very small [27]. The particularity of this report is that SARS-CoV-2 reinfection resulted in worse disease than the first infection, requiring oxygen support and hospitalization [27]. The patient had positive antibodies after the reinfection, but whether he had pre-existing antibody after the first infection is unknown [27]. Both cases reported from Nevada and Hong Kong seem to confirm the possibility that the reinfections are due to a different variant of SARS-CoV-2.

The first important question to be answered is: are all cases reported in the literature as reinfection by SARS-COV-2 true reinfections?

A distinction must be made between true reinfection, relapsed infection, recurrence of positive (re-positive) nucleic acid detection [17,153], in fact one of the features of SARS-CoV2 infection is prolonged virus shedding. Several studies reported persistent or recurrent elimination of viral RNA in nasopharyngeal samples starting from first contact with a positive subject [18-20]. Several explanations can exist in order to explain this phenomenon without it being a true reinfection. One possible explanation for testing positive after a previously negative result could be that the negative results after patient recovery were really false-negative results [154]. Literature reported that false-negative rates can be as high as 30\% for SARS-CoV-2 PCR testing [155]. However, actually the KCDC (Korean Control Disease Center) determined recovery as two separate negative PCR results within $24 \mathrm{~h}$ [156]. In this way, patients positive after having two consecutive negative results would be positive for an increase in viral genetic material due to reinfection [156]. It is difficult to have two previous consecutive false-negative results [156]. Another possible explanation could be the contamination of the samples, but most testing centers are requiring testers to change personal protective equipment (e.g., gloves, gowns and masks) [156]. However, surely one of the main points to consider is the basis of PCR testing: the test is able to amplify nucleic acid in the sample, not fully active viral particles. The genetic material (RNA and DNA) left behind degrades over time [157]. Thus, positive PCR results after recovery may not necessarily signify reinfection, but rather the presence of leftover genetic material from previously active infection [156]. Therefore, a patient who retests positive for virus might not necessarily be experiencing a second, new SARS-CoV-2 infection [158]. True reinfection has criteria that must be considered, including isolation of the complete genome of the virus (and not just genomic fragments) in the second episode, identification of two different virus strains in two episodes of infection based on phylogenetic analysis; proof of virus infectivity in the second episode by virus isolation and evaluation of its cytopathic effect in cell culture; investigation of immune responses and their comparison in two episodes; 
epidemiologic data such as re-exposure history to COVID-19 patient in the second event and timing between episodes, with a longer time interval between two episodes favoring the reinfection hypothesis $[17,159]$. To date, positive retesting more than 83 days after the first positive test, along with other criteria, favors confirmation of reinfection, even if Turner et al. recently reported a patient with prolonged viral RNA shedding lasting 87 days after the initial positive clinical PCR test and 97 days after the onset of symptoms, probably due to the poor CD8+ T cell response during the first three months of his illness [160]. In addition to the abovementioned reasons, the disease clinical data are also useful in confirming the second episode, although the second episode may be asymptomatic [17]. A time interval where the patient is free of clinical signs between the two episodes is also necessary. In conclusion, only cases with clinical symptoms and RT-PCR positivity after negative tests following recovery from COVID-19 could be considered true SARS-CoV-2 reinfections. Recently Raveendran et al. suggested an interesting approach in order to individuate the reasons for a persistent RT-PCR positivity (Figure 7) [161]. According to this flow chart it is possible to individuate cases of persistent RT-PCR positivity due to reinfection or to presence of dead viral fragment or to persistent viral shedding.

\section{$1^{\circ}$ episode of RT-PCR positivity}
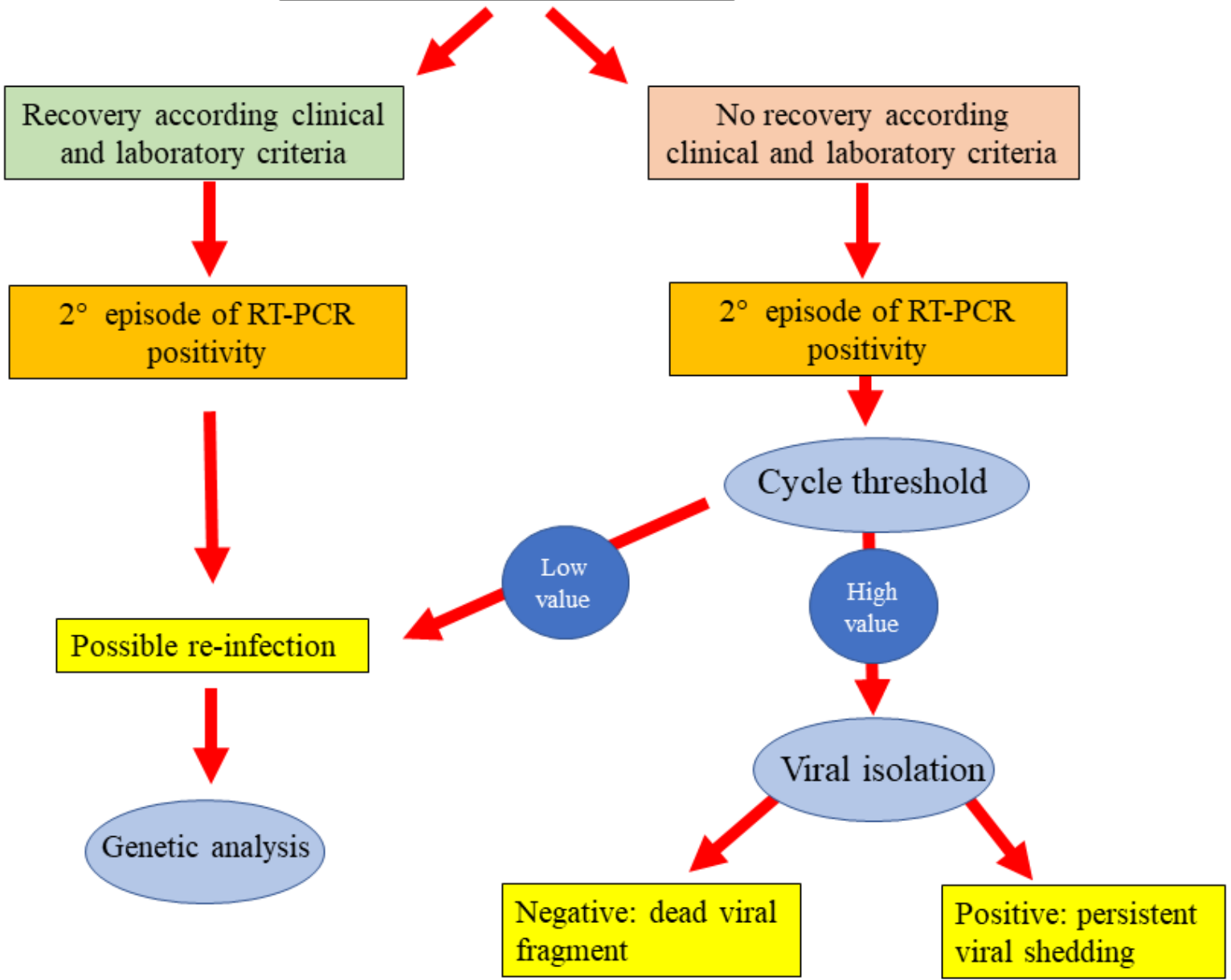

Figure 7. Flow diagram in order to determine the cause of persistent RT-PCR positivity for SARS-CoV-2, modified by Raveendran, A.V. et al. [161].

The second important question to be answered is: can SARS-CoV-2 re-infect a patient after recovery?

When any unwanted virus comes into contact with our body, also in the case of SARS-CoV-2 infection, most patients are able to develop specific antibodies neutralizing 
the spike proteins of this virus [5]. A recent study of Pilz et al. pointed out that the relatively low tentative reinfection rate (40 cases in 14,840 COVID-19 survivors of first wave- $-0.27 \%$ ) ensures a good protection after natural infection for SARS-CoV-2 [162]. However there are three main mechanisms for reinfection: the immune response can be ineffective, strain-specific, or short-lived [156].

Monoclonal antibodies formed against the SARS-CoV-2 virus target the Spike (S) glycoprotein component, the receptor-binding domain of the virion [156]. SARS-CoV-2, however, has been shown to develop "escape mutants," or alterations, in the epitope of the $S$ protein that contribute to host tropism and viral virulence [156]. Sui et al. reported that major variations exist in the S protein at positions 360, 479, and 487 [163]. They found that altering 1-2 amino acids at those positions led previously efficacious neutralizing antibodies to SARS-CoV-2 to a $20-50 \%$ reduction in binding capacity [163]. Theoretically, if SARS-CoV-2 is also able to form "escape mutants" in the S protein, IgG antibodies formed in patients may be less ineffective, though not completely, in neutralizing the virus [156]. This could mean that patients remain resistant to SARS-CoV-2 infection even after mutations, with antibody responses that are 50-80\% efficacious [156].

Another possibility that could allow the reinfection of a patient is the duration of the body immune response [156]. Recent findings suggested that protective immunity does not occur in all infected individuals [164], supporting the possibility of reinfection [103], even if $93 \%$ of the infected produce neutralizing antibodies [165]. Their function is to prevent the virus from entering cells between 6 and 20 days after infection [166] with this mechanism: after the infection, B lymphocytes are activated and produce IgM, IgG and IgA antibodies. A subset of them (IgG and IgA) then manage to make the new viral particles harmless. The neutralizing antibodies, in turn, are accompanied by the activation of killer cells ( $\mathrm{T}$ lymphocytes), specialized in recognizing and destroying the virus [167].

Seroconversion of IgM and IgG antibodies occurs the first week after onset of symptoms, seroconversion rates rise until the fourth week and decline thereafter, by the seventh week IgM antibodies are not detected in most cases, even if some reports showed IgM antibodies to persist for up to 8 months post-COVID-19 [168], whereas IgG antibodies persist longer for a period of time yet unknown [169]. Immunoglobulins alone are not truly sufficient to confer long-term immunity to coronavirus [156]. CD4+ T-cells and memory CD8+ T-cells with their products, such as effector cytokines and IFN- $\gamma$, are important in providing protection from coronavirus [170]. In fact, when the infection is over, in the following weeks or months, the antibodies drop: the virus is no longer there, they are no longer needed. However, the memory cells remain in the body, ready to intervene in case of need. All the studies so far show that a long-lasting immune response occurs. A very recent study carried out in collaboration between the Policlinico San Matteo in Pavia and the Karolinska Institute in Stockholm quantifies this "time" more precisely: memory cells persist for at least 6-8 months after infection [171]. Considering that the disease erupted just under a year ago, this is the maximum observation time possible to date, but it could be much longer [171]. Previous studies showed that virus-specific memory CD8+ T-cells were found to persist for up to 6 years after a SARS associated coronavirus infection, but memory B-cells and accompanying antibodies were undetectable at that time [172]. However Vetter et al. hypothesized that reinfection can be due to a loss of protection elicited after the first episode for a progressive reduction of protective antibody titers [144,173].

We can conclude that antibody formation and longevity of immunity in a subject could be dependent by the strain of virus, its severity and age of subject [174].

Khoshkam et al. tried to classify the recovered and immunized subjects in four categories:

(1) Infected cases with very mild symptoms or asymptomatic without any humoral immune response or elicited memory.

(2) Infected cases with mild to moderate symptoms with low humoral immunity and low cellular immunity. 
(3) Infected cases with moderate or severe symptoms with highly activated humoral immunity and elicited memory.

(4) Infected cases with moderate or severe symptoms with highly activated humoral immunity and low cellular immunity [175].

They hypothesized that reinfection may happen in groups 1 and 2, which may also develop the severe disease in the future due to the absence or low levels of acquired immunity [175]. Individuals in group 3 are more protective against further exposures and they may show long-term immunity since they develop increased elicited memory in defense of SARS-CoV-2 [175]. The last group may show rapid response against reinfection; they may not be safe for longer periods because of the non-imprinted memory of immunity [175].

The question to be solved is whether these antibodies can neutralize each SARS-CoV-2 clade and guarantee immunity to subsequent contact. Reinfection from SARS-CoV-2 with a genetically distinct strain of SARS-CoV-2 is, in theory, possible in patients immediately after recovery from COVID-19. SARS-CoV-2 infection may not confer immunity against a different SARS-CoV-2 strain, so more research is needed. SARS-CoV-2, even if it is a virus similar to that of the flu, seems to have a more stable genome and the response that the immune system generates is towards several fragments of the viral proteins and not just one. In fact, the mutations observed so far (and, perhaps, also the new English variant, at least until proven otherwise) are not associated with a change in the severity of the disease.

The new variants are accumulating mutations in different spike domains, such as the alpha variant or B.1.1.7 lineage (also known as 501Y.V1 or VOC202012/01), the beta variant or B.1.351 lineage (501Y.V2), the gamma variant or P.1 lineage (501Y.V3) and the delta variant or B.1.617.2 lineage [176]. All these variants have cumulated at least nine non-synonymous mutations/deletions throughout the Spike coding region. For example, the case reported by Harrington et al. showed that anti-SARS-CoV-2 antibodies were still present shortly before onset of reinfection, with no evidence of antibody waning [82]. This may raise some concerns about immune evasion by the alpha variant, which is a concern with the high number of spike region mutations seen. However, the study has a bias: there were no assays for SARS-CoV-2 antibodies recognizing spike antigen in the second reinfection, while the tested antibodies recognized " $\mathrm{N}$ " antigen, so it is difficult to point out an evident role of antibodies in the reinfection. The 501Y.V2 variant, or beta variant, is characterized by eight mutations in the spike protein-coding sequences that can improve its ability to transmission [151]. The case reported by Zucman et al. showed that beta variant can be more aggressive than non-VOC SARS-CoV-2 [151]. The last, the delta variant, is characterized by P681R and L452R mutations that can help the delta variant spread. For all these reasons it is necessary to investigate urgently the possibility of these new variants to escape the vaccine action. The immune responses generated by mRNA and adenoviral vector-based vaccines are restricted to the Spike glycoprotein, so new variants with big antigenic drift could reduce their efficiency and determine a growing number of reinfections.

Another possibility that could allow the reinfection of a patient is the reactivation of dormant virus which is commonly seen in immunosuppressed patients with some viruses, such as Epstein Barr, cytomegalovirus and herpes groups [90], but it is necessary to sequence viral genome for differential diagnosis between viral reactivation or reinfection with a different strain.

For all these reasons, it is important to identify cases of reinfection to understand if the "immunological memory" affects the symptoms during a second infection, a crucial fact, in particular, to predict the effectiveness of the vaccination campaign. If in the second time the symptoms are generally reduced, as in the Hong Kong [5], Belgium and the Netherlands [29] patients, this suggests that the immune system is responding as it should. However, if symptoms are consistently more severe during a second COVID-19 attack, as in the case of the Nevada [27] or Ecuador [28] subjects, it may be that the immune system makes matters worse. The mechanisms that could account for a more severe secondary infection can only be speculated. First, a very high dose of virus might have led to the 
second instance of infection and induced more severe disease [177]. Second, it is possible that reinfection was caused by a more virulent variant of the virus, or more virulent in this patient's context [27]. Third, a mechanism of antibody-dependent enhancement might be the cause, a means by which specific Fc-bearing immune cells become infected with virus by binding to specific antibodies [27]. In fact, the clinical course of some severe COVID-19 cases has been worsened by abnormal immune responses that damage healthy tissue. Patients who experienced that problem during a first infection may have immune cells that are induced to respond disproportionately the second time too. Sometimes antibodies produced in response to SARS-CoV-2 can facilitate the virus during a second infection rather than fight it [178-184]. The phenomenon [185-189] is rare, but researchers have found worrying signs of it while trying to develop vaccines against the coronaviruses responsible for severe acute respiratory syndrome and Middle East respiratory syndrome [190] and against SARS-CoV-2 [191-194].

As researchers accumulate more examples of reinfection, the situation should become clearer. Depending on the criteria used, rates of reinfection can vary widely [195]. There are some reports about retrospective observational study such as that of Pilz et al. that reported 40 cases of tentative reinfection in Austria, but these data are limited by the lack of detailed clinical characteristics [162]. For this reason, in November 2020 the Centers for Disease Control and Prevention pointed out the following criteria to define reinfection with SARS-CoV-2: detection of SARS-CoV-2 RNA (with Ct values $<33$ if detected by RT-PCR) $>90$ days after the first detection of viral RNA whether or not symptoms were present and paired respiratory specimens from each episode that belong to different clades of virus or have genomes with $>2$ nucleotide differences per month [32]. Cases in which detection of SARS-CoV-2 RNA is present $>45$ days to 89 days apart are considered reinfections if the second symptomatic episode had no obvious alternate explanation for the COVID-19-like symptoms or there was close contact with a person known to have laboratory diagnosed COVID-19 and paired specimens are available with the Ct values and sequence diversity noted above.

However, the ability to re-infect does not mean that a SARS-CoV-2 vaccine cannot be effective. Some vaccines, for example, require a "booster" dose to maintain protection. Learning more about reinfection could help researchers in developing truly effective vaccines by showing them which immune responses are important for maintaining immunity. For example, researchers may find that people become vulnerable to reinfection after antibodies drop below a certain level, and so they can modify vaccination strategies accordingly using a booster dose to maintain that level of antibodies. At a time when health authorities are grappling with the dizzying logistical difficulties of vaccinating the world population against SARS-CoV-2, the need for a booster injection is a necessity that complicates the management of the vaccination campaign, but it does not make long-term immunity from SARS-CoV-2 impossible. However, some researchers fear that vaccines will only reduce symptoms during a second infection, rather than prevent it altogether. While giving some advantages, this possibility could turn vaccinated individuals into asymptomatic carriers of SARS-CoV-2, putting vulnerable populations at risk. The elderly, for example, are among the most affected by COVID-19, but they tend not to respond well to vaccines. For all these reasons, it would be interesting to see data on how much virus SARS-CoV-2 reinfected individuals spread.

The real problem to be solved is, therefore, the duration of immunity conferred by a COVID-19 episode. There is evidence in the literature that the COVID-19 immune response is variable and patient-specific with respect to the development of antibodies and to antibody persistence in serum over time [146]. In considering the protective effect of antibodies against a reinfection, the evidence is still inadequate, and more research is necessary in order to clarify the interplay between the roles of adaptive and innate immunity. A recent study of Gudbjartsson et al. reported that Icelandic humoral response to SARS-CoV-2 infection was persistent within the 120-day timeframe used with a modest decline in antibody titers after 120 days [196]. Iyer et al. observed declining antibody 
titers over 90 days, with "median times to sero-reversion of 71 and 49 days following symptom onset" [197].

The genetic analysis of all the new cases reported as reinfection would help in understanding if the reinfection would be due to a new infection by a different SARS-CoV-2 or a reinfection by the same virus for a decline of immune response, but unfortunately genomic analysis is not available for some of these cases.

\section{Conclusions}

All these findings are useful and contribute towards the role of vaccination in response to the COVID-19 infections. Collected data show a wide range of situations: spanning a broad distribution of ages, risk groups, baseline health status and reinfection severity compared to the initial infection. Reinfection occurred as early as 45 days or $>300$ days after the initial infection. Common explanations for reinfection can be either waning SARS-CoV-2 antibodies or the presence of viral escape mutations [198]. While several cases of SARS-CoV2 reinfection did involve infection with a different clade, it is noteworthy that mutations were identified throughout the genomes and the frequency of mutations within the $S$ gene was not elevated relative to the rest of the genome [199]. In addition, individuals with more severe reinfections did not have significantly greater frequency of S gene mutations [199]. Finally, the presence of rare mutations was uncommon in the re-infecting virus, which largely mirrored the contemporaneously circulating variants in the region of infection, as reported by Choudhary et al. [199]. Concerning the problem of recognizing reinfection and persistent infection, two factors generally differentiated them. First, reinfections have so far been largely described in immunocompetent individuals while the majority of persistent COVID cases have been in immunosuppressed patients [199]. Secondly, phylogenetic analysis can generally differentiate between reinfection and persistent infection, especially in cases where persistent infection allowed the longitudinal collection of $>2$ sequences [199]. Due to the reinfection cases with SARS-CoV-2, it is evident that the level of immunity is not $100 \%$ for all individuals. Reinfection with SARS-CoV-2 is a possibility in both vaccinated and unvaccinated individuals, because vaccines to the virus may not translate to total immunity [199]. Recently breakthrough infections were reported following mRNA vaccination in healthy subjects [200,201], despite evidence of effective immune response among the breakthrough subjects [202]. Another study reported that eight symptomatic SARS-CoV-2 infections occurred in fully vaccinated healthcare workers (incidence rate 4.7 per 100,000 person-days adjusted) [203]. This type of challenge was also observed during the process of vaccine preparation for influenza [204]. Even though several vaccines are ready, the presence of more than 80 genotypical variants of the virus, possibility of reinfection, and short duration of seropositivity for neutralizing antibodies raise the concern that vaccination may not result in an effective and long-term immunity against SARS-CoV2. Furthermore, immunoglobulin levels may not correlate with viral shedding and risk of transmissibility of SARS-CoV-2 [205]. Additionally, the short duration of immunity against the virus may not allow for increasing homogeneity of affected populations in a nonspecific time frame. These factors raise concerns that eliminating the COVID-19 pandemic may not be as feasible as once assumed and that we must rely more on prevention of transmission until more aspects of the virus and its pathogenicity are discovered. A recent study suggested that among persons with previous SARS-CoV-2 infection, full vaccination provides additional protection against reinfection [206]. In fact, among previously infected Kentucky residents, those who were not vaccinated were more than twice as likely to be reinfected compared with those with full vaccination [206]. Data from literature are comforting: out of hundreds of millions of people infected with the virus and then cured, only a few are reported cases of confirmed reinfection [199]. Despite the appearance of different variants of the virus, vaccines seem to help us for the near future. However, the presence of immunosuppressed or transplanted subjects requires us to continue to observe the precautionary rules useful to prevent the spread of the virus. In fact, it is imperative that all individuals, whether previously diagnosed with COVID-19 or not should take identical 
precautions to avoid reinfection with SARS-CoV-2 till the time when community immunity had been achieved [207]. All eligible persons should be offered vaccination, including those with previous SARS-CoV-2 infection, to reduce their risk for future infection [206].

This report highlights how it is necessary to continue to observe all the prescriptions recently indicated in the literature [208-210] in order to avoid new contagion for all patients after healed from COVID-19 or asymptomatic positive, since the infection does not ensure complete immunity in $100 \%$ of cases.

Author Contributions: Conceptualization, L.L.M.; methodology, L.L.M.; validation, E.L.M. and M.A.; formal analysis, M.A.; investigation, M.F.A.Q.; resources, L.L.M.; data curation, L.L.M.; writingoriginal draft preparation, L.L.M., M.A., E.L.M.; writing-review and editing, M.F.A.Q.; visualization, M.A.; supervision, L.L.M. All authors have read and agreed to the published version of the manuscript.

Funding: This research received no external funding.

Institutional Review Board Statement: Not applicable.

Informed Consent Statement: Not applicable.

Conflicts of Interest: The authors declare no conflict of interest.

\section{References}

1. Zhu, N.; Zhang, D.; Wang, W.; Li, X.; Yang, B.; Song, J.; Zhao, X.; Huang, B.; Shi, W.; Lu, R.; et al. A Novel Coronavirus from Patients with Pneumonia in China, 2019. N. Engl. J. Med. 2020, 382, 727-733. [CrossRef]

2. Wang, C.; Horby, P.W.; Hayden, F.G.; Gao, G.F. A novel coronavirus outbreak of global health concern. Lancet 2020, 395, 470-473. [CrossRef]

3. World Health Organization. Rolling Updates on Corona Virus Disease (COVID-19). Health Emergencies. 2020. Available online: https:/ / www.who.int/emergencies/diseases/novel-coronavirus-2019/events-as-they-happen (accessed on 1 October 2021).

4. John Hopkins University. COVID-19 Dashboard by the Center for Systems Science and Engineering (CSSE) at Johns Hopkins University (JHU). Available online: https:/ / coronavirus.jhu.edu/map.html (accessed on 17 October 2021).

5. To, K.K.; Hung, I.F.; Ip, J.D.; Chu, A.W.; Chan, W.M.; Tam, A.R.; Fong, C.H.; Yuan, S.; Tsoi, H.W.; Ng, A.C.; et al. COVID-19 re-infection by a phylogenetically distinct SARS-coronavirus-2 strain confirmed by whole genome sequencing. Clin. Infect. Dis. 2020, ciaa1275. [CrossRef]

6. Babiker, A.; Marvil, C.E.; Waggoner, J.J.; Collins, M.H.; Piantadosi, A. The Importance and Challenges of Identifying SARS-CoV-2 Reinfections. J. Clin. Microbiol. 2021, 59, e02769-20. [CrossRef]

7. Edridge, A.W.D.; Kaczorowska, J.; Hoste, A.C.R.; Bakker, M.; Klein, M.; Loens, K.; Jebbink, M.F.; Matser, A.; Kinsella, C.M.; Rueda, P.; et al. Seasonal coronavirus protective immunity is short-lasting. Nat. Med. 2020, 26, 1691-1693. [CrossRef] [PubMed]

8. Kiyuka, P.K.; Agoti, C.N.; Munywoki, P.K.; Njeru, R.; Bett, A.; Otieno, J.R.; Otieno, G.P.; Kamau, E.; Clark, T.G.; van der Hoek, L.; et al. Human Coronavirus NL63 Molecular Epidemiology and Evolutionary Patterns in Rural Coastal Kenya. J. Infect. Dis. 2018, 217, 1728-1739. [CrossRef] [PubMed]

9. Glezen, W.P.; Taber, L.H.; Frank, A.L.; Kasel, J.A. Risk of primary infection and reinfection with respiratory syncytial virus. Am. J. Dis. Child. 1986, 140, 543-546. [CrossRef] [PubMed]

10. Perera, R.A.; Mok, C.K.; Tsang, O.T.; Lv, H.; Ko, R.L.; Wu, N.C.; Yuan, M.; Leung, W.S.; Chan, J.M.; Chik, T.S.; et al. Serological assays for severe acute respiratory syndrome coronavirus 2 (SARS-CoV-2), March 2020. Eurosurveill 2020, 25, 2000421. [CrossRef] [PubMed]

11. Hachim, A.; Kavian, N.; Cohen, C.A.; Chin, A.W.H.; Chu, D.K.W.; Mok, C.K.P.; Tsang, O.T.Y.; Yeung, Y.C.; Perera, R.; Poon, L.L.M.; et al. ORF8 and ORF3b antibodies are accurate serological markers of early and late SARS-CoV-2 infection. Nat. Immunol. 2020, 21, 1293-1301. [CrossRef]

12. Addetia, A.; Crawford, K.H.D.; Dingens, A.; Zhu, H.; Roychoudhury, P.; Huang, M.L.; Jerome, K.R.; Bloom, J.D.; Greninger, A.L. Neutralizing Antibodies Correlate with Protection from SARS-CoV-2 in Humans during a Fishery Vessel Outbreak with a High Attack Rate. J. Clin. Microbiol. 2020, 58, e02107-20. [CrossRef]

13. Sharma, R.; Sardar, S.; Mohammad Arshad, A.; Ata, F.; Zara, S.; Munir, W. A Patient with Asymptomatic SARS-CoV-2 Infection Who Presented 86 Days Later with COVID-19 Pneumonia Possibly Due to Reinfection with SARS-CoV-2. Am. J. Case Rep. 2020, 21, e927154. [CrossRef]

14. Azkur, A.K.; Akdis, M.; Azkur, D.; Sokolowska, M.; van de Veen, W.; Bruggen, M.C.; O’Mahony, L.; Gao, Y.; Nadeau, K.; Akdis, C.A. Immune response to SARS-CoV-2 and mechanisms of immunopathological changes in COVID-19. Allergy 2020, 75, 1564-1581. [CrossRef]

15. Long, Q.X.; Tang, X.J.; Shi, Q.L.; Li, Q.; Deng, H.J.; Yuan, J.; Hu, J.L.; Xu, W.; Zhang, Y.; Lv, F.J.; et al. Clinical and immunological assessment of asymptomatic SARS-CoV-2 infections. Nat. Med. 2020, 26, 1200-1204. [CrossRef] 
16. Amikishiyev, S.; Demir, E.; Aghamuradov, S.; Garayeva, N.; Artan, A.S.; Gul, A.; Turkmen, A. Reinfection with SARS-CoV-2 in a kidney transplant recipient. Transpl. Infect. Dis. 2021, 23, e13695. [CrossRef]

17. Falahi, S.; Kenarkoohi, A. COVID-19 reinfection: Prolonged shedding or true reinfection? New Microbes New Infect. 2020, 38 , 100812. [CrossRef] [PubMed]

18. Xiao, A.T.; Tong, Y.X.; Gao, C.; Zhu, L.; Zhang, Y.J.; Zhang, S. Dynamic profile of RT-PCR findings from 301 COVID-19 patients in Wuhan, China: A descriptive study. J. Clin. Virol. 2020, 127, 104346. [CrossRef] [PubMed]

19. Lan, L.; Xu, D.; Ye, G.; Xia, C.; Wang, S.; Li, Y.; Xu, H. Positive RT-PCR Test Results in Patients Recovered From COVID-19. JAMA 2020, 323, 1502-1503. [CrossRef] [PubMed]

20. Gombar, S.; Chang, M.; Hogan, C.A.; Zehnder, J.; Boyd, S.; Pinsky, B.A.; Shah, N.H. Persistent detection of SARS-CoV-2 RNA in patients and healthcare workers with COVID-19. J. Clin. Virol. 2020, 129, 104477. [CrossRef]

21. Centers for Disease Control and Prevention. Common Investigation Protocol for Investigating Suspected SARS-CoV-2 Reinfection. Available online: https:/ / www.cdc.gov/ coronavirus/2019-ncov/php/reinfection.html (accessed on 30 December 2020).

22. Qureshi, A.I.; Baskett, W.I.; Huang, W.; Lobanova, I.; Naqvi, S.H.; Shyu, C.R. Re-infection with SARS-CoV-2 in Patients Undergoing Serial Laboratory Testing. Clin. Infect. Dis. 2021. [CrossRef]

23. Leidi, A.; Koegler, F.; Dumont, R.; Dubos, R.; Zaballa, M.E.; Piumatti, G.; Coen, M.; Berner, A.; Darbellay Farhoumand, P.; Vetter, P.; et al. Risk of reinfection after seroconversion to SARS-CoV-2: A population-based propensity-score matched cohort study. Clin. Infect. Dis. 2021. [CrossRef]

24. Breathnach, A.S.; Riley, P.A.; Cotter, M.P.; Houston, A.C.; Habibi, M.S.; Planche, T.D. Prior COVID-19 significantly reduces the risk of subsequent infection, but reinfections are seen after eight months. J. Infect. 2021, 82, e11-e12. [CrossRef] [PubMed]

25. Bongiovanni, M.; Marra, A.M.; Bini, F.; Bodini, B.D.; Carlo, D.D.; Giuliani, G. COVID-19 reinfection in healthcare workers: A case series. J. Infect. 2021, 82, e4-e5. [CrossRef]

26. Vitale, J.; Mumoli, N.; Clerici, P.; De Paschale, M.; Evangelista, I.; Cei, M.; Mazzone, A. Assessment of SARS-CoV-2 Reinfection 1 Year After Primary Infection in a Population in Lombardy, Italy. JAMA Intern. Med. 2021, 181, 1407-1408. [CrossRef]

27. Tillett, R.L.; Sevinsky, J.R.; Hartley, P.D.; Kerwin, H.; Crawford, N.; Gorzalski, A.; Laverdure, C.; Verma, S.C.; Rossetto, C.C.; Jackson, D.; et al. Genomic evidence for reinfection with SARS-CoV-2: A case study. Lancet Infect. Dis. 2021, 21, 52-58. [CrossRef]

28. Prado-Vivar, B.; Becerra-Wong, M.; Guadalupe, J.J.; Marquez, S.; Gutierrez, B.; Rojas-Silva, P.; Grunauer, M.; Trueba, G.; Barragan, V.; Cardenas, P. A case of SARS-CoV-2 reinfection in Ecuador. Lancet Infect. Dis. 2021, 21, e142. [CrossRef]

29. Van Elslande, J.; Vermeersch, P.; Vandervoort, K.; Wawina-Bokalanga, T.; Vanmechelen, B.; Wollants, E.; Laenen, L.; Andre, E.; Van Ranst, M.; Lagrou, K.; et al. Symptomatic Severe Acute Respiratory Syndrome Coronavirus 2 (SARS-CoV-2) Reinfection by a Phylogenetically Distinct Strain. Clin. Infect. Dis. 2021, 73, 354-356. [CrossRef]

30. Goldman, J.D.; Wang, K.; Roltgen, K.; Nielsen, S.C.A.; Roach, J.C.; Naccache, S.N.; Yang, F.; Wirz, O.F.; Yost, K.E.; Lee, J.Y.; et al. Reinfection with SARS-CoV-2 and Failure of Humoral Immunity: A case report. medRxiv 2020. [CrossRef]

31. Klein, J.; Brito, A.F.; Trubin, P.; Lu, P.; Wong, P.; Alpert, T.; Pena-Hernandez, M.A.; Haynes, W.; Kamath, K.; Liu, F.; et al. Case Study: Longitudinal immune profiling of a SARS-CoV-2 reinfection in a solid organ transplant recipient. medRxiv 2021. [CrossRef]

32. Centers for Disease Control and Prevention. Investigative Criteria for Suspected Cases of SARS-CoV-2 Reinfection (ICR). Available online: https: / / www.cdc.gov/ coronavirus/2019-ncov/php/invest-criteria.html (accessed on 2 July 2021).

33. Murad, M.H.; Sultan, S.; Haffar, S.; Bazerbachi, F. Methodological quality and synthesis of case series and case reports. BMJ Evid. Based Med. 2018, 23, 60-63. [CrossRef]

34. World Health Organization. Clinical Management of Severe Acute Respiratory Infection When COVID-19 Is Suspected: Interim Guidance. 13 March 2020. Available online: https:/ / www.who.int/docs/default-source/coronaviruse/clinical-management-ofnovel-cov.pdf?sfvrsn=bc7da517_2 (accessed on 26 May 2020).

35. Abu-Raddad, L.J.; Chemaitelly, H.; Malek, J.A.; Ahmed, A.A.; Mohamoud, Y.A.; Younuskunju, S.; Ayoub, H.H.; Al Kanaani, Z.; $\mathrm{Al}$ Khal, A.; Al Kuwari, E.; et al. Assessment of the risk of SARS-CoV-2 reinfection in an intense re-exposure setting. Clin. Infect. Dis. 2020, 73, e1830-e1840. [CrossRef] [PubMed]

36. Adrielle Dos Santos, L.; Filho, P.G.G.; Silva, A.M.F.; Santos, J.V.G.; Santos, D.S.; Aquino, M.M.; de Jesus, R.M.; Almeida, M.L.D.; da Silva, J.S.; Altmann, D.M.; et al. Recurrent COVID-19 including evidence of reinfection and enhanced severity in thirty Brazilian healthcare workers. J. Infect. 2021, 82, 399-406. [CrossRef]

37. Aguilar-Shea, A.L.; Gutierrez-Martin-Arroyo, J.; Vacas-Cordoba, M.; Gallardo-Mayo, C. Reinfection by SARS-CoV-2: The first one in a family reported in Spain. Med. Clin. 2021. [CrossRef]

38. Ahmadian, S.; Fathizadeh, H.; Shabestari Khiabani, S.; Asgharzadeh, M.; Kafil, H.S. COVID-19 reinfection in a healthcare worker after exposure with high dose of virus: A case report. Clin. Case Rep. 2021, 9, e04257. [CrossRef]

39. Ahmed, A.; Sana, F.; Ikram, A.; Yousaf, S.; Khan, A. Reinfection or relapse of COVID-19 in health care workers; case series of 2 patients from Pakistan. New Microbes New Infect. 2021, 42, 100896. [CrossRef]

40. Ak, R.; Yilmaz, E.; Seyhan, A.U.; Doganay, F. Recurrence of COVID-19 Documented with RT-PCR. J. Coll. Physicians Surg. Pak. 2021, 30, S26-S28. [CrossRef]

41. Aldossary, B.; Hassan, A.; Moussa, M.; Alsaif, H.S.; Alfaraj, D. Fulminant hepatic failure in a patient testing re-positive for SARS-CoV-2: A case report. Int. J. Emerg. Med. 2021, 14, 24. [CrossRef]

42. Ali, A.M.; Ali, K.M.; Fatah, M.H.; Tawfeeq, H.M.; Rostam, H.M. SARS-CoV-2 Reinfection in Patients Negative for Immunoglobulin G Following Recovery from COVID-19. New Microbes New Infect. 2021, 43, 100926. [CrossRef] [PubMed] 
43. AlFehaidi, A.; Ahmad, S.A.; Hamed, E. SARS-CoV-2 re-infection: A case report from Qatar. J. Infect. 2021, 82, 414-451. [CrossRef]

44. Alshukairi, A.N.; El-Kafrawy, S.A.; Dada, A.; Yasir, M.; Yamani, A.H.; Saeedi, M.F.; Aljohaney, A.; AlJohani, N.I.; Bahaudden, H.A.; Alam, I.; et al. Re-infection with different SARS-CoV-2 clade and prolonged viral shedding in a patient with hematopoietic stem cell transplantation: SARS-CoV-2 Re-infection with different clade. Int. J. Infect. Dis. 2021, 110, 267-271. [CrossRef] [PubMed]

45. Amorim, M.R.; Souza, W.M.; Barros, A.C.G., Jr.; Toledo-Teixeira, D.A.; Dos-Santos, K.B.; Simeoni, C.L.; Parise, P.L.; Vieira, A.; Forato, J.; Claro, I.M.; et al. Respiratory Viral Shedding in Healthcare Workers Reinfected with SARS-CoV-2, Brazil, 2020. Emerg. Infect. Dis. 2021, 27, 1737-1740. [CrossRef]

46. Arteaga-Livias, K.; Panduro-Correa, V.; Pinzas-Acosta, K.; Perez-Abad, L.; Pecho-Silva, S.; Espinoza-Sanchez, F.; Damaso-Mata, B.; Rodriguez-Morales, A.J. COVID-19 reinfection? A suspected case in a Peruvian patient. Travel Med. Infect. Dis. 2021, $39,101947$. [CrossRef]

47. Atici, S.; Ek, O.F.; Yildiz, M.S.; Sikgenc, M.M.; Guzel, E.; Soysal, A. Symptomatic recurrence of SARS-CoV-2 infection in healthcare workers recovered from COVID-19. J. Infect. Dev. Ctries. 2021, 15, 69-72. [CrossRef]

48. Awada, H.; Nassereldine, H.; Hajj Ali, A. Severe acute respiratory syndrome coronavirus 2 reinfection in a coronavirus disease 2019 recovered young adult: A case report. J. Med. Case Rep. 2021, 15, 382. [CrossRef]

49. Bader, N.; Khattab, M.; Farah, F. Severe reinfection with severe acute respiratory syndrome coronavirus 2 in a nursing home resident: A case report. J. Med. Case Rep. 2021, 15, 392. [CrossRef]

50. Baiswar, S.; Mittal, R.; Tiwary, T.; Jinnur, P. Re-Positive SARS-CoV-2 With Respiratory Failure and Cerebrovascular Accident: Is This a Reinfection? Cureus 2021, 13, e15825. [CrossRef]

51. Bellesso, M.; Bruniera, F.R.; Trunkel, A.T.; Nicodemo, I.P. Second COVID-19 infection in a patient with multiple myeloma in Brazil-Reinfection or reactivation? Hematol. Transfus. Cell Ther. 2021, 43, 109-111. [CrossRef]

52. Bongiovanni, M. COVID-19 re-infection in an healthcare worker. J. Med. Virol. 2020, 93, 4058-4059. [CrossRef]

53. Bonifacio, L.P.; Pereira, A.P.S.; Araujo, D.; Balbao, V.; Fonseca, B.; Passos, A.D.C.; Bellissimo-Rodrigues, F. Are SARS-CoV-2 reinfection and Covid-19 recurrence possible? a case report from Brazil. Rev. Soc. Bras. Med. Trop. 2020, 53, e20200619. [CrossRef] [PubMed]

54. Borgogna, C.; De Andrea, M.; Griffante, G.; Lai, A.; Bergna, A.; Galli, M.; Zehender, G.; Castello, L.; Ravanini, P.; Cattrini, C.; et al. SARS-CoV-2 reinfection in a cancer patient with a defective neutralizing humoral response. J. Med. Virol. 2021, 93, 6444-6446. [CrossRef]

55. Brehm, T.T.; Pfefferle, S.; von Possel, R.; Kobbe, R.; Norz, D.; Schmiedel, S.; Grundhoff, A.; Olearo, F.; Emmerich, P.; Robitaille, A.; et al. SARS-CoV-2 Reinfection in a Healthcare Worker Despite the Presence of Detectable Neutralizing Antibodies. Viruses 2021, 13, 661. [CrossRef] [PubMed]

56. Buddingh, E.P.; Vossen, A.; Lamb, H.J.; van der Palen, R.L.F.; Brinkman, D.M.C. Reinfection With Severe Acute Respiratory Syndrome Coronavirus 2 Without Recurrence of Multisystem Inflammatory Syndrome in Children. Pediatr. Infect. Dis. J. 2021. [CrossRef] [PubMed]

57. Caralis, P. Case Reports of COVID 19 Recurrence. J. Prim. Care Community Health 2021, 12, 2150132720982752. [CrossRef]

58. Cavanaugh, A.M.; Thoroughman, D.; Miranda, H.; Spicer, K. Suspected Recurrent SARS-CoV-2 Infections Among Residents of a Skilled Nursing Facility During a Second COVID-19 Outbreak-Kentucky, July-November 2020. MMWR Morb. Mortal. Wkly. Rep. 2021, 70, 273-277. [CrossRef] [PubMed]

59. Colson, P.; Finaud, M.; Levy, N.; Lagier, J.C.; Raoult, D. Evidence of SARS-CoV-2 re-infection with a different genotype. J. Infect. 2021, 82, 84-123. [CrossRef] [PubMed]

60. Das, P.; Satter, S.M.; Ross, A.G.; Abdullah, Z.; Nazneen, A.; Sultana, R.; Rimi, N.A.; Chowdhury, K.; Alam, R.; Parveen, S.; et al. A Case Series Describing the Recurrence of COVID-19 in Patients Who Recovered from Initial Illness in Bangladesh. Trop. Med. Infect. Dis. 2021, 6, 41. [CrossRef]

61. Daw, M.A.; Daw, A.M.; Miftah, M.M.; El-Bouzedi, A.; Ahmed, M.O.; Libyan Study Group of COVID-19. Familial Clustering and Reinfection With 2019 Novel Coronavirus (COVID-19, SARS-CoV-2) in the Libyan Community. Disaster Med. Public Health Prep. 2021, 1-3. [CrossRef]

62. de Brito, C.A.A.; Lima, P.M.A.; de Brito, M.C.M.; de Oliveira, D.B. Second Episode of COVID-19 in Health Professionals: Report of Two Cases. Int. Med. Case Rep. J. 2020, 13, 471-475. [CrossRef]

63. Diaz, Y.; Ortiz, A.; Weeden, A.; Castillo, D.; Gonzalez, C.; Moreno, B.; Martinez-Montero, M.; Castillo, M.; Vasquez, G.; Saenz, L.; et al. SARS-CoV-2 reinfection with a virus harboring mutation in the Spike and the Nucleocapsid proteins in Panama. Int. J. Infect. Dis. 2021, 108, 588-591. [CrossRef]

64. Dimeglio, C.; Herin, F.; Miedouge, M.; Martin-Blondel, G.; Soulat, J.M.; Izopet, J. Protection of healthcare workers against SARS-CoV-2 reinfection. Clin. Infect. Dis. 2021. [CrossRef]

65. Dobano, C.; Ramirez-Morros, A.; Alonso, S.; Vidal-Alaball, J.; Ruiz-Olalla, G.; Vidal, M.; Rubio, R.; Cascant, E.; Parras, D.; Rodrigo Melero, N.; et al. Persistence and baseline determinants of seropositivity and reinfection rates in health care workers up to 12.5 months after COVID-19. BMC Med. 2021, 19, 155. [CrossRef]

66. Duggan, N.M.; Ludy, S.M.; Shannon, B.C.; Reisner, A.T.; Wilcox, S.R. Is novel coronavirus 2019 reinfection possible? Interpreting dynamic SARSCoV-2 test results through a case report. Am. J. Emerg. Med. 2020, 39, 256.e1-256.e3. [CrossRef] [PubMed] 
67. Elzein, F.; Ibrahim, A.; Alshahrani, F.; Mahrous, M.; Murshid, E.; Aldhehyan, T.; Almutiri, G.; Altowairqi, M.; Ahmed, M.; Alsaeed, M.; et al. Reinfection, recurrence, or delayed presentation of COVID-19? Case series and review of the literature. J. Infect. Public Health 2021, 14, 474-477. [CrossRef] [PubMed]

68. Fageeh, H.; Alshehri, A.; Fageeh, H.; Bizzoca, M.E.; Lo Muzio, L.; Quadri, M.F.A. Re-infection of SARS-CoV-2: A case in a young dental healthcare worker. J. Infect. Public Health 2021, 14, 685-688. [CrossRef] [PubMed]

69. Fabianova, K.; Kyncl, J.; Vlckova, I.; Jirincova, H.; Kostalova, J.; Liptakova, M.; Orlikova, H.; Sebestova, H.; Limberkova, R.; Mackova, B.; et al. COVID-19 reinfections. Epidemiol. Mikrobiol. Imunol. 2021, 70, 62-67. [PubMed]

70. Fernandes, A.C.; Figueiredo, R. SARS-CoV-2 reinfection: A case report from Portugal. Rev. Soc. Bras. Med. Trop. 2021, 54, e0002-2021. [CrossRef] [PubMed]

71. Ferrante, L.; Livas, S.; Steinmetz, W.A.; Almeida, A.C.L.; Leao, J.; Vassao, R.C.; Tupinambas, U.; Fearnside, P.M.; Duczmal, L.H. The First Case of Immunity Loss and SARS-CoV-2 Reinfection by the Same Virus Lineage in Amazonia. J. Racial Ethn. Health Disparities 2021, 8, 821-823. [CrossRef]

72. Fintelman-Rodrigues, N.; da Silva, A.P.D.; Dos Santos, M.C.; Saraiva, F.B.; Ferreira, M.A.; Gesto, J.; Rodrigues, D.A.S.; Vale, A.M.; de Azevedo, I.G.; Soares, V.C.; et al. Genetic Evidence and Host Immune Response in Persons Reinfected with SARS-CoV-2, Brazil. Emerg. Infect. Dis. 2021, 27, 1446-1453. [CrossRef]

73. Fonseca, V.; de Jesus, R.; Adelino, T.; Reis, A.B.; de Souza, B.B.; Ribeiro, A.A.; Guimaraes, N.R.; Livorati, M.; Neto, D.F.L.; Kato, R.B.; et al. Genomic evidence of SARS-CoV-2 reinfection case with the emerging B.1.2 variant in Brazil. J. Infect. 2021, 5126. [CrossRef]

74. Garduno-Orbe, B.; Sanchez-Rebolledo, J.M.; Cortes-Rafael, M.; Garcia-Jimenez, Y.; Perez-Ortiz, M.; Mendiola-Pastrana, I.R.; Lopez-Ortiz, E.; Lopez-Ortiz, G. SARS-CoV-2 Reinfection among Healthcare Workers in Mexico: Case Report and Literature Review. Medicina (Kaunas) 2021, 57, 442. [CrossRef]

75. Garg, J.; Agarwal, J.; Das, A.; Sen, M. Recurrent COVID-19 infection in a health care worker: A case report. J. Med. Case Rep. 2021, 15, 363. [CrossRef]

76. Garvey, M.I.; Casey, A.L.; Wilkinson, M.A.C.; Ratcliffe, L.; McMurray, C.; Stockton, J.; Holden, E.; Osman, H.; Loman, N.J. Details of SARS-CoV-2 reinfections at a major UK tertiary centre. J. Infect. 2021, 82, e29-e30. [CrossRef] [PubMed]

77. Goel, N.; Jain, D.; Haddad, D.B. Coronavirus Disease-19 and Re-infection: Unknown of the Unknown. Saudi J. Kidney Dis. Transpl. 2021, 32, 261-264. [CrossRef] [PubMed]

78. Gulati, K.; Prendecki, M.; Clarke, C.; Willicombe, M.; McAdoo, S. COVID-19 Reinfection in a Patient Receiving Immunosuppressive Treatment for Antineutrophil Cytoplasmic Antibody-Associated Vasculitis. Arthritis Rheumatol. 2021, 73, 1091-1092 [CrossRef] [PubMed]

79. Gupta, V.; Bhoyar, R.C.; Jain, A.; Srivastava, S.; Upadhayay, R.; Imran, M.; Jolly, B.; Divakar, M.K.; Sharma, D.; Sehgal, P.; et al. Asymptomatic reinfection in two healthcare workers from India with genetically distinct SARS-CoV-2. Clin. Infect. Dis. 2020. [CrossRef] [PubMed]

80. Habadi, M.I.; Balla Abdalla, T.H.; Hamza, N.; Al-Gedeei, A. COVID-19 Reinfection. Cureus 2021, 13, e12730. [CrossRef] [PubMed]

81. Hanif, M.; Haider, M.A.; Ali, M.J.; Naz, S.; Sundas, F. Reinfection of COVID-19 in Pakistan: A First Case Report. Cureus 2020, 12, e11176. [CrossRef] [PubMed]

82. Harrington, D.; Kele, B.; Pereira, S.; Couto-Parada, X.; Riddell, A.; Forbes, S.; Dobbie, H.; Cutino-Moguel, T. Confirmed Reinfection with SARS-CoV-2 Variant VOC-202012/01. Clin. Infect. Dis. 2021. [CrossRef] [PubMed]

83. Hayes, B.; Stanley, J.; Peppers, B.P. COVID-19 Recurrence Without Seroconversion in a Patient With Mannose-Binding Lectin Deficiency. Allergy Rhinol. (Providence) 2021, 12, 21526567211024140. [CrossRef]

84. Hunsinger, D.H.P.; Kutti Sridharan, D.G.; Rokkam, D.; Fantry, D.L.E. COVID-19 Reinfection in An Immunosuppressed Patient Without An Antibody Response. Am. J. Med. Sci. 2021, 362, 103. [CrossRef]

85. Hussein, N.R.; Musa, D.H.; Saleem, Z.S.M.; Naqid, I.A.; Ibrahim, N. Possible COVID-19 reinfection case in Duhok City, Kurdistan: A case report. J. Fam. Med. Prim. Care 2021, 10, 2035-2037. [CrossRef]

86. Hussein, N.R.; Rashad, B.H.; Almizori, L.A.; Yousif, S.S.; Sadeeq, A.T.; Abdulkareem, Y.R.; Mahmood, A.M.; Salih, Z.K. The Risk of SARS-CoV-2 Reinfection in Duhok city, Kurdistan Region of Iraq. Mediterr. J. Hematol. Infect. Dis. 2021, 13, e2021035. [CrossRef]

87. Ibrahim, M.; Vegel, A.; Niu, A.; Panse, K.; Chen, R.; Safah, H.; Socola, F.; Luk, A.; Saba, N.S. Reinfection versus failure of viral clearance in a COVID-19 patient with hematologic malignancy. Leuk. Res. 2021, 101, 106514. [CrossRef]

88. Inada, M.; Ishikane, M.; Terada, M.; Matsunaga, A.; Maeda, K.; Tsuchiya, K.; Miura, K.; Sairenji, Y.; Kinoshita, N.; Ujiie, M.; et al Asymptomatic COVID-19 re-infection in a Japanese male by elevated half-maximal inhibitory concentration (IC50) of neutralizing antibodies. J. Infect. Chemother. 2021, 27, 1063-1067. [CrossRef] [PubMed]

89. Jain, A.; Kaur, J.; Rai, A.K.; Pandey, A.K. Anosmia: A Clinical Indicator of COVID-19 Reinfection. Ear Nose Throat J. 2021, 100, 180S-181S. [CrossRef] [PubMed]

90. Kapoor, R.; Nair, R.K.; Nayan, N.; Bhalla, S.; Singh, J. Reinfection or Reactivation of Coronavirus-19 in Patients with Hematologic Malignancies: Case Report Series. SN Compr. Clin. Med. 2021, 3, 670-674. [CrossRef] [PubMed]

91. Krishna, V.N.; Ahmad, M.; Overton, E.T.; Jain, G. Recurrent COVID-19 in Hemodialysis: A Case Report of 2 Possible Reinfections. Kidney Med. 2021, 3, 447-450. [CrossRef]

92. Kulkarni, O.; Narreddy, S.; Zaveri, L.; Kalal, I.G.; Tallapaka, K.B.; Sowpati, D.T. Evidence of SARS-CoV-2 reinfection without mutations in Spike protein. Clin. Infect. Dis. 2021, 73, e1239-e1241. [CrossRef] 
93. Larson, D.; Brodniak, S.L.; Voegtly, L.J.; Cer, R.Z.; Glang, L.A.; Malagon, F.J.; Long, K.A.; Potocki, R.; Smith, D.R.; Lanteri, C.; et al. A Case of Early Re-infection with SARS-CoV-2. Clin. Infect. Dis. 2020. [CrossRef]

94. Lechien, J.R.; Chiesa-Estomba, C.M.; Vaira, L.A.; Saussez, S.; Hans, S. COVID-19 Reinfection and Second Episodes of Olfactory and Gustatory Dysfunctions: Report of First Cases. Ear Nose Throat J. 2020, 145561320970105. [CrossRef]

95. Lee, J.S.; Kim, S.Y.; Kim, T.S.; Hong, K.H.; Ryoo, N.H.; Lee, J.; Park, J.H.; Cho, S.I.; Kim, M.J.; Kim, Y.G.; et al. Evidence of Severe Acute Respiratory Syndrome Coronavirus 2 Reinfection After Recovery from Mild Coronavirus Disease 2019. Clin. Infect. Dis. 2020. [CrossRef]

96. Leung, S.; Hossain, N. Recurrence and Recovery of COVID-19 in an Older Adult Patient with Multiple Comorbidities: A Case Report. Gerontology 2021, 67, 445-448. [CrossRef]

97. Luciani, M.; Bentivegna, E.; Spuntarelli, V.; Lamberti, P.A.; Cacioli, G.; Del Porto, F.; Sesti, G.; Martelletti, P.; De Biase, L. Recurrent COVID-19 pneumonia in the course of chemotherapy: Consequence of a weakened immune system? J. Med. Virol. 2021, 93, 1882-1884. [CrossRef]

98. Mahajan, N.N.; Gajbhiye, R.K.; Lokhande, P.D.; Bahirat, S.; Modi, D.; Mathe, A.M.; Bharmal, R.; Rathi, S.; Mohite, S.C.; Tilve, A. Clinical Presentation of Cases with SARS-CoV-2 Reinfection/ Reactivation. J. Assoc. Physicians India 2021, 69, 16-18. [PubMed]

99. Marquez, L.; Koy, T.; Spinler, J.K.; Luna, R.A.; Tocco, L.; Fasciano, L.; Dunn, J.; Campbell, J.R. Reinfection with severe acute respiratory syndrome coronavirus 2 (SARS-CoV-2) B.1.1.7 variant in an immunocompromised adolescent. Infect. Control. Hosp. Epidemiol 2021, 1-2. [CrossRef] [PubMed]

100. Massanella, M.; Martin-Urda, A.; Mateu, L.; Marin, T.; Aldas, I.; Riveira-Munoz, E.; Kipelainen, A.; Jimenez-Moyano, E.; Rodriguez de la Concepcion, M.L.; Avila-Nieto, C.; et al. Critical Presentation of a Severe Acute Respiratory Syndrome Coronavirus 2 Reinfection: A Case Report. Open Forum Infect. Dis. 2021, 8, ofab329. [CrossRef] [PubMed]

101. Mohseni, M.; Albus, M.; Kaminski, A.; Harrison, M.F. A Case of COVID-19 Re-Infection in a Liver Transplant Patient. Cureus 2021, 13, e14916. [CrossRef] [PubMed]

102. Mulder, M.; van der Vegt, D.; Oude Munnink, B.B.; GeurtsvanKessel, C.H.; van de Bovenkamp, J.; Sikkema, R.S.; Jacobs, E.M.G.; Koopmans, M.P.G.; Wegdam-Blans, M.C.A. Reinfection of SARS-CoV-2 in an immunocompromised patient: A case report. Clin. Infect. Dis. 2020. [CrossRef] [PubMed]

103. Munoz Mendoza, J.; Alcaide, M.L. COVID-19 in a patient with end-stage renal disease on chronic in-center hemodialysis after evidence of SARS-CoV-2 IgG antibodies. Reinfection or inaccuracy of antibody testing. IDCases 2020, 22, e00943. [CrossRef]

104. Nachmias, V.; Fusman, R.; Mann, S.; Koren, G. The first case of documented Covid-19 reinfection in Israel. IDCases 2020, 22, e00970. [CrossRef]

105. Naveca, F.; da Costa, C.; Nascimento, V.; Souza, V.; Corado, A.; Nascimento, F.; Costa, A.; Duarte, D.; Silva, G.; Mejía, M.; et al. Three SARS-CoV-2 reinfection cases by the new Variant of Concern (VOC) P.1/501Y.V3. Res. Sq. 2021. [CrossRef]

106. Nazir, N.; Ahirwar, A.; Jain, S. Reinfection in a healthcare worker with COVID-19 in a hospital in North India. Anaesth. Pain Intensive Care 2020, 24, 572-573. [CrossRef]

107. Nicholson, E.G.; Avadhanula, V.; Fragoso, S.; Stroh, R.; Ye, X.; Bond, N.; Santarcangelo, P.; Stroh, J.; Piedra, P.A. SARS-CoV-2 re-infection versus prolonged shedding: A case series. Influenza Other Respir Viruses 2021. [CrossRef]

108. Nonaka, C.K.V.; Franco, M.M.; Graf, T.; de Lorenzo Barcia, C.A.; de Avila Mendonca, R.N.; de Sousa, K.A.F.; Neiva, L.M.C.; Fosenca, V.; Mendes, A.V.A.; de Aguiar, R.S.; et al. Genomic Evidence of SARS-CoV-2 Reinfection Involving E484K Spike Mutation, Brazil. Emerg. Infect. Dis. 2021, 27, 1522-1524. [CrossRef]

109. Novoa, W.; Miller, H.; Mattar, S.; Faccini-Martinez, A.A.; Rivero, R.; Serrano-Coll, H. A first probable case of SARS-CoV-2 reinfection in Colombia. Ann. Clin. Microbiol. Antimicrob. 2021, 20, 7. [CrossRef]

110. Ozaras, R.; Ozdogru, I.; Yilmaz, A.A. Coronavirus disease 2019 re-infection: First report from Turkey. New Microbes New Infect. 2020, 38, 100774. [CrossRef] [PubMed]

111. Pow, T.; Allen, S.; Brailovsky, Y.; Darki, A. Acute submassive pulmonary embolism after SARS-CoV-2 infection: A case report of reinfection or prolonged hypercoagulable state. Eur. Heart J. Case Rep. 2021, 5, ytab103. [CrossRef] [PubMed]

112. Quiroga, B.; Fernandez Ramos, A.; Delgado Arroyo, A. COVID-19 reinfection in a kidney transplant recipient, time for rethinking? Nefrologia 2021. [CrossRef] [PubMed]

113. Ramirez, J.D.; Munoz, M.; Ballesteros, N.; Patino, L.H.; Castaneda, S.; Rincon, C.A.; Mendez, C.; Oliveros, C.; Perez, J.; Marquez, E.K.; et al. Phylogenomic Evidence of Reinfection and Persistence of SARS-CoV-2: First Report from Colombia. Vaccines 2021, 9 , 282. [CrossRef] [PubMed]

114. Rani, P.R.; Imran, M.; Lakshmi, J.V.; Jolly, B.; Jain, A.; Surekha, A.; Senthivel, V.; Chandrasekhar, P.; Divakar, M.K.; Srinivasulu, D.; et al. Symptomatic reinfection of SARS-CoV-2 with spike protein variant N440K associated with immune escape. J. Med. Virol. 2021, 93, 4163-4165. [CrossRef] [PubMed]

115. Resende, P.C.; Bezerra, J.F.; Teixeira Vasconcelos, R.H.; Arantes, I.; Appolinario, L.; Mendonca, A.C.; Paixao, A.C.; Duarte, A.C.; Silva, T.; Rocha, A.S.; et al. Severe Acute Respiratory Syndrome Coronavirus 2 P.2 Lineage Associated with Reinfection Case, Brazil, June-October 2020. Emerg. Infect. Dis. 2021, 27, 1789-1794. [CrossRef]

116. Rodriguez-Espinosa, D.; Broseta Monzo, J.J.; Casals, Q.; Pineiro, G.J.; Rodas, L.; Vera, M.; Maduell, F. Fatal SARS-CoV-2 reinfection in an immunosuppressed patient on hemodialysis. J. Nephrol. 2021, 34, 1041-1043. [CrossRef] 
117. Romano, C.M.; Felix, A.C.; Paula, A.V.; Jesus, J.G.; Andrade, P.S.; Candido, D.; Oliveira, F.M.; Ribeiro, A.C.; Silva, F.C.D.; Inemami, M.; et al. SARS-CoV-2 reinfection caused by the P.1 lineage in Araraquara city, Sao Paulo State, Brazil. Rev. Inst. Med. Trop. Sao Paulo 2021, 63, e36. [CrossRef] [PubMed]

118. Salcin, S.; Fontem, F. Recurrent SARS-CoV-2 infection resulting in acute respiratory distress syndrome and development of pulmonary hypertension: A case report. Respir. Med. Case Rep. 2021, 33, 101314. [CrossRef] [PubMed]

119. Salehi-Vaziri, M.; Omrani, M.D.; Pouriayevali, M.H.; Fotouhi, F.; Banifazl, M.; Farahmand, B.; Sadat Larijani, M.; Ahmadi, Z.; Fereydouni, Z.; Tavakoli, M.; et al. SARS-CoV-2 presented moderately during two episodes of the infection with lack of antibody responses. Virus Res. 2021, 299, 198421. [CrossRef] [PubMed]

120. Salehi-Vaziri, M.; Jalali, T.; Farahmand, B.; Fotouhi, F.; Banifazl, M.; Pouriayevali, M.H.; Sadat Larijani, M.; Afzali, N.; Ramezani, A. Clinical characteristics of SARS-CoV-2 by re-infection vs. reactivation: A case series from Iran. Eur J. Clin. Microbiol. Infect. Dis. 2021, 40, 1713-1719. [CrossRef]

121. Salzer, H.J.F. Emerging COVID-19 reinfection four months after primary SARS-CoV-2 infection. Wien. Med. Wochenschr. 2021. [CrossRef]

122. Sanyang, B.; Kanteh, A.; Usuf, E.; Nadjm, B.; Jarju, S.; Bah, A.; Bojang, A.; Grey-Johnson, M.; Jones, J.C.; Gai, A.; et al. COVID-19 reinfections in The Gambia by phylogenetically distinct SARS-CoV-2 variants-first two confirmed events in west Africa. Lancet Glob. Health 2021, 9, e905-e907. [CrossRef]

123. Scarpati, G.; Piazza, O.; Pagliano, P.; Rizzo, F. COVID-19: A confirmed case of reinfection in a nurse. BMJ Case Rep. 2021, 14, e244507. [CrossRef]

124. Selhorst, P.; Van Ierssel, S.; Michiels, J.; Marien, J.; Bartholomeeusen, K.; Dirinck, E.; Vandamme, S.; Jansens, H.; Arien, K.K. Symptomatic SARS-CoV-2 reinfection of a health care worker in a Belgian nosocomial outbreak despite primary neutralizing antibody response. Clin. Infect. Dis. 2020. [CrossRef]

125. Selvaraj, V.; Herman, K.; Dapaah-Afriyie, K. Severe, Symptomatic Reinfection in a Patient with COVID-19. R I Med. J. 2020, 103, 24-26.

126. Sen, M.K.; Gupta, N.; Yadav, S.R.; Kumar, R.; Singh, B.; Ish, P. Contentious Issue in Recurrent COVID-19 Infection: Reactivation or Reinfection. Turk. Thorac. J. 2020, 21, 463-466. [CrossRef]

127. Sevillano, G.; Ortega-Paredes, D.; Loaiza, K.; Zurita-Salinas, C.; Zurita, J. Evidence of SARS-CoV-2 reinfection within the same clade in Ecuador: A case study. Int. J. Infect. Dis. 2021, 108, 53-56. [CrossRef]

128. Shastri, J.; Parikh, S.; Agrawal, S.; Chatterjee, N.; Pathak, M.; Chaudhary, S.; Sharma, C.; Kanakan, A.; Vivekanand, A.; Srinivasa Vasudevan, J.; et al. Clinical, Serological, Whole Genome Sequence Analyses to Confirm SARS-CoV-2 Reinfection in Patients From Mumbai, India. Front. Med. (Lausanne) 2021, 8, 631769. [CrossRef]

129. Shoar, S.; Khavandi, S.; Tabibzadeh, E.; Khavandi, S.; Naderan, M.; Shoar, N. Recurrent coronavirus diseases 19 (COVID-19): A different presentation from the first episode. Clin. Case Rep. 2021, 9, 2149-2152. [CrossRef]

130. Sicsic, I., Jr.; Chacon, A.R.; Zaw, M.; Ascher, K.; Abreu, A.; Chediak, A. A case of SARS-CoV-2 reinfection in a patient with obstructive sleep apnea managed with telemedicine. BMJ Case Rep. 2021, 14, e240496. [CrossRef]

131. Siqueira, J.D.; Goes, L.R.; Alves, B.M.; da Silva, A.C.P.; de Carvalho, P.S.; Cicala, C.; Arthos, J.; Viola, J.P.B.; Soares, M.A. Distinguishing SARS-CoV-2 bonafide re-infection from pre-existing minor variant reactivation. Infect. Genet. Evol. 2021, 90, 104772. [CrossRef]

132. Silva, M.S.D.; Demoliner, M.; Hansen, A.W.; Gularte, J.S.; Silveira, F.; Heldt, F.H.; Filippi, M.; Pereira, V.; Silva, F.P.D.; Mallmann, L.; et al. Early detection of SARS-CoV-2 P.1 variant in Southern Brazil and reinfection of the same patient by P.2. Rev. Inst. Med. Trop. Sao Paulo 2021, 63, e58. [CrossRef]

133. Staub, T.; Arendt, V.; Lasso de la Vega, E.C.; Braquet, P.; Michaux, C.; Kohnen, M.; Tsobo, C.; Abdelrahman, T.; WieneckeBaldacchino, A.; Francois, J.H. Case series of four re-infections with a SARS-CoV-2 B.1.351 variant, Luxembourg, February 2021. Euro Surveill 2021, 26, 2100423. [CrossRef] [PubMed]

134. Takeda, C.F.V.; de Almeida, M.M.; Gomes, R.G.D.; Souza, T.C.; Mota, M.A.D.; Cavalcanti, L.P.D.; Colares, J.K.B. Case Report: Recurrent Clinical Symptoms of COVID-19 in Healthcare Professionals: A Series of Cases from Brazil. Am. J. Trop. Med. Hyg. 2020, 103, 1993-1996. [CrossRef] [PubMed]

135. Tang, C.Y.; Wang, Y.; McElroy, J.A.; Li, T.; Hammer, R.; Ritter, D.; Lidl, G.M.; Webby, R.; Hang, J.; Wan, X.F. Reinfection with two genetically distinct SARS-CoV-2 viruses within 19 days. J. Med. Virol. 2021, 93, 5700-5703. [CrossRef] [PubMed]

136. Tuan, J.; Spichler-Moffarah, A.; Ogbuagu, O. A new positive SARS-CoV-2 test months after severe COVID-19 illness: Reinfection or intermittent viral shedding? BMJ Case Rep. 2021, 14, e240531. [CrossRef] [PubMed]

137. Teka, I.A.; BenHasan, M.H.; Alkershini, A.A.; Alatresh, O.K.; Abulifa, T.A.; Lembagga, H.A.; Alhudiri, I.M.; Elzagheid, A. Reinfection with SARS-CoV-2: A case report from Libya. Travel Med. Infect. Dis. 2021, 41, 102040. [CrossRef]

138. To, K.K.; Hung, I.F.; Chan, K.H.; Yuan, S.; To, W.K.; Tsang, D.N.; Cheng, V.C.; Chen, Z.; Kok, K.H.; Yuen, K.Y. Serum Antibody Profile of a Patient With Coronavirus Disease 2019 Reinfection. Clin. Infect. Dis. 2021, 72, e659-e662. [CrossRef] [PubMed]

139. Chan, P.K.S.; Lui, G.; Hachim, A.; Ko, R.L.W.; Boon, S.S.; Li, T.; Kavian, N.; Luk, F.; Chen, Z.; Yau, E.M.; et al. Serologic Responses in Healthy Adult with SARS-CoV-2 Reinfection, Hong Kong, August 2020. Emerg. Infect. Dis. 2020, 26, 3076-3078. [CrossRef] [PubMed] 
140. Tomkins-Tinch, C.H.; Daly, J.S.; Gladden-Young, A.; Theodoropoulos, N.M.; Madaio, M.P.; Yu, N.; Vanguri, V.K.; Siddle, K.J.; Adams, G.; Krasilnikova, L.A.; et al. SARS-CoV-2 Reinfection in a Liver Transplant Recipient. Ann. Intern. Med. 2021, 174, 1178-1180. [CrossRef]

141. Tomassini, S.; Kotecha, D.; Bird, P.W.; Folwell, A.; Biju, S.; Tang, J.W. Setting the criteria for SARS-CoV-2 reinfection-Six possible cases. J. Infect. 2021, 82, 282-327. [CrossRef] [PubMed]

142. Torres, D.A.; Ribeiro, L.; Riello, A.; Horovitz, D.D.G.; Pinto, L.F.R.; Croda, J. Reinfection of COVID-19 after 3 months with a distinct and more aggressive clinical presentation: Case report. J. Med. Virol. 2020, 93, 1857-1859. [CrossRef] [PubMed]

143. Ul-Haq, Z.; Khan, A.; Fazid, S.; Noor, F.; Yousafzai, Y.M.; Sherin, A. First documented reinfection of SARS-COV-2 in second wave from Pakistan. J. Ayub. Med. Coll. Abbottabad 2020, 32 (Suppl. 1), S704-S705.

144. Vetter, P.; Cordey, S.; Schibler, M.; Vieux, L.; Despres, L.; Laubscher, F.; Andrey, D.O.; Martischang, R.; Harbarth, S.; Cuvelier, C.; et al. Clinical, virological and immunological features of a mild case of SARS-CoV-2 re-infection. Clin. Microbiol. Infect. 2021, 27, 791.e1-791.e4. [CrossRef]

145. Vora, T.; Vora, P.; Vora, F.; Sharma, K.; Desai, H.D. Symptomatic reinfection with COVID-19: A first from Western India. J. Fam. Med. Prim. Care 2021, 10, 1496-1498. [CrossRef]

146. West, J.; Everden, S.; Nikitas, N. A case of COVID-19 reinfection in the UK. Clin. Med. (Lond) 2021, 21, e52-e53. [CrossRef]

147. Yeleti, R.; Guglin, M.; Saleem, K.; Adigopula, S.V.; Sinha, A.; Upadhyay, S.; Everett, J.E.; Ballut, K.; Uppuluri, S.; Rao, R.A. Fulminant myocarditis: COVID or not COVID? Reinfection or co-infection? Future Cardiol. 2021. [CrossRef] [PubMed]

148. Yu, A.L.F.; Liphaus, B.L.; Ferreira, P.M.; Tanamachi, A.T.; Masuda, E.T.; Trevisan, C.M.; Lucas, P.C.C.; Bugno, A.; Carvalhanas, T. SARS-CoV-2 reinfection: Report of two cases in Southeast Brazil. Rev. Inst. Med. Trop. Sao Paulo 2021, 63, e50. [CrossRef] [PubMed]

149. Zare, F.; Teimouri, M.; Khosravi, A.; Rohani-Rasaf, M.; Chaman, R.; Hosseinzadeh, A.; Jamali Atergeleh, H.; Binesh, E.; Emamian, M.H. COVID-19 re-infection in Shahroud, Iran: A follow-up study. Epidemiol. Infect. 2021, 149, e159. [CrossRef] [PubMed]

150. Zhang, K.; Yiu-Nam Lau, J.; Yang, L.; Ma, Z. SARS-CoV-2 reinfection in two patients who have recovered from COVID-19. Precis. Clin. Med. 2020, 3, 292-293. [CrossRef]

151. Zucman, N.; Uhel, F.; Descamps, D.; Roux, D.; Ricard, J.D. Severe reinfection with South African SARS-CoV-2 variant 501Y.V2: A case report. Clin. Infect. Dis. 2021. [CrossRef]

152. Tirado, S.M.; Yoon, K.J. Antibody-dependent enhancement of virus infection and disease. Viral Immunol. 2003, 16, 69-86. [CrossRef]

153. Yahav, D.; Yelin, D.; Eckerle, I.; Eberhardt, C.S.; Wang, J.; Cao, B.; Kaiser, L. Definitions for coronavirus disease 2019 reinfection, relapse and PCR re-positivity. Clin. Microbiol. Infect. 2021, 27, 315-318. [CrossRef]

154. Xiao, A.T.; Tong, Y.X.; Zhang, S. False negative of RT-PCR and prolonged nucleic acid conversion in COVID-19: Rather than recurrence. J. Med. Virol. 2020, 92, 1755-1756. [CrossRef]

155. Wang, W.; Xu, Y.; Gao, R.; Lu, R.; Han, K.; Wu, G.; Tan, W. Detection of SARS-CoV-2 in Different Types of Clinical Specimens. JAMA 2020, 323, 1843-1844. [CrossRef]

156. Chaturvedi, R.; Naidu, R.; Sheth, S.; Chakravarthy, K. Efficacy of Serology Testing in Predicting Reinfection in Patients With SARS-CoV-2. Disaster Med. Public Health Prep. 2020, 15, e29-e31. [CrossRef]

157. Atkinson, B.; Petersen, E. SARS-CoV-2 shedding and infectivity. Lancet 2020, 395, 1339-1340. [CrossRef]

158. Anonymous. COVID-19 reinfection: Are we ready for winter? EBioMedicine 2020, 62, 103173. [CrossRef] [PubMed]

159. Gousseff, M.; Penot, P.; Gallay, L.; Batisse, D.; Benech, N.; Bouiller, K.; Collarino, R.; Conrad, A.; Slama, D.; Joseph, C.; et al. Clinical recurrences of COVID-19 symptoms after recovery: Viral relapse, reinfection or inflammatory rebound? J. Infect. 2020, 81, 816-846. [CrossRef] [PubMed]

160. Turner, J.S.; Day, A.; Alsoussi, W.B.; Liu, Z.; O’Halloran, J.A.; Presti, R.M.; Patterson, B.K.; Whelan, S.P.J.; Ellebedy, A.H.; Mudd, P.A. SARS-CoV-2 Viral RNA Shedding for More Than 87 Days in an Individual With an Impaired CD8+ T Cell Response. Front. Immunol. 2020, 11, 618402. [CrossRef] [PubMed]

161. Raveendran, A.V. COVID-19 re-infection: Diagnostic challenges and proposed diagnostic criteria. Diabetes Metab. Syndr. 2021, 15, 645-648. [CrossRef]

162. Pilz, S.; Chakeri, A.; Ioannidis, J.P.; Richter, L.; Theiler-Schwetz, V.; Trummer, C.; Krause, R.; Allerberger, F. SARS-CoV-2 re-infection risk in Austria. Eur. J. Clin. Investig. 2021, 51, e13520. [CrossRef] [PubMed]

163. Sui, J.; Li, W.; Roberts, A.; Matthews, L.J.; Murakami, A.; Vogel, L.; Wong, S.K.; Subbarao, K.; Farzan, M.; Marasco, W.A. Evaluation of human monoclonal antibody 80R for immunoprophylaxis of severe acute respiratory syndrome by an animal study, epitope mapping, and analysis of spike variants. J. Virol. 2005, 79, 5900-5906. [CrossRef] [PubMed]

164. Zhao, J.; Yuan, Q.; Wang, H.; Liu, W.; Liao, X.; Su, Y.; Wang, X.; Yuan, J.; Li, T.; Li, J.; et al. Antibody Responses to SARS-CoV-2 in Patients With Novel Coronavirus Disease 2019. Clin. Infect. Dis. 2020, 71, 2027-2034. [CrossRef]

165. Del Fante, C.; Franchini, M.; Baldanti, F.; Percivalle, E.; Glingani, C.; Marano, G.; Mengoli, C.; Mortellaro, C.; Viarengo, G.; Perotti, C.; et al. A retrospective study assessing the characteristics of COVID-19 convalescent plasma donors and donations. Transfusion 2020, 61, 830-838. [CrossRef] [PubMed]

166. Long, Q.X.; Liu, B.Z.; Deng, H.J.; Wu, G.C.; Deng, K.; Chen, Y.K.; Liao, P.; Qiu, J.F.; Lin, Y.; Cai, X.F.; et al. Antibody responses to SARS-CoV-2 in patients with COVID-19. Nat. Med. 2020, 26, 845-848. [CrossRef] 
167. Cassaniti, I.; Novazzi, F.; Giardina, F.; Salinaro, F.; Sachs, M.; Perlini, S.; Bruno, R.; Mojoli, F.; Baldanti, F.; Members of the San Matteo Pavia, C.-T.F. Performance of VivaDiag COVID-19 IgM/IgG Rapid Test is inadequate for diagnosis of COVID-19 in acute patients referring to emergency room department. J. Med. Virol 2020, 92, 1724-1727. [CrossRef] [PubMed]

168. Bichara, C.; Amoras, E.; Vaz, G.; Bichara, C.; Amaral, I.; Vallinoto, A. Persistence of Anti-SARS-CoV-2 IgM Antibody up to 8 Months Post-COVID-19. Case Rep. Clin. Med. 2021, 10, 227-231. [CrossRef]

169. Sethuraman, N.; Jeremiah, S.S.; Ryo, A. Interpreting Diagnostic Tests for SARS-CoV-2. JAMA 2020, 323, 2249-2251. [CrossRef]

170. Channappanavar, R.; Fett, C.; Zhao, J.; Meyerholz, D.K.; Perlman, S. Virus-specific memory CD8 T cells provide substantial protection from lethal severe acute respiratory syndrome coronavirus infection. J. Virol. 2014, 88, 11034-11044. [CrossRef]

171. Sherina, N.; Piralla, A.; Du, L.; Wan, H.; Kumagai-Braesh, M.; Andréll, J.; Braesch-Andersen, S.; Cassaniti, I.; Percivalle, E.; Sarasini, A.; et al. Persistence of SARS-CoV-2 specific B- and T-cell responses in convalescent COVID-19 patients 6-8 months after the infection. BioRxiv 2020. [CrossRef]

172. Enjuanes, L.; Zuniga, S.; Castano-Rodriguez, C.; Gutierrez-Alvarez, J.; Canton, J.; Sola, I. Molecular Basis of Coronavirus Virulence and Vaccine Development. Adv. Virus Res. 2016, 96, 245-286. [CrossRef]

173. Figueiredo-Campos, P.; Blankenhaus, B.; Mota, C.; Gomes, A.; Serrano, M.; Ariotti, S.; Costa, C.; Nunes-Cabaco, H.; Mendes, A.M.; Gaspar, P.; et al. Seroprevalence of anti-SARS-CoV-2 antibodies in COVID-19 patients and healthy volunteers up to 6 months post disease onset. Eur. J. Immunol. 2020, 50, 2025-2040. [CrossRef]

174. Krishna, E.; Pathak, V.K.; Prasad, R.; Jose, H.; Kumar, M.M. COVID-19 reinfection: Linked Possibilities and future outlook. J. Fam. Med. Prim. Care 2020, 9, 5445-5449. [CrossRef]

175. Khoshkam, Z.; Aftabi, Y.; Stenvinkel, P.; Paige Lawrence, B.; Rezaei, M.H.; Ichihara, G.; Fereidouni, S. Recovery scenario and immunity in COVID-19 disease: A new strategy to predict the potential of reinfection. J. Adv. Res. 2021, 31, 49-60. [CrossRef] [PubMed]

176. Prevost, J.; Finzi, A. The great escape? SARS-CoV-2 variants evading neutralizing responses. Cell Host Microbe 2021, 29 , 322-324. [CrossRef] [PubMed]

177. Guallar, M.P.; Meirino, R.; Donat-Vargas, C.; Corral, O.; Jouve, N.; Soriano, V. Inoculum at the time of SARS-CoV-2 exposure and risk of disease severity. Int. J. Infect. Dis. 2020, 97, 290-292. [CrossRef] [PubMed]

178. Arvin, A.M.; Fink, K.; Schmid, M.A.; Cathcart, A.; Spreafico, R.; Havenar-Daughton, C.; Lanzavecchia, A.; Corti, D.; Virgin, H.W. A perspective on potential antibody-dependent enhancement of SARS-CoV-2. Nature 2020, 584, 353-363. [CrossRef]

179. Negro, F. Is antibody-dependent enhancement playing a role in COVID-19 pathogenesis? Swiss Med. Wkly. 2020, 150, w20249. [CrossRef] [PubMed]

180. Peron, J.P.S.; Nakaya, H. Susceptibility of the Elderly to SARS-CoV-2 Infection: ACE-2 Overexpression, Shedding, and Antibodydependent Enhancement (ADE). Clinics (Sao Paulo) 2020, 75, e1912. [CrossRef] [PubMed]

181. Ulrich, H.; Pillat, M.M.; Tarnok, A. Dengue Fever, COVID-19 (SARS-CoV-2), and Antibody-Dependent Enhancement (ADE): A Perspective. Cytom. A 2020, 97, 662-667. [CrossRef] [PubMed]

182. Wan, Y.; Shang, J.; Sun, S.; Tai, W.; Chen, J.; Geng, Q.; He, L.; Chen, Y.; Wu, J.; Shi, Z.; et al. Molecular Mechanism for Antibody-Dependent Enhancement of Coronavirus Entry. J. Virol. 2020, 94, e02015-19. [CrossRef]

183. Wen, J.; Cheng, Y.; Ling, R.; Dai, Y.; Huang, B.; Huang, W.; Zhang, S.; Jiang, Y. Antibody-dependent enhancement of coronavirus. Int. J. Infect. Dis. 2020, 100, 483-489. [CrossRef]

184. Yager, E.J. Antibody-dependent enhancement and COVID-19: Moving toward acquittal. Clin. Immunol. 2020, $217,108496$. [CrossRef]

185. Bournazos, S.; Gupta, A.; Ravetch, J.V. The role of IgG Fc receptors in antibody-dependent enhancement. Nat. Rev. Immunol. 2020, 20, 633-643. [CrossRef]

186. Eroshenko, N.; Gill, T.; Keaveney, M.K.; Church, G.M.; Trevejo, J.M.; Rajaniemi, H. Implications of antibody-dependent enhancement of infection for SARS-CoV-2 countermeasures. Nat. Biotechnol. 2020, 38, 789-791. [CrossRef]

187. Fleming, A.B.; Raabe, V. Current studies of convalescent plasma therapy for COVID-19 may underestimate risk of antibodydependent enhancement. J. Clin. Virol. 2020, 127, 104388. [CrossRef]

188. Kumar, R.; Gupta, N.; Kodan, P.; Mittal, A.; Soneja, M.; Wig, N. Is there antibody-dependent enhancement in SARS Coronavirus 2? J. Fam. Med. Prim. Care 2020, 9, 2589-2590. [CrossRef]

189. Nechipurenko, Y.D.; Anashkina, A.A.; Matveeva, O.V. Change of Antigenic Determinants of SARS-CoV-2 Virus S-Protein as a Possible Cause of Antibody-Dependent Enhancement of Virus Infection and Cytokine Storm. Biophysics (Oxford) 2020, 65, 703-709. [CrossRef] [PubMed]

190. Yip, M.S.; Leung, N.H.; Cheung, C.Y.; Li, P.H.; Lee, H.H.; Daeron, M.; Peiris, J.S.; Bruzzone, R.; Jaume, M. Antibody-dependent infection of human macrophages by severe acute respiratory syndrome coronavirus. Virol. J. 2014, 11, 82. [CrossRef] [PubMed]

191. Lee, W.S.; Wheatley, A.K.; Kent, S.J.; DeKosky, B.J. Antibody-dependent enhancement and SARS-CoV-2 vaccines and therapies. Nat. Microbiol. 2020, 5, 1185-1191. [CrossRef] [PubMed]

192. Kabir, K.M.A.; Tanimoto, J. Cost-efficiency analysis of voluntary vaccination against n-serovar diseases using antibody-dependent enhancement: A game approach. J. Theor. Biol. 2020, 503, 110379. [CrossRef]

193. Kadkhoda, K. Severe acute respiratory syndrome coronavirus 2, original antigenic sin, and antibody-dependent enhancement: Ménage à trois. Curr. Opin. Rheumatol. 2020, 32, 458-461. [CrossRef] 
194. Karthik, K.; Senthilkumar, T.M.A.; Udhayavel, S.; Raj, G.D. Role of antibody-dependent enhancement (ADE) in the virulence of SARS-CoV-2 and its mitigation strategies for the development of vaccines and immunotherapies to counter COVID-19. Hum. Vaccines Immunother. 2020, 16, 3055-3060. [CrossRef]

195. Cohen, J.I.; Burbelo, P.D. Reinfection with SARS-CoV-2: Implications for Vaccines. Clin. Infect. Dis. 2020. [CrossRef] [PubMed]

196. Gudbjartsson, D.F.; Norddahl, G.L.; Melsted, P.; Gunnarsdottir, K.; Holm, H.; Eythorsson, E.; Arnthorsson, A.O.; Helgason, D.; Bjarnadottir, K.; Ingvarsson, R.F.; et al. Humoral Immune Response to SARS-CoV-2 in Iceland. N. Engl. J. Med. 2020, 383, 1724-1734. [CrossRef] [PubMed]

197. Iyer, A.S.; Jones, F.K.; Nodoushani, A.; Kelly, M.; Becker, M.; Slater, D.; Mills, R.; Teng, E.; Kamruzzaman, M.; Garcia-Beltran, W.F.; et al. Persistence and decay of human antibody responses to the receptor binding domain of SARS-CoV-2 spike protein in COVID-19 patients. Sci. Immunol. 2020, 5, eabe0367. [CrossRef]

198. Weisblum, Y.; Schmidt, F.; Zhang, F.; DaSilva, J.; Poston, D.; Lorenzi, J.C.; Muecksch, F.; Rutkowska, M.; Hoffmann, H.H.; Michailidis, E.; et al. Escape from neutralizing antibodies by SARS-CoV-2 spike protein variants. Elife 2020, 9, e61312. [CrossRef]

199. Choudhary, M.C.; Crain, C.R.; Qiu, X.; Hanage, W.; Li, J.Z. SARS-CoV-2 Sequence Characteristics of COVID-19 Persistence and Reinfection. Clin. Infect. Dis. 2021. [CrossRef]

200. Ulhaq, Z.S.; Soraya, G.V.; Indriana, K. Breakthrough COVID-19 case after full-dose administration of CoronaVac vaccine. Indian J. Med. Microbiol. 2021. [CrossRef]

201. Hacisuleyman, E.; Hale, C.; Saito, Y.; Blachere, N.E.; Bergh, M.; Conlon, E.G.; Schaefer-Babajew, D.J.; DaSilva, J.; Muecksch, F.; Gaebler, C.; et al. Vaccine Breakthrough Infections with SARS-CoV-2 Variants. N. Engl. J. Med. 2021, 384, 2212-2218. [CrossRef] [PubMed]

202. Dyer, O. Covid-19: Chinese vaccines may need changes to improve efficacy, admits official. BMJ 2021, 373, n969. [CrossRef]

203. Angel, Y.; Spitzer, A.; Henig, O.; Saiag, E.; Sprecher, E.; Padova, H.; Ben-Ami, R. Association Between Vaccination With BNT162b2 and Incidence of Symptomatic and Asymptomatic SARS-CoV-2 Infections Among Health Care Workers. JAMA 2021, 325, 2457-2465. [CrossRef] [PubMed]

204. Osterholm, M.T.; Kelley, N.S.; Sommer, A.; Belongia, E.A. Efficacy and effectiveness of influenza vaccines: A systematic review and meta-analysis. Lancet Infect. Dis. 2012, 12, 36-44. [CrossRef]

205. Roy, S. COVID-19 Reinfection: Myth or Truth? SN Compr. Clin. Med. 2020, 2, 710-713. [CrossRef]

206. Cavanaugh, A.M.; Spicer, K.B.; Thoroughman, D.; Glick, C.; Winter, K. Reduced Risk of Reinfection with SARS-CoV-2 After COVID-19 Vaccination-Kentucky, May-June 2021. MMWR Morb. Mortal. Wkly. Rep. 2021, 70, 1081-1083. [CrossRef] [PubMed]

207. Al-Tawfiq, J.A.; Rabaan, A.A.; Al-Omari, A.; Al Mutair, A.; Al-Qahtani, M.; Tirupathi, R. Learning from SARS and MERS: COVID-19 reinfection where do we stand? Travel Med. Infect. Dis. 2021, 41, 102024. [CrossRef]

208. Bizzoca, M.E.; Campisi, G.; Lo Muzio, L. An innovative risk-scoring system of dental procedures and safety protocols in the COVID-19 era. BMC Oral Health 2020, 20, 301. [CrossRef]

209. Bizzoca, M.E.; Campisi, G.; Lo Muzio, L. Covid-19 Pandemic: What Changes for Dentists and Oral Medicine Experts? A Narrative Review and Novel Approaches to Infection Containment. Int. J. Environ. Res. Public Health 2020, 17, 3793. [CrossRef]

210. Campisi, G.; Bazzano, M.; Mauceri, R.; Panzarella, V.; Di Fede, O.; Bizzoca, M.E.; Lo Muzio, L. The patient-doctor relationship: New insights in light of the current Ministerial recommendations regarding Phase 2 of the COVID-19 pandemic. Minerva Stomatol. 2020, 69, 251-255. [CrossRef] 